\title{
AVALIAÇÃO NEUROCOMPORTAMENTAL DA EXPOSIÇÃO AO n-HEXANO EM TRABALHADORES DE INDÚSTRIAS DE EXTRAÇÃO DE ÓLEO VEGETAL
}

André Amaral Bravin

Brasília, Dezembro de 2014. 


\title{
AVALIAÇÃO NEUROCOMPORTAMENTAL DA EXPOSIÇÃO AO n-HEXANO EM TRABALHADORES DE INDÙSTRIAS DE EXTRAÇÃO DE ÓLEO VEGETAL
}

\author{
André Amaral Bravin \\ Orientador: Prof. PhD. Lincoln da Silva Gimenes \\ Co-Orientador: Prof. PhD. David Allan Eckerman
}

Tese apresentada ao Programa de PósGraduação em Ciências do Comportamento, do Departamento de Processos Psicológicos Básicos da Universidade de Brasília, como parte dos requisitos para obtenção do título de Doutor em Ciência do Comportamento (Área de concentração: Análise do Comportamento).

Brasília, Dezembro de 2014. 


\section{BANCA EXAMINADORA}

Prof. PhD. David Alan Eckerman - Presidente

Universidade de Brasília / University of North Carolina at Chapel Hill

Prof. Dr. Cristiano Coelho - Membro Externo

Pontifícia Universidade Católica de Goiás / Instituto Brasileiro de Geografia e Estatística

Prof. PhD. Timothy Martin Mulholland - Membro Externo

Universidade de Brasília

Prof. Dr. José Eduardo Pandossio - Membro Efetivo

Universidade de Brasília

Profa. Dra. Neice Müller Xavier Faria - Membro Externo

Universidade Federal de Pelotas

Profa. Dra. Laércia Abreu Vasconcelos - Suplente

Universidade de Brasília

Tese defendida e aprovada em 10 de dezembro de 2014. 
Programa de Pós-Graduação em Ciências do Comportamento

Departamento de Processos Psicológicos Básicos

Instituto de Psicologia

Universidade de Brasília - UnB

Ao Prof. Lincoln.

Por todos os ensinamentos e oportunidades

profissionais, sociais e pessoais. 


\section{AGRADECIMENTO}

Às instituições governamentais: Ao Governo Federal, representados pela Universidade Federal de Goiás e pela Universidade de Brasília. A primeira, por ter permitido meu afastamento para doutoramento, o que viabilizou na execução deste projeto. A segunda, por ter amparado parcialmente os gastos da realização deste projeto. À Fundação de Apoio à Pesquisa do Distrito Federal, por ter amparado parcialmente os gastos para a finalização deste projeto na University of Iowa.

Às indústrias e seus colaboradores (em todos os níveis de hierarquia): Por motivos éticos não posso citar nomes, mas vocês sabem quem são e eu sou eternamente grato pela disponibilidade de todos os envolvidos. Desde os trabalhadores (por terem cedido os dados para o presente estudo), até os gestores e gerentes (por terem autorizado a coleta de dados nas indústrias, durante o horário de serviço dos empregados, e cedido dados de seus bancos e registros), passando pelos demais funcionários que colaboraram com a logística do estudo (porteiros, telefonistas, técnicos de segurança do trabalho e auxiliares administrativos). Sem TODOS vocês, este estudo nunca aconteceria. Desculpem pela insistência em diversos momentos, e por gerar demandas extras de trabalho às suas atribuladas rotinas.

Aos colaboradores e pessoas que conheci durante este percurso: ao Prof. Dr. Fábio Baia da Universidade de Rio Verde (UniRV) e ao Curso de História (na pessoa do Prof. Dr. Marcos de Menezes) da Universidade Federal de Goiás - campus Jataí (UFGJataí), pelo empréstimo das filmadoras. À aluna Hanailly Gomes da UFG-Jataí, aos técnicos Osvaldo Pinto (e seu companheiro Gilmar Correia) e Eva Prado da UEG, aos técnicos Renato Borges e Rosimeire da Silva do Laboratório Modelo; agradeço pela coleta e/ou processamento de sangue, e seu devido armazenamento. À Profa. Dra. Cláudia da UEG e ao Hamilton Chiba do Laboratório Modelo; por cederem o laboratório e seus funcionários para processamento e guarda do material biológico. À Ellen Portilho, pelo empenho em me ajudar com a hospedagem e rotinas de coleta.

À Banca (que muito me ensinou e ensinará): Em primeiro lugar, por terem aceitado o convite. Ao Cristiano Coelho, Timothy Mulholland e Neice Faria pela leitura cautelosa e valorosas contribuições. Alimento a expectativa de que possamos 
empreender trabalhos juntos em um futuro próximo. Ao Eduardo Pandossio, por ser um de meus pais - e modelo - acadêmicos. É como ver um ciclo se fechando (e reiniciando, espero eu!). A culpa de eu estar aqui hoje é sua! Devo MUITO a você. Ao David Eckerman, por ser um dos analistas do comportamento mais reforçadores e contingentes que conheço. É sempre agradável e fácil estar ao seu lado. Agradeço por ter aceitado a incumbência que the foi ofertada, pelos ensinamentos teóricos, pela modelagem de meu repertório social e da língua inglesa, pelos contatos e pelo tempo dispendido em Iowa City. À Laércia Vasconcelos. A quem devo creditar um maravilhoso ensinamento: equilíbrio. Saber ponderar entre vida acadêmica e pessoal. Entre rotinas de trabalho e à família. Ao Lincoln Gimenes, outro pai e modelo acadêmico. Por tudo que pude aprender contigo, social, pessoal e profissionalmente. Um adoecimento nunca é bem vindo. Mas mesmo acometido por sua enfermidade, mostrou-se um homem forte e ávido pela vida. Expõe nossas fragilidades e forças. Junto com os ensinamentos da Laércia, faz-me atentar para a temperança e para aquilo que tem real valor na vida.

Aos professores e membros do PPB: Em tempo, agradeço a todos aos professores do departamento de Processos Psicológicos Básicos, sobretudo àqueles que foram meus professores diretamente: Josele Abreu-Rodrigues, David Eckerman, Jorge Oliveira-Castro, Pedro Cruz, Wânia Souza, Sergio Leme, Laércia Vasconcelos, Vitor Motta, Elenice Hanna, Timothy Mulholland e, novamente, Lincoln Gimenes. À Joyce, por sua competência, proatividade, eficiência, prestatividade, preocupação e carinho.

For those that I met in Iowa City: Daissy Owen (the best B\&B ever!); Josie Rudolphi; Jaime Butler-Dawson, her husband (Jon) and son (Skylar); Megan TePoe; Kristin Mara, Khalid Khan, Fred Gerr and Kai Wang. And also thanks for all the Occupational and Environmental Health Building Staff, for the reception, care and the office. Special thanks for David Eckerman, Diane Rohlman and Kant Anger, to allowing me use BARS for free. And also for the hosts that were my Family in the US for three weeks: Diane Rohlman, her husband Joe, her son Sam and daughter Lucy, her father Ron Schertlerand, and Curtis! I had with you all one of the highest moments in my life. You all - uniquely - helped me, teached me, and amused me. I hope that we'll became new (and not only) work partners. You are all welcome in Brazil, anytime you want! Be my guests! 
À minha equipe (e em certa medida, estendendo-se aos colaboradores supracitados): Rodrigo Oliveira, Vanessa Menezes, Katrine Silva, Rita Solimani, Raphael Cardoso, Cléber Ramos e Lidiane Gaban. Vocês me provaram cotidianamente que ciência é feita de cooperação. Vocês me ensinaram valorosas lições: solicitar ajuda, delegar tarefas, confiar no outro, acreditar no trabalho e nas pessoas, e aceitar o que não controlamos.

Aos amigos da UnB: Ana Karina de-Farias, Ana Rita Naves, Andréia Kroger, Carlos Böhm, Júnia Moreira, Márcio Moreira; Luciana Verneque, Pablo Souza, Virginia Fava. Em especial aos outros dois mosqueteiros: Fábio Baia (Fabinho) e Juliano Kanamota.

Aos eternos amigos: Marcelo Coelho (Marcelinho), Gustavo Nassif (Bode), Renato Lobo (Batata), Rubens Ferreira (Fax), Rafael Gotti (Gotti), Gustavo Almeida (Gugu), Wilson Bomfin Jr. (Monstro Torto), Jean Leite (Jean mesmo...).

À família e familiares: Aos meus pais (Maria Rosa e Clarindo Bravin) e meus irmãos (com suas/seu respectivo anexo): Fábio/Poliana (e minha sobrinha Lara), Michelle/Rodrigo, Flávio/Simone (e meus sobrinhos Beatriz e Carlos Eduardo), Lúcio/Juliana (e minha sobrinha Catarina). Por serem quem são e ocuparem o lugar que ocupam em minha vida. Sei que sempre poderei contar com vocês.

À minha espoiva, Rita Solimani, por tolerar o intolerável e suportar o insuportável.

Todos vocês me ensinaram a ser um humano melhor. Obrigado! 


\section{ÍNDICE}

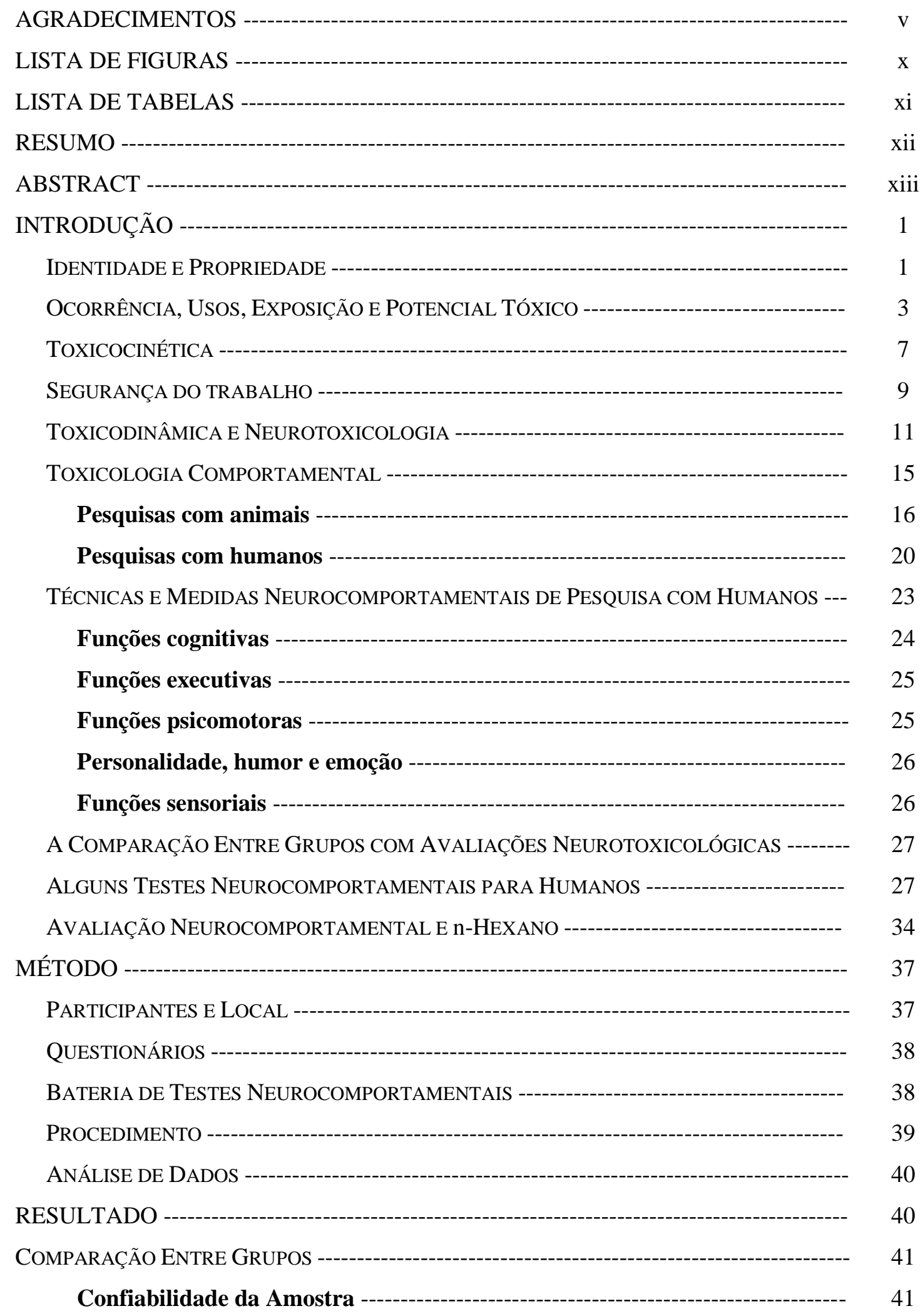


Finger Tapping Test (TAP) ------------------------------------------------ 44

Symbol Digit Test (SDT) ---------------------------------------------- 45

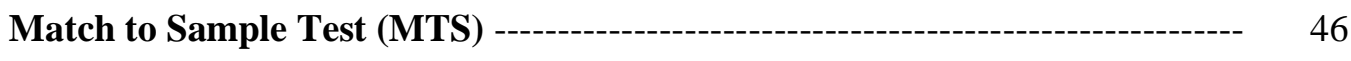

Digit Span Test (DST) ---------------------------------------------------- 48

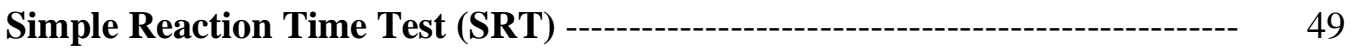

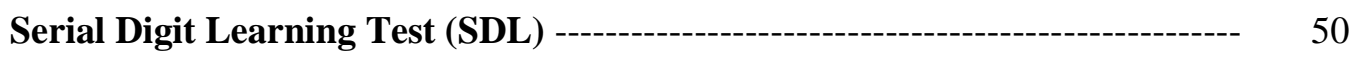

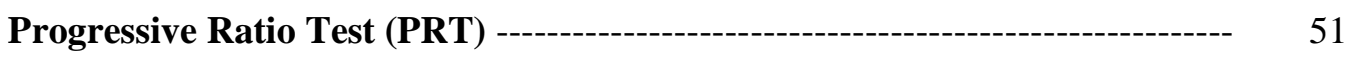

Selective Attention Test (SAT) --- 52

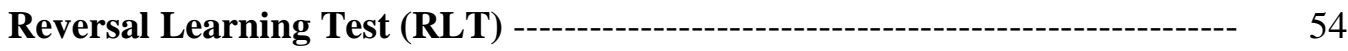

Teste de Romberg (Rom) ----------------------------------------------- 55

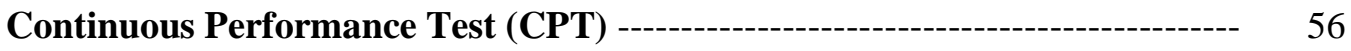

ANÁLISE INTERGRUPO COM CONTROLE DE VARIÁVEIS CONSTITUCIONAIS --------------- 58

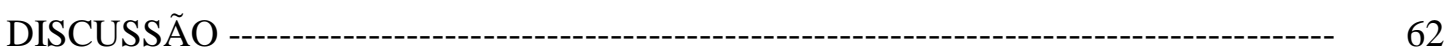

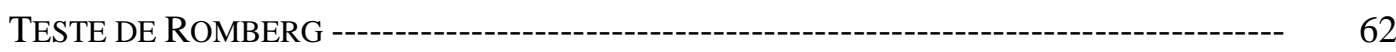

BEHAVIORAL ASSESSMENT AND RESEARCH SYSTEM - BARS ----------------------- 64

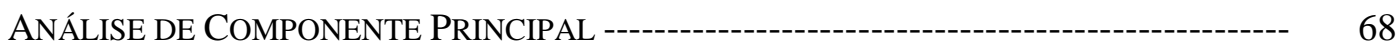

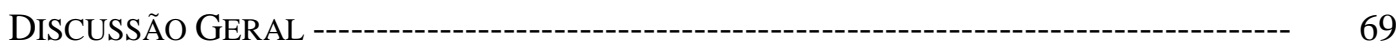

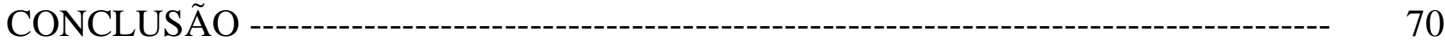

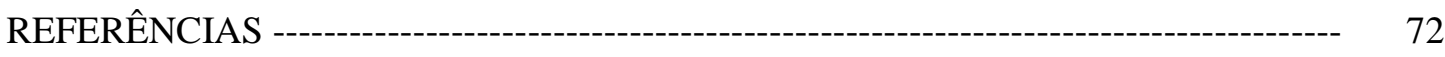

APÊNDICE 01 - TERMO DE CONSENTIMENTO LIVRE E ESCLARECIDO ------- 77

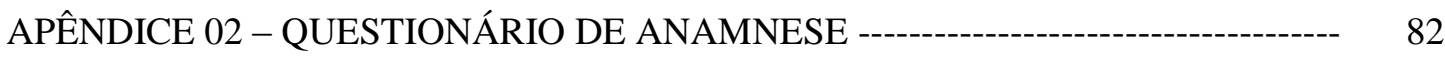

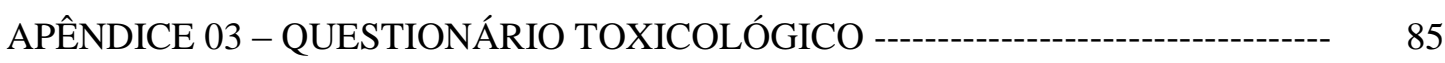

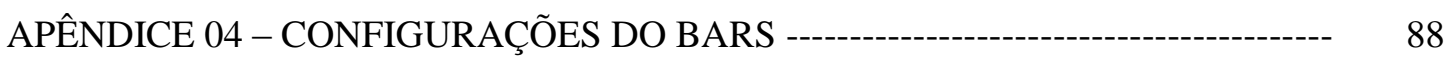

ANEXO 01 - PARECER CONSUBSTANCIADO DO COMITÊ DE ÉTICA ----------- 94 


\section{LISTA DE FIGURAS}

Figura 1: Fórmulas estruturais do hexano

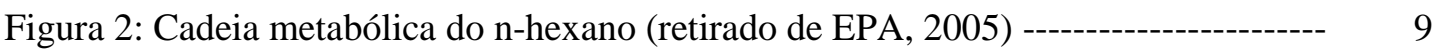

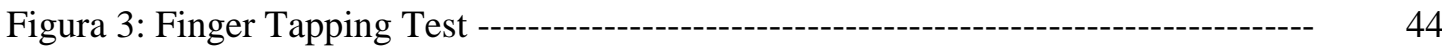

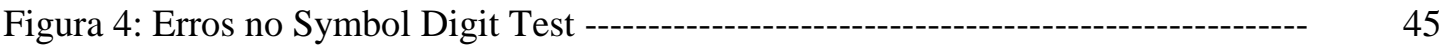

Figura 5: Latências no Symbol Digit Test -------------------------------------------- 46

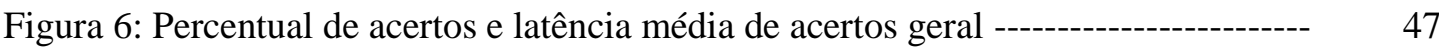

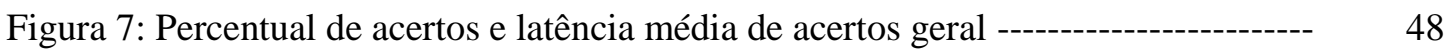

Figura 8: Acertos no Digit Span Test --_- 49

Figura 9: Latências no Simple Reaction Time Test -----a- 50

Figura 10: Serial Digit Learning Test --------------------------------------------- 51

Figura 11: Número de respostas e reforços no PRT ----------------------------------- 52

Figura 12: Número de tentativas, ISI e latência de acertos no SAT ----------------- 53

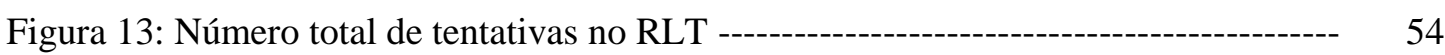

Figura 14: Contagens e latência média de repetições no RLT ------- 55

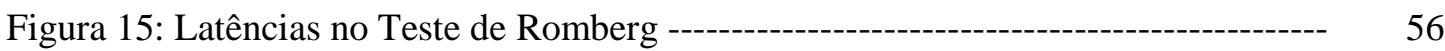

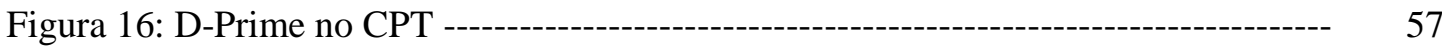

Figura 17: Latências de Acerto e Falso Alarme no CPT ------------------------- 57

Figura 18: Diferença padronizada média das medidas neurocomportamentais entre expostos e não expostos, controladas para idade e educação 


\section{LISTA DE TABELAS}

Tabela 1: Propriedades Físicas, Químicas e Toxicocinéticas do n-Hexano

Tabela 2: Parâmetro de controle biológico de exposição ocupacional ao hexano

Tabela 3: Parâmetros ambientais e biológicos de exposição ocupacional ao hexano no Brasil e nos EUA

Tabela 4: Caracterização das principais abordagens epidemiológicas em toxicologia com

humanos

Tabela 5: Caracterização dos testes neurocomportamentais que compõem o Behavioral

Assessment and Research System - BARS

Tabela 6: Origem e distribuição dos participantes em seus respectivos grupos

Tabela 7: Números absolutos/percentual de testes completados pelos participantes

Tabela 8: Confiabilidade da amostra

Tabela 9: O desempenho de trabalhadores expostos e não expostos nas medidas comportamentais avaliadas. Os modelos foram ajustados para idade e escolaridade

Tabela 10: Análise de Componente Principal para as medidas neurocomportamentais avaliadas- 


\section{RESUMO}

O hexano é um solvente industrial utilizado, dentre outras aplicações, na extração de óleo vegetal. A substância é volátil e lipofílica, sendo facilmente absorvida em caso de exposição. A intoxicação pode desenvolver diferentes graus de uma axonopatia retrógrada, reversível ou não. Pouco se sabe sobre a implicação isolada do hexano em exposições crônicas e de baixa concentração. O objetivo deste estudo foi realizar uma triagem neurocomportamental com o uso do Behavior Assessment and Research System (BARS) e do teste de Romberg, a fim de investigar se a rotina de trabalhadores da indústria de extração de óleo vegetal (e presumível exposição ao hexano), pode acometer funções neurocomportamentais preditoras de neuropatias. Oitenta e um trabalhadores de 2 indústrias compuseram um grupo exposto $(n=35)$ e controle $(n=45)$. A aplicação da bateria ocorreu no início da retomada da jornada de trabalho. O levantamento de variáveis confundidoras foi realizado por meio de questionários. Foram adotadas duas abordagens estatísticas. A primeira utilizou o teste de permutação para sistematicamente comparar os grupos controle e exposto para confundidores e medidas neurocomportamentais. A segunda abordagem realizou uma regressão linear ajustando o modelo para idade e escolaridade. No primeiro caso, os resultados demonstraram que: grupo controle e exposto não diferiram para nenhuma variável confundidora; grupo exposto apresentou uma diminuição na latência de balanço no teste de Romberg ( $\mathrm{p}<$ 0,05), e um sutil aumento no quinto bloco do percentual de acertos de Tempo de Reação Simples $(\mathrm{p}<0,05)$. No segundo caso, os resultados demonstraram inexistência de diferença estatisticamente significativa entre os grupos, para qualquer das variáveis investigadas. Foi observado que a diferença nas medidas neurocomportamentais do grupo exposto ocorreu naquelas variáveis que, tradicionalmente, a literatura de solventes aponta como prejudicada em casos de intoxicação por solventes, embora não tenham apresentado significância estatística. Discute-se que a adoção da segunda abordagem estatística é mais consonante com a natureza dos dados da pesquisa de campo e que a falta de diferença entre os grupos pode ter sido efeito da escolha pelo isolamento da exposição crônica, em detrimento da exposição aguda. Sugerem-se novos estudos onde os trabalhadores sejam reavaliados ao final da jornada de trabalho e/ou condições de exposição mais críticas, como a de limpeza dos equipamentos.

Palavras-chave: n-Hexano; Avaliação Neurocomportamental; Funções Cognitivas; Toxicologia Comportamental; Segurança do Trabalho. 


\begin{abstract}
Hexane is an industrial solvent used in vegetable oil extraction. It's a volatile and lipofilic substance, easily absorbed in case of exposure. If intoxicated, it can lead to different degrees of a retrograde neuropathy, reversible or not. Little is known about the isolated chronic and low concentration exposure. The aim of this study is to do a neurobehavioral screening using the Behavior Assessment and Research System (BARS) and the Romberg Test, in order to investigate if workers in soybean mill (and presumed exposure to hexane), could have affected neurobehavioral functions known to demonstrate neurotoxic impairment of solvents. 81 workers from 2 industries composed an exposed $(n=35)$ and control $(n=45)$ groups. The neurobehavioral battery was administered at the beginning of their work week. Confounding variables were analyzed by surveys. Two statistical approaches were used. The first used the permutation test to compare control and exposed groups for potential confounding variables and neurobehavioral measures. The second used a linear regression adjusted for age and education. In the first case, the results show that: control and exposed group did not differ on confounders; exposed group showed a lower sway latency on Romberg test ( $p$ $<0,05)$, and a slight increase in the fifth block of correct responses on Simple Reaction Time $(\mathrm{p}<0,05)$. For the second analysis, there was no statistical difference between the groups for any of the variables under investigation. It was observed, however, that most of the neurobehavioral measures typically related to solvent exposure in the research literature were lower for the exposed group, although these diferences did not reach statistical significance. Thus, the second statistical approach encourages a more careful evaluation to evaluate the possibility that the non-difference between groups may have resulted from the choice to isolate the chronic to the acute exposure. New studies are suggested with workers that would be reevaluated at the end of their work week and/or at the time of their more critical exposure conditions, such as when washing the equipment.
\end{abstract}

Key-Word: n-Hexane; Neurobehavioral Assessment; Cognitive Functions; Behavior Toxicology; Work Safety. 
Dentre as substâncias químicas encontram-se as substâncias orgânicas, isto é, moléculas formadas predominantemente por carbono e hidrogênio (hidrocarbonetos). As substâncias orgânicas são classificados em função de sua formulação química, gerando distintas classes, dentre as quais os hidrocarbonetos aromáticos (i.e., compostos por anéis benzênicos) ou alifáticos (i.e, não possuem anéis benzênicos em sua estrutura). Hidrocarbonetos alifáticos contendo entre 5 e 17 carbonos em sua estrutura são líquidos à temperatura ambiente. Um subconjunto desses (hidrocarbonetos alifáticos) são os solventes, substâncias líquidas à temperatura ambientes empregadas na forma pura ou misturados - como solubilizantes, dispersantes ou diluentes, em diferentes processos e produtos ocupacionais. Cada solvente possui diferentes características químicas (e.g., liposolubilidades e volatilidade) e, por essa razão, diferentes usos (Leite, 2008).

O n-hexano (normal-hexano), também conhecido pelos sinônimos de hexano, hexil hidrido ou Skellysolve B, é um hidrocarboneto alifático de cadeia aberta (i.e., saturado), que só possui ligações simples entre seus átomos (i.e., um alcano) derivado do petróleo, amplamente utilizado em produtos e processos ocupacionais. Esse agente é potencialmente nocivo à saúde causando, dentre outros, efeitos neurotóxicos e podendo acometer alterações comportamentais (DeCaprio, 2000; Leite, 2008; Sanagi, Seki, Sugimoto, \& Hirata, 1980; WHO, 1991).

Este capítulo apresentará o toxicante e descreverá as possíveis fontes de exposição, bem como ilustrará suas propriedades neurotóxicas e seus efeitos sobre o comportamento. Os dados apresentados contemplarão o maior número de informações, o que inclui a pureza do solvente, sua concentração (em $\mathrm{mg} / \mathrm{m}^{3}$ e $\mathrm{ppm}$ ) e o tipo e via de exposição (aguda, crônica, etc. / inalação, oral, etc.). Os fatores de conversão $\left(\mathrm{mg} / \mathrm{m}^{3}-\right.$ ppm e vice-versa), seguem (cf. WHO, 1991):

- $1 \mathrm{ppm}$ n-hexano no ar $=3,52 \mathrm{mg} / \mathrm{m}^{3}$

- $1 \mathrm{mg} / \mathrm{m}^{3}=0,284 \mathrm{ppm}$ de n-hexano no ar

\section{IDENTIDADE E PROPRIEDADES}

O hexano $\left(\mathrm{C}_{6} \mathrm{H}_{14}\right.$, ver Figura 1) é um solvente orgânico líquido, incolor, altamente volátil, inflamável, explosivo, pouco hidrossolúvel, muito lipossolúvel e solúvel na maioria dos solventes orgânicos (DeCaprio, 2000; NIOSH, 1983; WHO, 1991) (ver Tabela 1). 
Seu odor é característico e a concentração atmosférica para a obtenção de um valor para o limiar de odor varia em função da pureza da substância e sua forma de exposição. Laffort e Dravnieks (1973) registraram um limiar de odor para o n-hexano (pureza não especificada) de $211 \mathrm{mg} / \mathrm{m}^{3}$ (60 ppm), embora o International Programme on Chemical Safety (WHO, 1991), programa composto pelo Programa Ambiental das Nações Unidas, a Organização Internacional do Trabalho e a Organização Mundial da Saúde (OMS), argumente quanto a necessidade de concentrações superiores a 457,6 $\mathrm{mg} / \mathrm{m}^{3}$ (130 ppm) para se atingir o limiar de odor. Em misturas comercias, o odor característico do n-hexano é perceptível a $282 \mathrm{mg} / \mathrm{m}^{3}$ (80 ppm) com a exposição é intermitente ou $528 \mathrm{mg} / \mathrm{m}^{3}$ (150 ppm) com a exposição é contínua (Patty \& Yant, $1929^{1}$ citado em WHO, 1991).

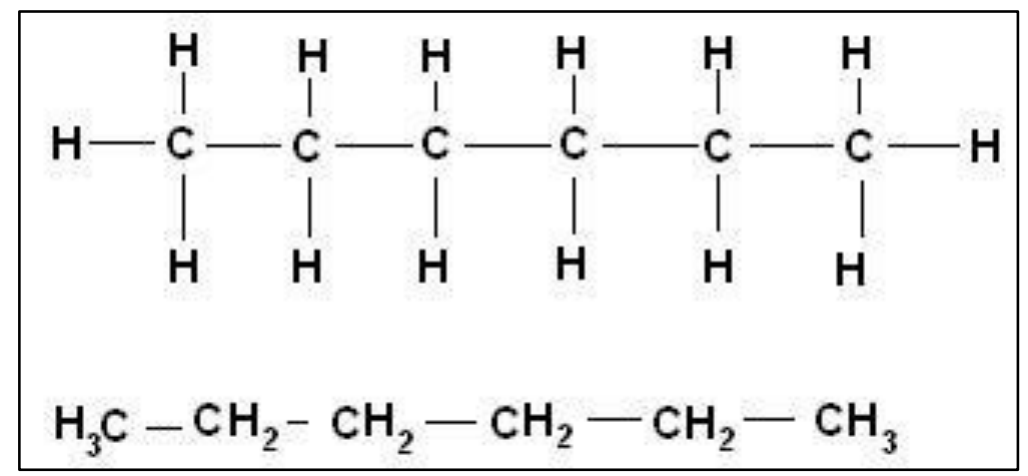

Figura 1. Fórmulas estruturais do hexano. A substância é encontrada no Chemical Abstracts Service (CAS) pelo registro 110-54-3.

A solução pura concentra entre 95 e 99,5\% de hexano, com pequenas quantias de seus isômeros e outras impurezas (Leite, 2008; Petrobras, 2011; WHO, 1991). Em geral, o hexano comercial varia sua concentração entre 20 e $80 \%$, sendo predominantemente uma mistura de isômeros da substância, e compostos relacionados ao 6-carbono, dentre os quais: 2-metilpentano; 3-metilpentano; 2,3-dimetilbutano; ciclohexano; metil ciclopentano; acetona; metil etilcetona; diclorometano; tricloroetileno e isômeros de pentano e heptano (DeCaprio, 2000; NIOSH, 1983; WHO, 1991).

No Brasil, o único fabricante de hexano é a Petrobras®. Segundo a Ficha de Informação de Segurança de Produto Químico (FISPQ) do fabricante, 97\% da solução é

\footnotetext{
${ }^{1}$ Patty, F. A. \& Yant, W. P. (1929). Odour intensity and symptoms produced by comercial propane, butane, pentane, hexane and heptane vapour. Repor $N^{o}$. RI 2979. Washington: US Bureaur of Mines.
} 
a própria substância, enquanto os $3 \%$ restantes são compostos por outros hidrocarbonetos insaturados e o benzeno ( $<0,10 \%$ do volume) (Petrobras, 2011).

Tabela 1. Propriedades Físicas, Químicas e Toxicocinéticas do n-Hexano.

\begin{tabular}{|c|c|c|}
\hline Propriedade & $\begin{array}{c}\text { Valores } \\
(\mathrm{WHO}, 1991)\end{array}$ & $\begin{array}{c}\text { Valores } \\
\text { (Petrobras, 2011) }\end{array}$ \\
\hline Ponto de fusão $\left({ }^{\circ} \mathrm{C}\right)$ & $-95,35$ & -96 \\
\hline $\begin{array}{l}\text { Ponto de ebuliçãa }\left({ }^{\circ} \mathrm{C}\right) \text { a } \\
(760 \mathrm{~mm} \mathrm{Hg})\end{array}$ & 68,74 & 68 \\
\hline Viscosidade $\left(25^{\circ} \mathrm{C}\right)$ & ------- & $0,45 \mathrm{cSt}$ \\
\hline Densidade relativa $\left(20^{\circ} \mathrm{C} / 4{ }^{\circ} \mathrm{C}\right) \mathrm{g} / \mathrm{cm}^{3}$ & 0,66 & 0,67 \\
\hline Pressão de vapor & $\begin{array}{c}20 \mathrm{kPa}(150 \mathrm{~mm} \mathrm{Hg}) \text { a } 25 \\
{ }^{\circ} \mathrm{C}\end{array}$ & $0,42 \mathrm{kgf} / \mathrm{cm}^{2}$ a $37,8{ }^{\circ} \mathrm{C}$ \\
\hline Densidade de vapor & 2,97 & 2,9 \\
\hline Taxa de Evaporação (Acetato de n-Butila = 1) & ------- & 6 \\
\hline Temperatura de autoignição $\left({ }^{\circ} \mathrm{C}\right)$ & 225 & 225 \\
\hline $\begin{array}{l}\text { Limites inferior e superior de inflamabilidade / } \\
\text { explosividade no ar (\% por volume) }\end{array}$ & $1,1-7,5$ & $1,2-6,9$ \\
\hline Flash point $\left({ }^{\circ} \mathrm{C}\right)$ & $-21,7$ & ------- \\
\hline $\begin{array}{l}\text { Ponto de Fulgor (vaso fechado) / Closed-cup } \\
\text { flash point }\left({ }^{\circ} \mathrm{C}\right)\end{array}$ & $-30,56$ & -35 \\
\hline Solubilidade em água (mg/l à $\left.25^{\circ} \mathrm{C}\right)$ & 9,5 & ------- \\
\hline Coeficiente de partição n-octanol/água & $3,6\left(\log \mathrm{P}_{\mathrm{ow}}\right.$ à $\left.25^{\circ} \mathrm{C}\right)$ & 3,9 (log kow) \\
\hline Índice de refração $\left(20^{\circ} \mathrm{C}\right)$ & 1,37 & ------- \\
\hline Color, Saybolt & +39 & ------- \\
\hline Meia-vida* & \multicolumn{2}{|c|}{ Valores } \\
\hline Atmosférica & \multicolumn{2}{|c|}{$2-2,4$ dias } \\
\hline $\begin{array}{ll}*--- & \text { Valores não informados } \\
& \text { Valores retirados de WHO (1991). }\end{array}$ & & \\
\hline
\end{tabular}

\section{OCORRÊNCIA, USOS, EXPOSIÇÃO E POTENCIAL TÓXICO}

De modo geral, os solventes têm ampla aplicação. Sua propriedade dispersante (favorece a limpeza de gordura em distintos materiais) e alta volatilidade (permite uma fácil remoção) favorecem sua utilização em produtos e processos industriais e ocupacionais (Dekant \& Anders, 2008). O hexano é, naturalmente, encontrado no gás natural e no petróleo bruto, de onde é refinado para futuro uso, quer seja isoladamente (solvente único) ou como componente em outras substâncias (Dekant \& Anders, 2008; Leite, 2008; NIOSH, 1983; WHO, 1991). Em geral faz parte de produtos como: colas para calçados, colas adesivas, lacas, tintas e seus solventes, solventes poliolefinas, solvente para polimerização e amaciamento de borracha, químico laboratorial e industrial, agentes de limpeza específicos como tíner e limpadores, produtos como gasolina e subprodutos de sua queima (liberada pelos escapamentos de veículos). Como parte de processos ocupacionais e industriais, o hexano pode ser empregado para: limpeza e desengorduramento de produtos metálicos, extração de óleo vegetal, fabricação de borrachas, pneus e plásticos, laminação de materiais plásticos, impressão, 
pintura, fabricação de móveis, limpeza a seco de têxteis, fabricação de termômetros de baixa temperatura, na produção farmacêutica, cosmética, têxtil, química e petroquímica. De modo geral, solventes derivados de petróleo com baixo ponto de ebulição, contem alta proporção de hexano (Cardona et al., 1996; DeCaprio, 2000; Dekant \& Anders, 2008; Ikeda, Katakura, Kishi, \& Miyake, 1993; NIOSH, 1983; Sanagi et al., 1980; WHO, 1991).

Segundo Leite (2008), o hexano é o hidrocarboneto alifático mais tóxico da classe dos alcanos e seu principal contexto de exposição é a ocupacional. O Instituto Nacional para Segurança e Saúde Ocupacional (National Institute for Occupational Safety and Health - NIOSH) dos Estados Unidos, estima que 2,5 milhões de trabalhadores estão expostos a essa substância (NIOSH, 1983). A maior parte dos casos documentados de intoxicação com hexano derivam das décadas de 1970 e 1980, principalmente de pequenas companhias, onde os trabalhadores eram expostos a compostos voláteis, em condições insalubres e por longos períodos de tempo (WHO, 1991).

Um dos usos industriais do hexano é para o processamento de alimentos, dentre os quais a extração de óleo vegetal (soja, azeitona, girassol, germe de milho, trigo, canola, amendoim, linhaça, açaí, algodão, cártamo, dentre outros). Embora raro, resíduos do solvente podem ser encontrados em alimentos (WHO, 1991). Mesmo em sistemas seguros e "fechados", como na extração de óleo vegetal, a perda do solvente é uma realidade. A exposição ocupacional dos trabalhadores varia em função de suas atividades e da engenharia das plantas e maquinário de extração. A habitual manutenção dos equipamentos e/ou seu mau funcionamento pode gerar escapes do solvente. Além do que, as rotinas de manutenção e limpeza dos equipamentos, em si mesmo, são potenciais fontes de exposição (NIOSH, 1983).

Nesse sentido, avaliações foram conduzidas em seis plantas de extração de azeite espanholas. Foram encontrados valores atmosféricos de hexano que variavam entre 3 e $341 \mathrm{mg} / \mathrm{m}^{3}$ (1 - 97 ppm) (Medinilla \& Espigares, 1989² citado em (WHO, 1991). Por sua vez, em uma indústria de extração de óleo de soja, por dois dias consecutivos, a NIOSH registrou concentrações atmosféricas de hexano (pureza não informada) para (a) zonas de respiração pessoal de dois funcionários (um da

\footnotetext{
${ }^{2}$ De_Medinilla, J. \& Espigares, M. (1989). Hexane levels in olive dreg extraction plants in Granada, Spain. L'igiene Moderna, 91 (4): 353-361.
} 
manutenção e um operador de extração) e (b) três diferentes locais da indústria. No primeiro caso, os valores registrados variaram entre 15,49 a $46,46 \mathrm{mg} / \mathrm{m}^{3}(4,4-13,2$ ppm), sendo que os maiores valores advieram dos operadores de extração. Já nas amostras de locais observou-se uma variação entre 46,46 a $94,69 \mathrm{mg} / \mathrm{m}^{3}(13,2$ - 26,9 ppm) (NIOSH, 1983).

Talvez a evidência mais clara dos efeitos tóxicos do hexano tenha vindo de seu uso por parte dos cheiradores de cola (e.g., cola e éter de petróleo). Em busca dos efeitos moderadamente desinibidores desse toxicante, a substância era utilizada por até 12 horas (concentração estimada de $154.880 \mathrm{mg} / \mathrm{m}^{3}$, isto é, $44.000 \mathrm{ppm}$ ). A inalação aguda gerava vertigem, sedação e irritação, e a inalação crônica gerava neuropatias. Investigações posteriores apontaram que o efeito neurotóxico do n-hexano era, na verdade, uma propriedade de um de seus metabólitos, o 2,5-hexanodiona (Boekelheide, 1987; Cardona et al., 1996; DeCaprio, 2000; Leite, 2008; Sanagi et al., 1980; Weiss, 1983; WHO, 1991), embora outros metabólitos, como a 2,5-hexanodiol e a 2-hexanona tenham gerado edema axonal generalizado, danos severos no trato óptico e degeneração axonal em fibras longas e de maior diâmetro (WHO, 1991).

Allen e colaboradores (1975) apontam o interesse do governo dos Estados Unidos nos efeitos tóxicos dessa substância após o episódio de Columbus (Ohio, EUA). Em 1973, trabalhadores de uma fábrica de impressão em tecido apresentaram sinais e sintomas semelhantes entre si. Um dos trabalhadores (operador de impressão) foi admitido no hospital após cerca de quatro meses de trabalho, apresentando queixas de neuropatia (e.g., fraqueza, rigidez e dificuldade em andar), sem causa definida. Em sua segunda consulta, dois meses depois, comentou que cinco de seus companheiros de serviço também apresentaram as mesmas queixas. Uma investigação se iniciou a fim de avaliar o ambiente ocupacional dos trabalhadores, o que incluía análise clínica e eletrodiagnóstica (velocidade de condução dos nervos) dos mesmos. Foram identificados 86 casos de neuropatia periférica em diferentes graus de severidade. Tipicamente, a neuropatia se iniciava com fraqueza e/ou parestesia nas extremidades, marcha claudicante, dificuldade no movimento de pinça e para segurar objetos pesados. A progressão da neuropatia incluía diminuição de reflexos e déficits motores. Em todos os casos, as perdas sensoriais eram simétricas e usualmente restritas aos dedos ou pés, ocasionalmente envolvendo as pernas e, raramente, ascendendo até o joelho. Correlacionado com a gravidade dos casos, observou-se uma diminuição na velocidade de condução dos nervos. Visitas in loco revelaram que os trabalhadores não só 
respiravam os solventes volatilizados no ambiente ocupacional, como também lavavam suas mãos e calçados com o solvente e, até mesmo, alimentavam-se na área de serviço. Observou-se que a severidade dos sintomas relacionava-se com o tipo de atividade exercida pelos trabalhadores (mais expostos apresentando sintomas mais severos e em maior número), bem como o tempo de exposição média (operadores de impressão: 47,2 horas/semana; controle: 42 horas/semana) (Allen et al., 1975). Após investigação, o metil n-butil cetona (MBK) foi apontado como o toxicante, e a 2,5-hexanodiona (2,5HD) isolado como um de seus metabólitos tóxicos (Allen et al., 1975; Bus, Deyo, \& Cox, 1982). Após "abolirem" o MBK da indústria, melhoria nas condições de ventilação e proibição de práticas como alimentar-se e lavar as mãos e roupas com o solvente, nenhum novo caso de neuropatia foi reportado e $71 \%$ dos casos apresentaram melhora enquanto a avaliação estava em curso (Allen et al., 1975).

Por ser nocivo e perigoso, ambientes ocupacionais que fazem uso desta substância devem atender às exigências arquitetônicas (e.g., ventilação exaustora, aterramento de elementos condutores, estocagem do hexano em local com solo impermeabilizado e com dique de contenção; em locais onde o produto é manipulado, devem-se conter chuveiros e lava-olhos de emergência). O hexano possui baixa solubilidade em água, porém, alta volatilidade. Isso faz com que o agente seja predominantemente transportado pelo ar. Embora a exposição a organismos aquáticos seja improvável, seus vapores prejudicam o meio ambiente. Por essa razão, os resíduos e as embalagens utilizadas devem ser descartadas em instalações autorizadas, a qual deve ser acompanhada por especialista e de acordo com legislação ambiental vigente.

Além disso, medidas de segurança no trabalho, como a utilização de ferramentas antifaiscantes e o uso de equipamentos de proteção individual (EPI), devem ser tomadas. Para proteção respiratória em baixas concentrações (até $1.760,00 \mathrm{mg} / \mathrm{m}^{3}$, isto é, 500 ppm), respirador com filtro químico para vapores orgânicos; em altas concentrações, equipamento de respiração autônoma ou conjunto de ar mandado. Para proteção dos olhos, óculos hermético ou proteção facial em atividades onde existe o risco de lançamento de respingos. Para a pele e corpo, botas, roupas impermeáveis, aventais e luvas de PVC em atividades de contato direto com o produto. As roupas e calçados devem ser higienizadas após o uso e devem ser separadas das roupas comuns. Ademais, não se deve comer, beber ou fumar nas áreas de manuseio ou estocagem do produto. 


\section{TOXICOCINÉTICA}

A exposição aos solventes orgânicos e seu potencial risco tóxico é influenciada pelas propriedades físico-químicas da substância (e.g., lipossolubilidade, pressão de vapor, densidade de vapor), fatores fisiológicos (e.g., frequência cardio-respiratória, estado hormonal, estado patológico), individuais (e.g., idade, peso, sexo, dieta, ingestão de substâncias lícitas ou não) e condições ambientais (e.g., temperatura, duração) de exposição dos organismos (DeCaprio, 2000; Eckert \& Müller, 2008; Leite, 2008). De modo geral, a principal via de exposição aos solventes é a pulmonar, cutânea ou oral (quando ocorre ingestão de alimento/água contaminados), destacando-se a primeira (DeCaprio, 2000; Dekant \& Anders, 2008; Eckert \& Müller, 2008; Leite, 2008; WHO, 1991). Nesse caso, a inalação de solventes volatilizados atinge os alvéolos pulmonares, e esses entram em contato com o sangue capilar, sendo então absorvidos se forem lipofílicos e distribuído pelo corpo.

A absorção transdérmica do hexano é restrita (com exposição crônica, cerca de $0,83 \mu \mathrm{g} / \mathrm{cm}^{2} /$ hora é absorvido pela pele íntegra - Leite, 2008) mas, quando ocorre o contato com a camada epidérmica da pele, os solventes orgânicos removem lípides da mesma, o que explica as irritações e lesões quando desse tipo de exposição. Por seu turno, essas lesões favorecem a absorção dos próprios solventes (Dekant \& Anders, 2008; Leite, 2008). Na absorção transdérmica do hexano, o pico plasmático ocorre após 1 hora de exposição, declinando rapidamente no período restante (Leite, 2008). A intoxicação por via oral, com hexano, é bastante rara (WHO, 1991). É importante distinguir a intoxicação aguda de uma intoxicação crônica de solventes. A exposição aguda a solventes orgânicos, em geral, causa uma depressão reversível do Sistema Nervoso Central (SNC), enquanto a exposição crônica de baixas doses pode resultar em degeneração de nervos periféricos (Eckert \& Müller, 2008).

O hexano é uma substância extremamente lipofílica. Inclusive, é essa característica que a faz ser amplamente empregada em indústrias de extração de óleo vegetal (Weiss, 1983). Essa propriedade faz que o hexano, quando inalado por mamíferos, seja rapidamente absorvido pelo sangue e amplamente distribuído pelo corpo e tecido fetal (o solvente atravessa facilmente a barreira placentária e, por essa razão, o sangue fetal possui concentrações do solvente semelhantes às encontradas no sangue materno). Sua distribuição ocorre dos tecidos mais vascularizados para os tecidos de eliminação (fígado e rins) e tecido adiposo (Leite, 2008). Sua distribuição e excreção são bifásicas, isto é, o solvente deixa rapidamente a corrente sanguínea (fase $\alpha$ 
com $\mathrm{t}_{1 / 2}$ de cerca de 12 a 36 minutos) e, à medida que o equilíbrio nos tecidos é alcançado, a saída do solvente da corrente sanguínea torna-se mais lenta (fase $\beta$ com t $\mathrm{t}_{1 / 2}$ de 1,5 a 4 horas). $O$ hexano tem afinidade por tecidos que apresentam elevado conteúdo lipídico (e.g., cérebro) e, no tecido adiposo, sua concentração se aproxima à capacidade máxima desse tecido em solubilizar o solvente (Leite, 2008; WHO, 1991).

A maior parte do hexano inalado é excretado de forma inalterada pelo ar exalado e, embora uma pequena parte dos metabólitos possam ser encontrados no ar exalado, sua principal via de excreção é a urina (DeCaprio, 2000; WHO, 1991). Em um experimento (Bus et al., 1982), ratos foram expostos ao hexano $(98,5 \%$ de pureza) marcado radioativamente, em concentrações que variavam entre 500 e 10.000 ppm $\left(1.760,00 \mathrm{mg} / \mathrm{m}^{3}\right.$ a $\left.35.200,00 \mathrm{mg} / \mathrm{m}^{3}\right)$. Após 6 horas de exposição, os animais foram alojados em gaiolas metabólicas para coleta de urina, fezes e ar expirado, por um período de 72 horas. A proporção de hexano recuperado (considerando a concentração de $500 \mathrm{ppm}$ ) foi de $12 \%$ no ar expirado, $35,4 \%$ na urina, $4,9 \%$ nas fezes e $8,7 \%$ na carcaça dos animais. A avaliação longitudinal no período de 72 horas mostrou uma excreção bifásica da substância, tanto no ar exalado quanto na urina, a despeito das concentrações as quais os grupos de animais foram expostos. Para o ar exalado, durante as primeiras 4 a 6 horas após a exposição, $90 \%$ do total do hexano radioativamente marcado foi recuperado e, após 48 horas, a excreção havia se completado. Quanto a urina, $90 \%$ do total foi recuperado após 24 horas de exposição.

Segundo Leite (2008), não existem diferenças qualitativas entre a biotransformação do n-hexano em animais experimentais e no homem, sendo a única diferença quantitativa. Nos humanos, estima-se que cerca de 15 a $30 \%$ do hexano inalado é absorvido pelos pulmões, isto é, a maior parte do solvente é excretado inalterado pelo ar (DeCaprio, 2000; Leite, 2008).

A biotransformação do hexano ocorre principalmente no fígado, embora também possa ocorrer nos pulmões e rins. A excreção urinária na forma inalterada ocorre em pequenas porções. No homem, os principais metabólitos urinários são a 2,5-HD (36\%), 2,5-dimetilfurano (32\%), valerolactona (30\%) e o 2-hexanol (2\%), e a excreção da 2,5HD é função direta da intensidade da exposição - ver Figura 2 (DeCaprio, 2000; Leite, 2008).

Como citado anteriormente, a 2,5-HD é reconhecida por sua propriedade neurotóxica, e em modelos animais, esse metabólito é encontrado no sistema nervoso, sobretudo nos nervos periféricos (WHO, 1991). O pico de concentração plasmática do 
2,5-HD ocorre em torno de 60 a 120 minutos após o início da exposição, quando atinge o equilíbrio (DeCaprio, 2000; Leite, 2008). Níveis similares de 2,5-HD foram registrados em trabalhadores ao final do dia e no início do dia seguinte e valores mais altos foram registrados ao final da semana de trabalho. Isso sugere que o hexano pode acumular-se no corpo (WHO, 1991). No caso de exposição única, Leite (2008) informa que a excreção dos metabólitos inativos da 2,5-HD se conclui entre 16 e 24 horas após a exposição.

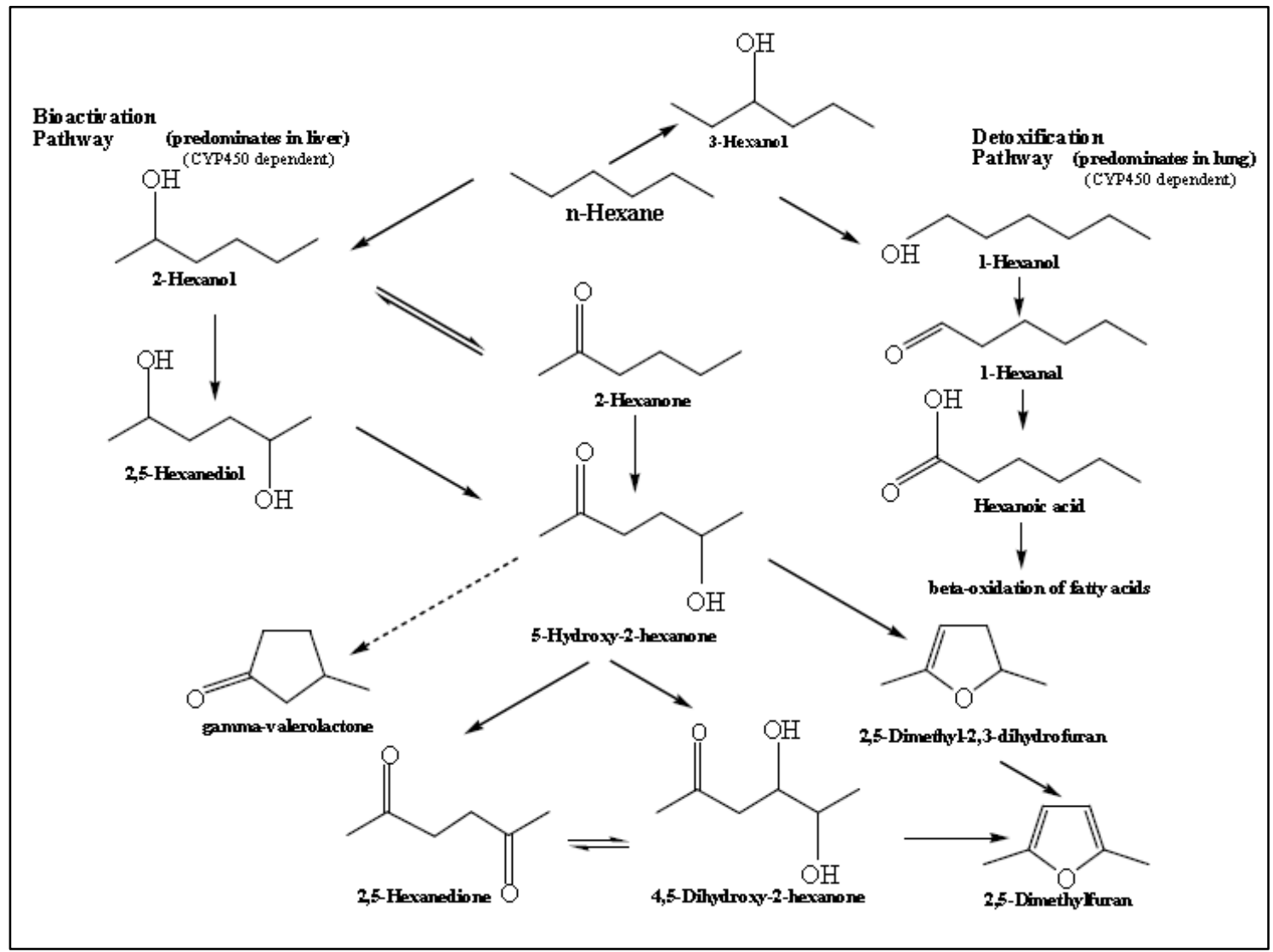

Figura 2. Cadeia metabólica o n-hexano (retirado de EPA, 2005).

\section{Segurança do Trabalho}

No Brasil, o Ministério do Trabalho e Emprego é responsável por legislar quanto à segurança e saúde dos trabalhadores expostos ao hexano. A Norma Regulamentadora número 7 (NR7) estabelece a obrigatoriedade do monitoramento biológico semestral dos trabalhadores expostos ao hexano, por meio da análise urinária do 2,5-HD ao final do último dia da jornada de trabalho (ver Tabela 2). Parece não existir valor de referência do 2,5-HD urinária no Brasil. Entretanto, alguns países encontraram valores basais na faixa de 0,12 a $0,98 \mathrm{mg} / \mathrm{l}$, provavelmente resultante da micropoluição 
ambiental ou da produção endógena do hexano (e.g., processos de peroxidação lipídica) (Brasil, 2013; Leite, 2008).

Tabela 2. Parâmetro de controle biológico de exposição ocupacional ao hexano (adaptado de Brasil, 2013).

\begin{tabular}{ccccccc}
\hline \multirow{2}{*}{ Agente } & \multicolumn{2}{c}{$\begin{array}{c}\text { Indicador } \\
\text { Biológico }\end{array}$} & VR & IBMP & Método Analítico & Amostragem \\
\cline { 2 - 4 } & $\begin{array}{c}\text { Material } \\
\text { Biológico }\end{array}$ & Análise & & & & \\
\hline Hexano & Urina & $2,5-\mathrm{HD}$ & ------ & $\begin{array}{c}5 \mathrm{mg} / \mathrm{g} \\
\text { creat. }\end{array}$ & $\begin{array}{c}\text { Cromatografia em } \\
\text { fase gasosa }\end{array}$ & $\begin{array}{c}\text { Final do último dia de } \\
\text { jornada de trabalho }\end{array}$ \\
\hline
\end{tabular}

2,5-HD: 2,5-hexanodiona; VR: Valor de Referência; ------- Valores não informados; IBMP: Índice Biológico Máximo Permitido.

Entretanto, a NR15 do Ministério do Trabalho e Emprego não inclui o hexano entre os agentes químicos de monitoramento ambiental regular (Brasil, 2014a). Nesses casos, a NR9 define que, na ausência desses valores de referência, os valores limites de exposição ocupacional da American Conference of Governmental Industrial Higyenists (ACGIH) devem ser adotados (Brasil, 2014b).

A ACGIH é uma associação científica não governamental, privada e sem fins lucrativos, composta por profissionais de segurança do trabalho e higienistas ocupacionais. Comissões da ACGIH analisam e compilam dados referentes a níveis de exposições de vários agentes físico-químicos encontrados em ambiente ocupacional. Anualmente, a ACGIH publica os valores-limite (Threshold Limit Values - TLVs) e os índices de exposição biológica (Biological Exposure Indices - BEIs) para facilitar a tomada de decisão em relação aos níveis seguros de exposição a esses agentes (Dekant \& Anders, 2008).

Entretanto, os TVLs estabelecidos pela ACGIH não possuem valor legal nos EUA. Os valores limite de exposição ocupacional (Permissible Exposure Limits - PEL) que possuem valor legal, são definidos pela Administração de Segurança e Saúde Ocupacional (OSHA) do Departamento de Trabalho dos Estados Unidos (ver Tabela 3) (Dekant \& Anders, 2008). 
Tabela 3. Parâmetros ambientais e biológicos de exposição ocupacional ao hexano no Brasil e nos EUA.

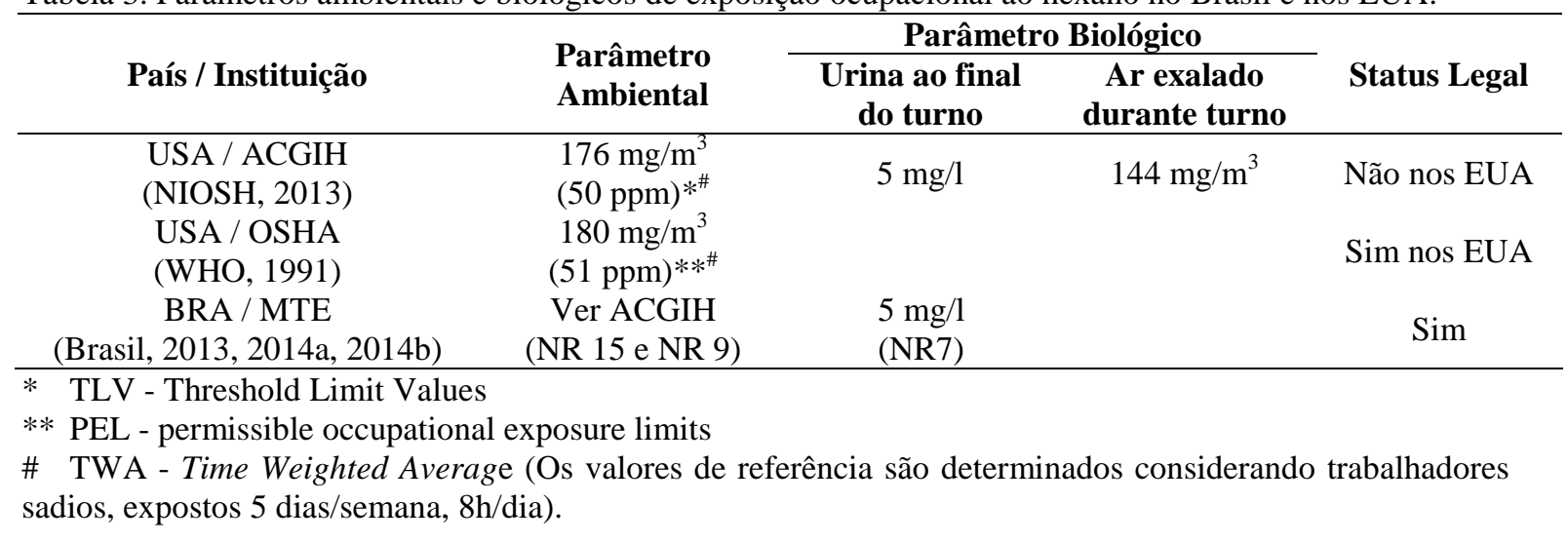

Esses indicadores biológicos apresentam correlação positiva com a exposição ao hexano. A variação nos valores é explicada pelas diferentes metodologias de amostragem do ar ocupacional, suas condições de amostragem (e.g., temperatura do dia), diferenças na metodologia da coleta urinária (dia e hora da coleta, transporte e armazenamento), a pureza das substâncias comercializadas, o fato da exposição ser simultânea ou não e o fato dessa estar ou não conjugada a algum outro agente que afete a sua toxicidade (e.g., tolueno, metil-n-butilcetona, metil-etilcetona e acetona), a eventual absorção cutânea, o uso ou não de EPI's, dentre outros (Leite, 2008).

A NIOSH também estabelece valores de exposição que não devem ser excedidos em nenhum momento (Immediately Dangerous to Life and Health), sendo 17.600 $\mathrm{mg} / \mathrm{m}^{3}$ (5.000 ppm) o parâmetro adotado, pois diz respeito à Concentração Letal do hexano (CL 50) em humanos para um intervalo de 10 min. (NIOSH, 2013; Petrobras, 2011). Em ratos adultos, a CL 50 varia em torno de $271.040 \mathrm{mg} / \mathrm{m}^{3}(77.000 \mathrm{ppm})$ para o período de 1 h de exposição. Já a Dose Letal (via oral) da substância (LD 50), em ratos adultos, varia entre 15.000-30.000 mg/kg (Petrobras, 2011; WHO, 1991).

\section{TOXICODINÂMICA E NEUROTOXICOLOGIA}

Por uma limitação de objeto, aqui serão descritos detalhes toxicológicos do hexano sobre o sistema nervoso. Para aprofundamento sobre outros órgãos e sistemas (i.e., pele, coração, testículos, olhos, sistema respiratório), ou outros efeitos (mutagenicidade, carcinogenicidade, teratogenicidade), ver EPA (2005), WHO (1991), Blake (2004) e Leite (2008).

A maior parte dos agentes voláteis é lipofílica, o que favorece sua penetração na barreira hemato-encefálica. Desse modo, os solventes são capazes de exercer efeitos no sistema nervoso e no comportamento (Blake, 2004; Eckert \& Müller, 2008; WHO, 
1991). O efeito neurotóxico pode ser estrutural e/ou funcional. Quando estrutural, pode ocorrer no corpo celular (neuropatia), axônio (axonopatia) ou especificamente na mielina (desmielinização). Quando funcional, pode modificar o funcionamento da neurotransmissão, sem necessariamente gerar danos estruturais ao sistema nervoso (Blake, 2004; Eckert \& Müller, 2008).

Dekant e Anders (2008) sugerem que quatro tipos de efeitos tóxicos podem ser distinguidos por exposição a solventes lipofílicos: (a) A exposição aguda em alta concentração via inalação, que gera rápida distribuição no organismo, resultando em altas concentrações no SNC, promovendo narcose (i.e., desorientação, euforia, vertigem, paralisia), dentre outros acometimentos (convulsões e eventual morte por parada cardíaca ou respiratória). Alguns desses efeitos são reversíveis após remoção da exposição. (b) A exposição ocupacional em limites superiores aos padrões aceitáveis, que geram reações no SNC (parestesia, déficits visuais ou auditivos, perda de memoria, irritabilidade, comportamento compulsivo, perda de coordenação e fadiga), detectáveis em testes comportamentais de toxicidade. (c) A exposição crônica, que revela toxicidade em vários órgãos ou sistemas. Essa toxicidade é variável em função das substâncias químicas, pois afetarão diferentes órgãos-alvo, dada a biotransformação de seus metabólitos tóxicos. E, (d) a exposição da pele, trazendo consequente irritação, hiperplasia celular, edema e outros danos à pele. Esses danos podem aumentar a taxa de penetração de outros componentes, quando em contato com a pele.

Quanto ao hexano, especificamente, já é sabido que sua neurotoxicidade é propriedade, principalmente, de um de seus metabólitos, a 2,5-HD. Mas esse metabólito também é comum a outros agentes, como o metil n-butil cetona (MBK) (Allen et al., 1975; DeCaprio, 2000; Eckert \& Müller, 2008; Weiss, 1983), ou outros hidrocarbonetos alifáticos (Leite, 2008). Além disso, a exposição conjunta de hexano com alguns toxicantes (e.g., methil-etil-cetona, metil-isobutil-cetona, acetato de chumbo, acetona ou hidrocarbonetos alifáticos), intensifica os efeitos tóxicos do hexano (Cardona et al., 1996; Leite, 2008; WHO, 1991), ao passo que outras substâncias (e.g., zinco), podem gerar menor intoxicação, dada a competição enzimática, funcionando como quimioprotetores (Blake, 2004; Ikeda et al., 1993; Mateus, Santos, \& Batoréu, 2002).

Verificou-se que a ação do hexano é majoritariamente sobre o axônio e a desmielinização produzida por ele é secundária ao efeito axonopático. Seu efeito sobre o axônio deixa o corpo celular intacto mas, quando o axônio progressivamente degenera, a mielina também é destruída (Blake, 2004). Hipóteses explicam que a 
axonopatia induzida pela hexano deriva de um comprometimento do sistema metabólico da célula. Em síntese, a 2,5-HD reage com organelas intracelulares formando pirroles. A ligação cruzada entre esses pirroles e neurofilamentos pirole-dependentes dificultam o transporte proteico intracelular, dado o estreitamento de regiões do axônio. Assim, um acúmulo de proteínas em uma região de constrição resulta na axonopatia (Boekelheide, 1987; Dekant \& Anders, 2008). Esse comprometimento gera, em primeiro lugar, uma degeneração da porção distal do axônio, visto que essa região é mais dependente dos mecanismos axonais de transporte energético (Boekelheide, 1987; DeCaprio, 2000; Eckert \& Müller, 2008). Se a exposição persistir, a degeneração progridirá para as partes mais proximais e, eventualmente, afetará toda a célula (Blake, 2004; DeCaprio, 2000). Essa degeneração distal-proximal é chamada de neuropatia retrógrada. Cabe salientar que essa é considerada uma reação morfológica comum após a exposição crônica ou subaguda a várias substâncias químicos industriais, não só ao hexano (Blake, 2004; DeCaprio, 2000; Eckert \& Müller, 2008; WHO, 1991). Essa degeneração axonal retrógrada inicia-se da porção distal do nervo, avança gradualmente para o centro com as fibras mielinizadas mais longas e maiores, degenerando-se antes das fibras menores e mais curtas (Blake, 2004; DeCaprio, 2000; Eckert \& Müller, 2008; Elsner, Fellmann, \& Zbinden, 1988). Portanto, em fases mais tardias de exposição, fibras mielinizadas curtas e fibras não mielinizadas também são afetadas pelo hexano (WHO, 1991). Nas axonopatias, as perdas sensoriais tendem a preceder a perda na função motora. A perda do reflexo patelar é um indicador precoce de axonopatia (Eckert \& Müller, 2008).

A depender das condições de exposição ao solvente, as células de Schwann podem sobreviver e conduzir uma regeneração axonal (Blake, 2004; DeCaprio, 2000). Se a exposição ao agente for descontinuada antes da morte do axônio, axônios do sistema nervoso periférico irão se regenerar (Blake, 2004; DeCaprio, 2000). Entretanto, a regeneração axonal de células do sistema nervoso central é muito pequena (DeCaprio, 2000) ou não ocorre (DeCaprio, 2000; Eckert \& Müller, 2008). A recuperação pode durar meses, anos ou nunca ocorrer completamente mas, quando ocorre, as funções são restabelecidas ao inverso da ordem com o que se deu a perda (DeCaprio, 2000).

Corroborando essa hipótese, estudos in-vitro e in-vivo demonstraram o edema axonal, degeneração de fibras nervosas centrais e periféricas e necrose de fibras musculares, sendo que o edema e a retração de mielina paranodal desenvolveu-se primeiro em regiões distais e paranodais de fibras de grande diâmetro, com raros registros de regeneração (WHO, 1991). Um exemplo vem de Politis, Pellegrino e 
Spencer (1980) que, em uma preparação, expuseram diretamente o nervo ciático de ratos ao 2,5-HD (diluído ou não), por 45 min. Como resultado, observaram a formação de edemas axonais característicos, afinamento da mielina e degeneração axonal após 4 dias de tratamento.

A exposição sistêmica ao hexano, em modelos animais, promove uma generalizada depressão do sistema nervoso central, levando à anestesia (dosedependente), parada respiratória, perda de reflexos posturais e, até mesmo, à morte (exposições de 7.040 a $316.800 \mathrm{mg} / \mathrm{m}^{3} ; 2000$ - 90.000 ppm). A letalidade depende da concentração da substância inalada, sua pureza e a temperatura a qual tal exposição ocorreu. Outros sintomas relatados são: hipotermia, ataxia, diminuição na atividade motora, sedação, apneia, crises convulsivas, irritação cutânea e redução no ganho de peso (DeCaprio, 2000; WHO, 1991). Em ratos expostos ao 2,5-HD, foram relatados aumento na concentração plasmática de acteilcolinesterase, redução do fluxo sanguíneo e na captura da glicose em várias áreas do cérebro, sendo o colículo inferior uma das regiões mais afetadas (WHO, 1991). Cabe citar que déficits eletrofisiológicos e comportamentais também foram identificados em experimentação animal após exposição ao hexano e seus metabólitos. Essas evidências serão tratadas mais adiante.

Em humanos, sintomas clínicos comuns da axonopatia podem manifestar-se como déficits na função sensorial, motora ou combinação de ambas. Geralmente, os primeiros sintomas são sensoriais e os sinais clínicos são simétricos nos braços e pernas. Formigamentos e insensibilidade nas mãos e pés (sintomas iniciais), podendo progredir para câimbras nas pernas, fraqueza nos braços e pernas, e ataxia. Por vezes, observa-se um moderado a severo comprometimento do reflexo aquiliano. Em resumo, as mudanças sensoriais são notadas mais proeminentemente, seguidas pelo envolvimento progressivo de neurônios motores gerando, comumente, sinais e sintomas motores (Blake, 2004; DeCaprio, 2000).

Não existe terapêutica específica para casos de neuropatia induzida por hexano. Quando a intoxicação ocorre, recomenda-se a remoção da pessoa da exposição e o emprego de medidas de suporte, tal como a fisioterapia (DeCaprio, 2000). A recuperação dos sintomas depende dos parâmetros da exposição e pode ser completa ou parcial. Essa recuperação sempre é gradual e lenta e, em casos severos, sinais residuais de neuropatia podem persistir por 2 a 5 anos em humanos (DeCaprio, 2000; WHO, 1991). 
Os estudos in vitro, somados aos estudos com modelos animais e os dados clínicos, sugerem que os primeiros sinais de uma neuropatia induzida por hexano são: alteração de sensibilidade; parestesia simétrica (que pode-se manifestar em forma de luva ou meia); fraqueza e redução na força de compressão. As extremidades inferiores geralmente são afetadas primeiro. Pode ocorrer prejuízo na marcha (ataxia) com eventual progressão para paralisia flácida de membros inferiores e, em quadros muito severos, quadriplegia (WHO, 1991).

Sintomas como dor de cabeça e tontura podem anteceder ou coincidir com a neuropatia. Além da dor de cabeça, a exposição aguda provoca náuseas, perturbações visuais e auditivas e desinibição comportamental. A continuidade da exposição pode gerar depressão moderada, seguida da falta de coordenação motora, confusão mental e eventual perda de consciência. O período de exposição que antecede uma clara neuropatia pode variar entre 2 meses e 5 anos, dependendo das condições de exposição e uma neuropatia leve pode ser assintomática (WHO, 1991). A exposição crônica gera, na maioria dos casos, redução do peso corporal e diminuição ou ausência de reflexos, além da já descrita "dying-back neuropathy". Em caso de ingestão, pode causar vômitos, diarreia e efeito narcotizante.

Evidências eletrofisiológicas de disfunção do SNC (redução na velocidade de condução em nervos motores e sensoriais, registrada no potencial evocado) têm sido relatadas em casos de neuropatia periférica (Mutti et al., 1982). Essas alterações ocorreram após exposição a uma grande amplitude de níveis de hexano no ar, variando entre 97 e $8.125 \mathrm{mg} / \mathrm{m}^{3}$ (28-2308 ppm).

\section{TOXICOLOGIA COMPORTAMENTAL}

A neurotoxicidade é descrita a partir do efeito adverso de toxicantes sobre a estrutura e/ou função do sistema nervoso e a disciplina que se ocupa desses estudos é a Neurotoxicologia. Toxicologia Comportamental refere-se às consequências funcionais da neurotoxicidade, como o efeito de toxicantes, sobre o comportamentos. Portanto, investigam-se relações entre agentes tóxicos e atenção, memória e percepção visoespacial, assim como processos relacionados à personalidade e o humor, função psicomotora e sensorial, e ainda alterações eletrofisiológicas (Blake, 2004; Seeber, 2008). Pesquisas nesta área mostram que a efeitos não observados no sistema nervoso pode se seguir outros efeitos comportamentais (Weiss, 1983). As investigações em 
toxicologia comportamental voltam-se para as consequências funcionais da toxicidade, e o comportamento é tido como indício de um efeito tóxico, tendo como complemento as informações de mecanismos tóxicos dos toxicantes (Seeber, 2008).

\section{Pesquisas com Animais}

Muitos neurotoxicantes têm sido apontados como responsáveis por afetar componentes da atividade motora (e.g., movimento, força, marcha), dentre os quais está o hexano (Cory-Slechta, 1989; DeCaprio, 2000). Para avaliar esses distintos componentes, diferentes testes e aparatos são utilizados. Algumas dessas tecnologias serão aqui descritas, a saber: a "automated hindlimb movement" (movimentação automatizada de membros traseiros) e a "response force titration" (titulação da força da resposta). Além desses, a "Functional Observational Battery" - FOB (bateria de observação funcional), é uma alternativa de triar variados efeitos, pois permite o estudo de sinais autonômicos, motores e sensoriais (ver Cory-Slechta (1989) para maior detalhamento).

O "automated hindlimb movement" é um procedimento automatizado desenvolvido por Tanger, Vanwersch e Wolthuis (1984) para diferenciar postura de movimento. Nesse procedimento os pesquisadores mediam o movimento da pata traseira esquerda de ratos na roda de atividade. O sistema detectava a trajetória da pata durante a travessia de um "degrau" ao outro na roda. Assim, os investigadores acessavam vários aspectos do andar, incluindo suas características topográficas (passos curtos corretos; passos longos corretos; passos em falso) e temporais (tempo total de apoio da pata esquerda traseira sobre os degraus da roda, tempo gasto nos pequenos e longos passos corretos, tempo gasto nos passos em falso e na falha em andar). Kulig, Vanwersch e Wolthuis (1985) fizeram a administração oral sub-crônica (3 semanas consecutivas, 5 dias por semana) de diferentes doses $(250$ e $600 \mathrm{mg} / \mathrm{kg}$ e grupo controle) de 2,5-HD em ratos que foram semanalmente avaliados, 24 h após a última administração, no "automated hindlimb movement". Os resultados demonstraram um prejuízo dose-dependente nos escores de movimentos coordenados para ambos os grupos, quando comparados ao grupo controle, durante as três semanas de tratamento com a 2,5-hexanodiona. Tão logo terminado o tratamento, os escores de movimentos coordenados passaram a se recuperar, e ao final das 8 semanas de experimentação, o grupo $250 \mathrm{mg} / \mathrm{kg}$ havia se recuperado, enquanto o $600 \mathrm{mg} / \mathrm{kg}$ não chegou a recuperar-se a ponto comparável ao grupo controle. 
Outros estudos corroboram o prejuízo que o hexano tem sobre o comportamento motor em membros inferiores de ratos (Krasavage, O’Donoghue, DiVincenzo \& Terhaar, 1980). Paralisia e enfraquecimento severo de membros inferiores, lesão em nervo tibial, edema axonal, remoção de mielina axonal e retração de mielina paranodal são os achados histológicos mais comuns (DeCaprio, 2000; WHO, 1991). Essa desmielinização paranodal é correlacionada com a diminuição da condução dos impulsos elétricos (DeCaprio, 2000), o que é empiricamente sustentado por estudos que apontam uma redução na velocidade de condução do nervo da cauda (Krasavage et al., 1980), após a administração oral e crônica de hexano.

Redução da atividade motora espontânea, diminuição da força de compressão de membros inferiores, redução na habilidade de escalada e diminuição das respostas de esquiva condicionada foram observadas em ratos Fischer-344 machos expostos (por inalação) ao n-hexano (95\% puro), a uma concentração de $3520 \mathrm{mg} / \mathrm{m}^{3}$ (1000 ppm), por 24 horas/dia, 5 dias por semana, ao longo de 11 semanas. Houve recuperação de alguns comportamentos após 18 (esquiva condicionada) e 36 (habilidade de escalada) semanas do término da exposição (Pryor \& Howd, $1982^{3}$ citado em WHO, 1991).

Ainda nesse sentido, observou-se redução na atividade motora, na resposta de sobressalto, na habilidade de escalada, na resposta de esquiva e na força de compressão em ratos Fischer-344 machos expostos (por inalação) ao n-hexano (95\% de pureza), a uma concentração de 7040 mg/m3 (2000 ppm), por 14 h/dia, 7 dias/semana, ao longo de 14 semanas. Medidas eletrofisiológicas indicativas de danos no sistema nervoso periférico (e.g., potencial de ação da cauda, potencial evocado, eletromiografia de membros inferiores) também foram afetados (Pryor, Dickinson, Howd \& Rebert, $1983^{4}$ citado em WHO, 1991).

Ladefoged, Rosswall e Larsen (1994) trataram ratos com 0,5\% de 2,5-HD dissolvidos em garrafas de água ao longo de seis semanas. Semanalmente, avaliações motoras (deambulação e levantamento no campo aberto; equilíbrio em um rotarod com gradual aumento da aceleração; medidas de força dos membros anteriores e posteriores) eram realizadas. Exames histopatológicos realizados na sexta semana de tratamento revelaram edema axonal e um gradual decremento nas medidas comportamentais

\footnotetext{
${ }^{3}$ Pryor, G. T. \& Howd, R.A. (1982). Developmental long-term effects of inhalants in animals. NIDA Quarterly Report No. 5. Washington: US National Institute of Drug Abuse.

${ }^{4}$ Pryor, G. T.; Dickinson, J.; Howd, R. A. \& Rebert, C. S. (1983). Neurobehavioural effects of subchronic exposure of weanling rats to toluene or hexane. Neurobehavioral Toxicology and Teratology, 5 (1): 47-52.
} 
ocorreu ao longo do tempo. A reversibilidade do efeito neurotóxico foi avaliada e, anterior ao período de 10 semanas, a deambulação no campo aberto foi revertida. Após atingir-se o período de 10 semanas, o efeito foi revertido para os levantamentos (no campo aberto) e equilíbrio no rotarod. Além de prejuízos motores (tempo para reposição da pata traseira à posição habitual), diminuição no peso também foi observado em ratos Charles River CD expostos (via oral) ao 2,5-HD (98\% de pureza), a uma concentração de 1\% diluído em água ad libitum ao longo de 4 semanas (Boekelheide, 1987).

O "response force titration" é um procedimento desenvolvido por Elsner, Fellmann e Zbinden (1988) para diferenciar alterações na força empregada para uma resposta, dos aspectos motivacionais relativos à mesma. Nesse procedimento ratos são treinados em uma caixa operante a pressionar uma barra (com uma dada força) para receberem reforço. É feita uma técnica de titulação (titration) onde a força exigida para pressão à barra em cada sessão experimental é aumentada ou diminuída se a exigência de força na sessão anterior foi, respectivamente, atingidas ou não. O critério de sucesso de cada sessão era atendido se o animal obtivesse 50\% dos reforços programados. Vários aspectos do desempenho motor podem ser mensurados nessa situação experimental, tais como: força máxima (a maior força que o animal conseguia atingir); força assintótica (reflete o desempenho que o rato consegue sustentar); soma da força (um indicativo da tolerância do rato); taxa de respostas, latência da resposta e duração da resposta, essas três últimas sendo utilizadas para avaliar aspectos motivacionais do desempenho que poderiam indiretamente afetar o comportamento motor. Elsner et al. (1988) expuseram ratos Sprague-Dawley a um tratamento subcrônico (oral via gavagem; concentração de 5m1/kg de água) com 2,5-HD (pureza não informada), a duas doses (250 ou $500 \mathrm{mg} / \mathrm{kg}$ ) em dias de semana por 14 (grupo $500 \mathrm{mg} / \mathrm{kg}$ ) ou 23 doses (grupos $250 \mathrm{mg} / \mathrm{kg}$ e controle). Os autores observaram efeitos distinguíveis após cerca de 7 doses, perdurando ao longo do experimento, de forma dose-dependente. De maneira geral, enquanto as medidas de força e peso diminuíam, as medidas de responsividade permaneceram intactas, sugerindo uma seletividade do agente ao prejuízo motor (e não motivacional). Ademais, a histopatologia mostrou edema axonal nos lados proximais aos nodos de Ranvier, com retração paranodal da mielina no nervo ciático de dois animais (um de cada grupo experimental).

A FOB foi utilizada para investigar efeitos da administração intraperitonial de 2,5-HD (98\%), em doses de 150, 225 ou $350 \mathrm{mg} / \mathrm{kg}$, por dia, por 28 doses. Várias alterações comportamentais foram observadas, particularmente naquelas tarefas que 
testavam as funções motoras (e.g., nível de atividade do animal, marcha, reflexos, força de apreensão das patas traseiras). Isso ocorreu logo após uma semana de exposição e se intensificou com o passar do tempo (Shell, Rozum, Jortner, \& Ehrich, 1992).

Quanto às pesquisas envolvendo esquemas de reforçamento, o efeito do hexano já foi investigado na esquiva sinalizada (Ikeda, Katakura, Kishi \& Miyake, 1993). Os experimentadores avaliaram o efeito que o hexano ( $99 \%$ de pureza) poderia ter com o tolueno. Para tanto, ratos Wistar foram divididos em três grupos (hexano; tolueno; hexano + tolueno) e sofreram exposição aguda (via inalação) das substâncias ao longo de 240 minutos, em diferentes concentrações (50, 100, 200, 400 e 800 ppm, em ordem ascendente). Durante a linha de base, os animais apresentavam uma taxa de esquiva acima de $80 \%$; a taxa de respostas também foi avaliada. No que tange ao efeito do hexano, a inspeção visual dos gráficos sugere que, no geral, concentrações entre 100 e 400 ppm, entre 60 e 180 min de exposição, diminuem a taxa de esquiva e resposta, retornando gradualmente aos níveis basais entre os minutos 180 a 240 (em forma de U). $\mathrm{Na}$ menor concentração avaliada $(50 \mathrm{ppm})$, nos primeiros $60 \mathrm{~min}$., observou-se diminuição na taxa de esquiva (mas não na taxa de resposta). A avaliação pós-exposição (quinta hora de experimento 240 - 300 min.) mostra uma diminuição na taxa de esquiva sem alteração na taxa de respostas durante todos os 60 min. de avaliação. Alterações comportamentais nas concentrações de 100, 200 e 400 ppm não são claras em termos de tendências. Porém, a exposição a 800 ppm induziu um aumento na taxa de respostas ao longo de toda a exposição. Neste período não existiram alterações estatisticamente significativas nas taxas de esquiva. Durante a pós-exposição foi observado um retorno à linha de base. O efeito disrruptivo inicial ao hexano, mesmo em baixa concentração, é discutido pelos autores como efeito de irritação das substâncias sobre os olhos, garganta e nariz. Os experimentadores salientam que o efeito observado com 50 ppm, mas não com 100, 200 e 400 ppm, pode ser efeito de primeira exposição ao hexano e concluem que o hexano apresentou um efeito narcótico na concentração de 800 ppm, variável nas doses inferiores pesquisadas.

Uma vez que a exposição ocupacional aos solventes raramente ocorre isolada, trabalhos têm investigado o efeito de outras substâncias e do hexano sobre o organismo. Ikeda et al. (1993) mostraram que, em exposições agudas, o tolueno modifica o efeito neurocomportamental do hexano (concentração de $1.408 \mathrm{mg} / \mathrm{m}^{3} ; 400 \mathrm{ppm}$ ) de forma imprevisível e já foi sugerido que existe um efeito desses dois agentes sobre o sistema dopaminérgico (WHO, 1991). Ainda avaliando o efeito de interação, Lam et al., (1991) 
demonstraram que uma solução de acetona e 2,5-HD podem intensificar os prejuízos produzidos pela 2,5-HD em testes neurocomportamentais (rotarod e campo aberto) e neurofisiológicos. Ademais, observaram que a acetona adicionada a 2,5-HD prejudica a aquisição (mas não o desempenho) em uma atividade de aprendizagem espacial em um labirinto radial de 8 braços e, por sua vez, Mateus et al. (2002) demonstraram que o zinco pode funcionar como um quimioprotetor aos efeitos neurotóxicos do 2,5-HD, o que fora obtido com ratos em testes bioquímicos e neurocomportamentais (deambulação e levantamentos no campo aberto).

Em conjunto, os resultados supracitados apontam que o hexano (ou, mais precisamente, seu metabólito 2,5-HD) prejudica a função sensório-motora sem, contudo, trazer decremento na "motivação" para o comportamento. Quando associada a outros compostos, pode prejudicar a aprendizagem e agravar os prejuízos sensóriomotores (Maurissen, 1995).

\section{Pesquisas com Humanos}

No que tange ao hexano, pesquisas com humanos têm sido dificilmente documentadas, quer seja pelas limitações éticas de investigação, pela carência de informações adequadas sobre os níveis de exposição, ou pelo fato da exposição isolada ao hexano dificilmente ocorrer. Ademais, diferentes delineamentos, métodos e "settings" de investigação, etc., dificultam interpretações dos dados e dos níveis de exposição. Alguns trabalhos mostram que, após a exposição ao hexano comercial, entre 3520 a $17600 \mathrm{mg} / \mathrm{m}^{3}$ (1000 - $\left.5000 \mathrm{ppm}\right)$, entre 10 e 60 minutos, manifestam-se sinais de intoxicação caracterizados por sonolência, vertigem, tontura e depressão do SNC (WHO, 1991). Tem-se documentado a ocorrência de neuropatia sensório-motora periférica em exposições variando entre 106 a $8800 \mathrm{mg} / \mathrm{m}^{3}$ (30 - $\left.2500 \mathrm{ppm}\right)$, em trabalhadores japoneses que fabricavam sandálias $\left(176 \mathrm{mg} / \mathrm{m}^{3}-50 \mathrm{ppm}\right)$, ou impermeabilizadores tailandeses $\left(352 \mathrm{mg} / \mathrm{m}^{3}-100 \mathrm{ppm}\right)$ expostos por períodos que excediam 8h por dia (WHO, 1991).

Acidentes ocupacionais envolvendo o hexano remetem à fabricantes de calçados (Itália e Japão), trabalhadores de gráficas (Tailândia), indústria de moagem de tungstênio (Japão), indústria de extração de óleo vegetal (EUA) e indústria petrolífera (Brasil). Os trabalhos apresentam como sinais e sintomas comuns a sonolência, tontura, fraqueza muscular, parestesia, prejuízo sensorial, visão turva, frieza nas extremidades, diminuição dos reflexos dos tendões, alteração em parâmetros eletrofisiológicos 
(diminuição na velocidade de condução no nervo motor, amplitude e duração do potencial de ação em nervo motor, anormalidades em potencial de ação), ou mesmo o quadro clínico de polineuropatia (neuropatia sensorial, motora ou sensório-motora) instalado (Abbritti et al., 1976; DeCaprio, 2000; Di-Bosco \& Fonzi, $1974^{5}$ citado em WHO, 1991; Mutti et al., 1982; Sanagi et al., 1980).

Dado as dificuldades metodológicas e éticas, os estudos envolvendo humanos baseiam-se primordialmente em estudos de campo, considerando-se portanto situações de exposições agudas em nível altos, ou exposições crônicas e subclínicas. Eckerman et al. (2009) apontam que três diferentes tipos de abordagens epidemiológicas têm sido utilizadas em estudos de campo que estimam a exposição de humanos a algum agente tóxico, a saber: (a) comparações de grupos; (b) caracterização da exposição individual por meio de auto-relatos ou registros de arquivos e (c) avaliação biológica ou ambiental de exposição. Os próprios autores sugerem uma quarta alternativa: (d) observação direta e repetida do comportamento. Um quadro comparativo entre essas estratégias pode ser traçado, conforme a Tabela 4.

\footnotetext{
${ }^{5}$ Di-Bosco, M. \& Fonzi, S. (1974). So-called glue or shoe makers' polyneuropathy. Rivista Degli Infortuni e Delle Malatie Professionali, 61 (1): 165-192.
} 
Tabela 4. Caracterização das principais abordagens epidemiológicas em toxicologia com humanos (cf. Eckerman et al., 2009).

\begin{tabular}{|c|c|c|c|}
\hline Abordagem & Característica & Confiabilidade & Limitações \\
\hline $\begin{array}{l}\text { Comparação de } \\
\text { grupos }\end{array}$ & $\begin{array}{l}\text { Compara algum índice (e.g., } \\
\text { saúde) em um grupo não } \\
\text { exposto (grupo controle) ao de } \\
\text { um grupo exposto (grupo } \\
\text { experimental) }\end{array}$ & $\begin{array}{l}\text { - } \quad \text { Moderada a Baixa* } \\
\text { - } \quad \text { Não caracteriza grau de } \\
\text { exposição }\end{array}$ & $\begin{array}{l}\text { - A distribuição da concentração da exposição pode ser ampla dentro } \\
\text { dos grupos em graus que esses podem se sobrepor } \\
\text { - Os indivíduos dos grupos podem diferir em outros aspectos e gerar } \\
\text { confundidores na comparação (e.g., diferenças educacionais ou sócio- } \\
\text { econômicas) }\end{array}$ \\
\hline $\begin{array}{l}\text { Caracterização da } \\
\text { exposição individual } \\
\text { por meio de auto- } \\
\text { relatos ou registros } \\
\text { de arquivos }\end{array}$ & $\begin{array}{l}\text { Em alguns grupos a recordação } \\
\text { pode ser razoavelmente acurada } \\
\text { uma vez que esses mantem } \\
\text { algum tipo de registro }\end{array}$ & $\begin{array}{l}\text { - } \quad \text { Moderada a Alta* } \\
\text { - } \quad \text { Limitado na } \\
\text { caracterização do grau de } \\
\text { exposição }\end{array}$ & $\begin{array}{l}\text { - A validade do auto-relato retrospectivo não é confiável: a maioria } \\
\text { das pessoas não se lembra de detalhes (sobretudo de situações } \\
\text { aversivas/de risco), o contexto social pode enviesar o relato (super ou } \\
\text { subestimando atividades de risco) } \\
\text { - Arquivos não corrigem automaticamente os viéses do auto-relato, } \\
\text { sobretudo quanto às atividades de risco }\end{array}$ \\
\hline $\begin{array}{l}\text { Avaliação biológica } \\
\text { ou ambiental de } \\
\text { exposição }\end{array}$ & $\begin{array}{l}\text { Útil na avaliação de campo dos } \\
\text { efeitos da exposição tóxica à } \\
\text { saúde }\end{array}$ & $\begin{array}{l}\text { - } \quad \text { Alta* }^{*} \\
\text { - } \quad \text { Caracteriza grau de } \\
\text { exposição }\end{array}$ & $\begin{array}{l}\text { - Tóxicos de rápida metabolização podem gerar grande variabilidade } \\
\text { dentro e entre amostras de material (e.g., sangue) e, nesses casos, } \\
\text { amostras de urina devem ser evitadas por não proverem uma avaliação } \\
\text { precisa de exposição } \\
\text { - Tanto a avaliação biológica quanto a avaliação ambiental manterão } \\
\text { o questionamento do quanto o valor representa uma exposição de longo } \\
\text { prazo (histórica ou cumulativa) }\end{array}$ \\
\hline $\begin{array}{l}\text { Observação direta e } \\
\text { repetida do } \\
\text { comportamento }\end{array}$ & $\begin{array}{l}\text { Observação de comportamentos } \\
\text { predeterminados como de } \\
\text { exposição ao risco e de } \\
\text { prevenção ao risco }\end{array}$ & $\begin{array}{l}\text { - } \quad \text { Moderada a Alta* } \\
\text { - } \quad \text { Permite uma estimativa } \\
\text { do grau de exposição }\end{array}$ & - $\quad$ Custos. \\
\hline
\end{tabular}

* Este julgo é do presente texto e não compõe o texto original de Eckerman et al. (2009). 
Um estudo que relaciona a avaliação biológica e ambiental de exposição do nhexano é o de Cardona et al. (1996). Os autores investigaram a concentração ambiental do hexano com sua concentração no ar exalado e em seus metabólitos urinários de trabalhadores de manufatura de calçados na Espanha. Os resultados demonstraram uma alta correlação entre o grau de hexano livre no ambiente e sua concentração no ar exalado $(r=0,88)$ e nos metabólitos urinários $(2,5$-HD livre: $r=0,94 ; 2,5$-HD total: $r=$ 0,80). Mais que isso, os autores identificaram que a concentração dos metabólitos aumenta com o não uso de luvas pelos trabalhadores (absorção transdérmica) e com o avançar dos dias trabalhados ao longo da semana.

Ao considerar que cerca de dois mil novos agentes químicos são introduzidos a cada ano (Blake, 2004), surge a necessidade de triagens por possíveis efeitos tóxicos dessas substâncias. A Agencia de Proteção Ambiental dos Estados Unidos da América propôs uma série de testes com roedores. Em conjunto, os testes que compõem a Bateria de Observação Funcional (FOB) avaliam aspectos sensoriais, motores e autonômicos, que identificam mudanças e permitem avaliação neuropatológica (para detalhamento dessa e outras baterias neurocomportamentais ver Blake, 2004. Para efeito do 2,5-HD em medidas do FOB, ver Shell et al., 1992). Estudos com humanos mostraram também a necessidade de baterias de triagem que pudessem identificar o mais rapidamente possível, alterações em funções neurocomportamentais (e.g., atenção e memória). A busca por testes especializados que identifique o impacto dos toxicantes sobre o organismo é destacado por (Blake, 2004).

A seguir, métodos neurocomportamentais utilizados em pesquisas com humanos serão apresentados.

\section{TÉCNICAS E Medidas NeURocomportamentais de Pesquisa COM Humanos}

Medidas comportamentais podem derivar de distintas fontes, e da influência de um agente tóxico. As variáveis neurocomportamentais podem ser acompanhadas por outras fontes de controle a serem sistematicamente registradas. Sexo, idade, grau de escolaridade, nível sócio-econômico, condições motivacionais, físicas e de saúde, uso de substâncias, horário da aplicação do teste e país onde o teste foi aplicado, podem representar viéses nas medidas neurocomportamental de interesse. Portanto, a aplicação de métodos neurocomportamentais deve contar com o controle e análise de potenciais variáveis confundidoras, via delineamentos de pesquisas e/ou instrumentos estatísticos. 
Estes destaques evitam viéses de avaliações de agentes tóxicos (Anger et al., 1996; Kang et al., 2005; Rohlman et al., 2007; Seeber, 2008).

\section{Funções Cognitivas}

Funções cognitivas são aquelas relativas a informações aprendidas ou não. $\mathrm{O}$ sucesso em testes cognitivos exibem desempenhos que requerem velocidade, precisão e podem ser mensuradas em curtos intervalos de tempo, quer sejam por testes papel-lápis (inventários), quer sejam mediados por computador. Testes de aprendizagem e memória avaliam o "armazenamento" e a "evocação" da informação. Testes de pensamento avaliam a "organização mental" e a "reorganização da informação". Teste de função expressiva e atividade mental avaliam a maneira como uma informação atua sobre alguma operação cognitiva, na qual o nível de consciência é expresso. Testes de função receptiva mensuram a seleção, aquisição, classificação e integração da informação (Seeber, 2008).

Testes de tempo de reação simples ou de escolha são tidos por testes de atenção com baixa demanda cognitiva. O tempo de reação simples consiste em dar uma resposta simples frente a um estímulo (visual ou auditivo). Esse tempo de reação cobre o processamento desde a aparição do estímulo até o início da resposta. Por sua vez, o tempo de reação de escolha envolve, geralmente, dois ou mais estímulos e respostas correspondentes fixas. Nesse caso, cobre-se o processamento anterior à pressão do botão de resposta (Córdova, Bravin, Oliveira, \& Barros, 2003; Seeber, 2008).

Outro exemplo típico, derivado da escala Wechsler de inteligência, é o Digit Span. Na versão padronizada de papel-lápis, uma série de números padronizados é apresentada verbalmente e a resposta verbal a ser dada é a repetição dos números. A sequência mais longa de dígitos, oralmente reproduzida corretamente pelo testando tanto na ordem direta quanto inversa - gera o escore para o Digit Span Test (Seeber, 2008).

Ao considerar a memória, um teste utilizado e baseado em processamento visoespacial é o Teste de Benton, quer seja na versão papel-lápis, quer seja informatizado. Figuras mais ou menos complexas são apresentadas ao testando que deve reproduzi-las desenhando-as ou identificando o padrão similar à figura previamente mostrada, dentre múltiplas possibilidades (Seeber, 2008). 


\section{Funções Executivas}

As funções executivas relacionam-se às habilidades de manejo. Se funções executivas estão prejudicadas, o indivíduo apresenta dificuldade em organizar atividades paralelas ou manter relações sociais satisfatórias. Esse déficit afeta diferentes aspectos do comportamento, como: comprometimento na capacidade de auto-controle e auto-direcionamento; tendência à irritabilidade, excitabilidade, impulsividade e rigidez; dificuldade na mudança da atenção; prejuízo na capacidade de iniciar atividades; decremento na motivação e prejuízo no planejamento e na realização de atividades em sequência (Seeber, 2008).

O teste de mudança de atenção, que avalia a função executiva, é coberto por três sub-tarefas. Primeiro o participante deve reagir compativelmente à posição (esquerda/direita) de quadrados em uma tela - versão bloco. Depois, compativelmente na direção (esquerda/direita) indicativa de uma seta - versão da seta. Finalmente, o participante deve reagir, seja ao bloco, seja à seta, a depender da instrução dada antes da aparição dos estímulos. Velocidade e erros são as medidas registradas (Seeber, 2008).

\section{Funções Psicomotoras}

As funções psicomotoras envolvem comportamentos públicos e representam a interface entre o comportamento e o ambiente. Os marcadores utilizados em testes de atividade psicomotora incluem tempo, força, velocidade e limites espaciais da resposta. A perda da integração do movimento geralmente é derivada de alterações em estruturas corticais específicas. Alterações psicomotoras podem incluir tremores, postura distônica e alterações em taxas de piscar de olhos, geralmente relacionou-se com prejuízos nos núcleos da base. Nistagmo, perda de reflexos posturais e prejuízo na coordenação motora podem derivar de prejuízos no cerebelo. Diminuição na força de apreensão, mudanças na orientação das pernas e alterações de marcha, podem derivar de alterações em nervos periféricos e junção neuromuscular (Seeber, 2008).

Os testes psicomotores conduzidos com humanos compõem baterias que avaliam destreza manual. Dentro destas encontram-se subtestes tais como: (a) o de estabilidade segurar uma caneta sem deixar que ela toque as bordas de um quadro; (b) o desenho de linha - direcionar uma caneta em uma linha padrão sem deixar tocar suas bordas; (c) o de mira - direcionar uma caneta em contato rapidamente sobre um plano; (d) o das batidas [tapping] - tocar um plano suavemente em um tempo constante; (e) Peg Board - 
manipular pregos em pequenos buracos. Nessas avaliações, velocidade e precisão são medidos e o teste é realizado sequencialmente com as duas mãos (Seeber, 2008).

\section{Personalidade, Humor e Emoção}

A labilidade emocional é um sinal típico de mudanças cerebrais decorrentes de danos provocados por agentes tóxicos. Em geral, são aferidos por meio de testes, questionários, inventários e/ou entrevistas padronizadas, que avaliam sintomas de prejuízo físico e mental; tolerância à frustração; perda de sensibilidade emocional e capacidade de modulação de comportamento emocional e episódios de mudanças afetivas (Seeber, 2008).

A maioria dos testes utilizados para esse tipo de avaliação são inventários de auto-aplicação padronizados, os quais cobrem itens que avaliam efeitos neurotóxicos crônicos ou agudos. Um exemplo é o EUROQUEST, amplamente empregado para avaliar efeito de solventes. O inventário aborda problemas neurológicos, sintomas psicossomáticos, labilidade de humor, problemas de memória e concentração, cansaço e problemas de sono, bem como efeitos agudos de intoxicações por solventes, como a irritação. O EUROQUEST avalia também características de personalidade como ansiedade-traço, sensibilidade ambiental, dentre outros, no intuito de medir variáveis confundidoras. O teste é baseado em uma escala variando do "às vezes/nunca" até o "muito frequentemente" (Seeber, 2008).

\section{Funções Sensoriais}

A avaliação de funções sensoriais tem gradualmente aumentado, especialmente a discriminação de cores, empregada em avaliação de efeito crônico de exposição aos solventes. O teste de saturação de Lanthony Panel D-15 identifica prejuízo na visão e discriminação de cores do espectro azul-amarelo, classificada como discromatopsia adquirida. No teste, o participante recebe 15 tampas removíveis (que representam passos perceptivos idênticos), as quais o participante deve ordenar de acordo com a cor, a fim de formar um círculo de matiz natural. O escore é atribuído baseando-se no Índice de Confusão de Cores, que indica a distância que o indivíduo colocou a tampa de seu local adequado. A intoxicação por solventes (e.g., tolueno, estireno e misturas), gera um aumento representativo do índice (Seeber, 2008).

A avaliação do limiar auditivo tem sido empregada em algumas pesquisas que se interessam pela exposição aos solventes. A perda de audição para altas frequências pode 
decorrer de exposição aos solventes, especialmente o tolueno. De igual modo, a função olfativa e a estabilidade em pé têm sido alvo de pesquisas. Nesses dois casos, a alteração pode ser reversível e/ou modulada por outras condições (Seeber, 2008).

Investigações acerca das influências de agentes tóxicos sobre o comportamento podem ser conduzidas com delineamentos, que emprega o controle de fatores confundidores externos (ambientais) ou internos (pessoais) (Seeber, 2008). Assim, os métodos neurocomportamentais de pesquisa têm sido empregados em delineamentos epidemiológicos.

\section{A COMPARAÇÃO ENTRE GRUPOS COM AVALIAÇÕES NEUROTOXICOLÓGICAS}

Historicamente, os primeiros indícios do potencial neurotóxico de alguns agentes advêm de exposição humana acidental em ambientes ocupacionais. Esses estudos de caso geralmente incluem a história médica e exames neurológicos clínicos, algumas vezes acompanhados de testagem psicológica e psiquiátrica avaliando o status mental da pessoa (consciência, orientação, humor, etc.) e testes sensório-motores (marcha, coordenação, tônus muscular, sensibilidade ao toque e reflexos). Por vezes, essa abordagem inclui avaliações comportamentais, neurofisiológicas e técnicas de neuroimagem (Blake, 2004).

Pesquisas no ambiente natural, pesquisas de campo, envolvem limitações características da disponibilidade de tempo dos participantes e do consentimento das indústrias para medidas de exposição de seus trabalhadores. Outro fator que pode dificultar as pesquisas é a caracterização das exposições a substâncias químicas. A composição e pureza e as durações das exposições pode não ser precisamente isoladas (Anger, 1992). E, como citado anteriormente, muitos testes são sensíveis a fatores confundidores (e.g., idade e grau de escolaridade) e envolvem também dificuldades técnicas de estimativa de exposição passada, após uma história de mudanças tecnológicas em diferentes setores de uma indústria (Seeber, 2008).

\section{Alguns Testes Neurocomportamentais para Humanos}

Existem vários testes que podem ser empregados em investigações neurocomportamentais, que avaliam distintas características. Por exemplo, o Matching to Sample pode ser empregado para investigação da memória, enquanto o National Adult Reading Test (NART), para avaliação da inteligência verbal. Mais que isso, existem distintos testes/metodologias, empregados para avaliar uma mesma dimensão. 
O NART e o Testing of Vocabulary, por exemplo, são distintas metodologias para a avaliação da inteligência verbal (Seeber, 2008). Esses testes podem ser empregados de forma isolada ou como parte componente de uma bateria de avaliação (Seeber, 2008).

Diferenças também ocorrem quando da transposição entre um teste do tipo papel-lápis para softwares em computadores. Um exemplo é o Symbol Digit Substitution que, originalmente, pertence à escala de inteligência de Wechsler. Na forma papel-lápis (Digit-Symbol Test), o participante deve desenhar símbolos pertencentes a dígitos, de acordo com uma lista de códigos pré-estabelecida, dentro de um intervalo limitado de tempo. O número de acertos serve como escore. A versão computadorizada (Symbol-Digit Test) requer uma ordem inversa de ação (tradução de símbolos para dígitos e não dígitos para símbolos), isto é, o participante deve escolher, em um teclado, dígitos que correspondem a símbolos apresentados em uma ordem randômica, seguindo a lista de códigos, dentro de um intervalo de tempo. Além das medidas de acerto, medidas de tempo também podem ser registradas para gerar as comparações (Seeber, 2008). Segundo Seeber (2008), o Symbol-Digit requer mais que a versão Digit Symbol no que diz respeito às funções executivas e à flexibilidade cognitiva.

Desse modo, a diversidade de instrumentos de medida e de procedimentos de avaliação, dificulta a comparação dos dados obtidos. Diferentes baterias de testes e delineamentos acabam por destacar o controle para determinadas variáveis confundidoras. É neste cenário que se encontra as pesquisas dos impactos dos toxicantes sobre as funções neurocomportamentais.

Pesquisas de campo têm se voltado para o desenvolvimento de testes padronizados, particularmente baterias de triagem para a identificação de efeitos subclínicos de exposições químicas. Além da possibilidade das avaliações biológicas, baterias para avaliar funções neurocomportamentais são alternativas para pesquisas com humanos, pois proveem medidas quantitativas que podem ser empregadas em investigações epidemiológicas (Anger, 1992). Essas baterias são compostas por uma série de testes que fornecem uma avaliação não invasiva da integridade funcional do sistema nervoso, sendo sensíveis mesmo quando esses déficits estão em níveis subclínicos. Evidenciar os déficits, neste caso, seria indicativo de neurotoxicidade de um determinado agente químico (Gimenes, Eckerman, \& Vasconcelos, 2010). Alguns autores (Blake, 2004; Rohlman et al., 2000; Seeber, 2008) listam como exemplos mais comuns a: Neurobehavioral Core Test Battery - NCTB, da Organização Mundial da 
Saúde e National Institute for Occupational Safety and Health, a Adult Environmental Neurobehavioral Test Battery - AENTB, a Swedish Performance Evaluation System SPES, o Behavioral Assessment and Research System - BARS, o Neurobehavioral Evaluation System - NES2 e a Pediatric Environmental Neurobehavioral Test Battery PENTB, essa última desenvolvida especificamente para a avaliação de efeitos neurotóxicos em crianças.

A maioria dessas baterias não é computadorizada (e.g., NCTB e SPES) e quando é utiliza o hardware - teclado e mouse - padrão (e.g., NES2). Em geral, o princípio dos testes é comparável entre as baterias computadorizadas e os testes são do tipo papellápis. Embora o princípio dos testes se mantenha, o desenvolvimento de sistemas computacionais devem considerar: “(a) procedimentos padronizados de treino a fim de compensar a falta de experiência com computadores, (b) comunicação baseada em computador adaptada à fala, (c) dificuldades adaptáveis nas tarefas otimizadas para um ajuste de nível individualizado" (Seeber, 2008, p. 275). Essas características prejudicam a aplicação dos testes em populações que carecem de instrução, bem como aqueles que não possuem domínio do computador.

A NCTB foi extensamente utilizada por ser uma bateria de fácil administração, custo relativamente baixo e ampla base de dados para controle. Em conjunto com a NES, as baterias foram validadas internacionalmente por sua sensibilidade aos efeitos causados por substâncias neurotóxicas em contextos ocupacionais (Blake, 2004). Contudo, é importante frisar que essas baterias prestam-se a triagens toxicológicas iniciais e que eventuais alterações em suas medidas não devem ser consideradas isoladamente, devendo ser interpretadas à luz de novos dados/testes e experimentações mais específicas posteriormente.

O Behavior Assessment and Research System (BARS) foi desenvolvido para ser empregado considerando uma ampla diversidade de populações, com diferentes níveis culturais e educacionais, garantindo maior precisão em medidas neurocomportamentais (ver Gimenes, Eckerman e Vasconcelos, 2010, para maiores detalhamentos sobre o desenvolvimento da bateria e sua tradução para o português). Assim, Kent Anger, Diana Rohlman e colaboradores da Oregon Health \& Science University implementaram testes tradicionalmente utilizados pela neuropsicologia (e.g., Neurobehavioral Core Test Battery - NCTB) e adequaram aqueles utilizados na literatura animal, em uma única bateria de testes, alterando os aspectos problemáticos de engenharia que compunham as 
baterias neurocomportamentais tradicionalmente utilizadas, os quais serão relatados a seguir (Anger, 2003; Gimenes et al., 2010; Rohlman et al., 2007).

O BARS foi projetado para ser um sistema computadorizado que efetivamente ensina o desempenho exigido no teste com o mínimo de suporte humano (Anger et al., 1996; Kang et al., 2005; Rohlman et al., 2000, 2003, 2007; Rohlman, Sizemore, Anger, \& Kovera, 1996). Em um primeiro momento tentou-se a modelagem direta das respostas necessárias para o manejo do equipamento (computador e seu teclado especial - 9 Button()). Embora essa tenha sido eficiente, requeria muito esforço e tempo do participante e muito tempo e recursos financeiros por parte dos desenvolvedores dessa nova tecnologia. O passo seguinte foi escolher outra abordagem (igualmente comportamental), que implementava instruções verbais (regras) e modelagem. Essa mostrou-se efetiva se algumas providências fossem cumpridas, a saber: a instrução deveria ser dividida em pequenos passos e faladas na língua nativa do participante. As instruções estabelecem um pequeno objetivo a ser alcançado e, uma vez atingido esse critério, segue-se para o próximo objetivo (caso contrário, repete-se a etapa) (Anger et al., 1996; Eckerman, Anger, Gimenes, \& Angerami, 2004). Testes posteriores revelaram que variáveis de sujeitos (a saber, grau de instrução), ainda afetavam a sensibilidade do teste e, neste sentido, mudanças nas instruções e procedimentos foram realizadas a fim de diminuir ainda mais esse efeito, chegando em seu formato atual a partir do qual passou a ser traduzido para outras línguas (Anger, 2003; Rohlman et al., 2000, 2003, 1996).

O ensino (regra + modelagem) para o cumprimento das tarefas que serão solicitadas pelo próprio teste, deriva das técnicas de modelagem e instrução programada (Gimenes et al., 2010; Rohlman et al., 2003, 1996) e, no caso do BARS, contam com três elementos básicos: (a) instruções passo-a-passo, (b) instruções gravadas (faladas) apresentadas digitalmente e (c) um teclado especial (9Button $\left.{ }^{\circledR}\right)$ (Anger et al., 1996; Gimenes et al., 2010; Rohlman et al., 2000, 2003, 2007).

As instruções passo-a-passo são dadas em linguagem simples e direta, fragmentada em conceitos básicos que evoluem gradualmente (passo a passo). Após a apresentação de cada instrução, segue-se um treino de proficiência daquela dada instrução. Uma imagem de uma carinha com sorriso (:) é utilizada para reforçar o comportamento do usuário e uma carinha triste (:) é apresentada após um erro. Respostas incorretas ou muito lentas levam à repetição daquele passo, enquanto respostas acuradas e suficientemente rápidas levam ao próximo passo. Além disso, o 
mecanismo permite que sejam configurados alguns parâmetros (e.g., testes utilizados; número de tentativas de um teste; duração do teste; tamanho e forma dos estímulos; dificuldade do teste; linguagem e formato da instrução), o que é vantajoso em contexto experimental. Essas instruções são fornecidas pelo próprio sistema via palavra escrita (tela do computador) e/ou falada (fones de ouvido). As instruções já foram traduzidas do inglês para o espanhol, coreano, português (brasileiro), árabe e ucraniano (ver Tabela 5) e foram gravadas por um falante nativo. O emprego de instruções faladas com participantes de baixa escolaridade diminui viéses quando comparado à instrução somente escrita. Além disso, o teclado especial é utilizado para minimizar o efeito adverso do participante trabalhar em uma interface não familiar (teclado de computador, mouse, lápis e papel), um outro tipo de teclado é utilizado. Este outro teclado contém nove botões enumerados, grandes e resistentes - que podem ser iluminados - fixados em uma unidade extremamente reforçada, a qual é sobreposta ao teclado padrão de um "notebook". Esse instrumento favorece que a atenção do participante esteja focada no teste, com estímulos (números) familiares aos participantes.

As características de precisão na linguagem (instruções curtas, diretas, simples e fragmentadas), o foco na atenção (uso da tela do computador de maneira a dirigir a atenção do participante a estímulos críticos para a tarefa) e as instruções interativas com feedbacks (após cada resposta ou parte exigida desta), promovem o desempenho desejado nas tarefas (Anger et al., 1996; Rohlman et al., 1996). Portanto, o BARS é uma bateria neurocomportamental com administração padronizada que pode ser mais facilmente utilizada apesar da falta de familiaridade dos participantes com computadores. Isso ocorreu graças ao treinamento adequado dos participantes (regras + modelagem) e a engenharia adequada do equipamento - 9Button ${ }^{\circledR}$ (Anger et al., 1996; Eckerman et al., 2004; Rohlman et al., 2007).

A utilização do BARS se dá com a apresentação ininterrupta de uma série de testes sob controle do computador. Embora as instruções sejam fornecidas pelo próprio sistema, é comum um pesquisador permanecer no local para alocar o participante frente ao computador e tirar eventuais dúvidas, mas garantindo o mínimo de interação possível (e.g.,Rohlman et al., 2007). Os testes que compõem o BARS são apresentados na Tabela 5 que inclui também uma breve descrição da atividade, a função neurocomportamental avaliada, os parâmetros de análise e as línguas para as quais os testes já foram traduzidos. 
Tabela 5. Caracterização dos testes neurocomportamentais que compõem o Behavioral Assessment and Research System - BARS (cf. site do fabricante - nweta.com - Anger, 2003; Gimenes et al., 2010; Kang et al., 2005; Rohlman et al., 2000, 2003, 2007, 1996).

\section{Função}

Teste

Descrição

Neurocomportamental

Predominantemente

Parâmetros Medidos

Línguas*

Avaliada

Estímulos (formas geométricas) são sequencialmente apresentadas na tela do computador por alguns minutos.

Continuous

Performance

Test (CPT)

Quando uma dada forma é apresentada (estímulo alvo), o

participante deve apertar o botão (Single Target Version).

Uma variação possível é quando o estímulo alvo é antecedido por uma dica (Cue-Target Version).

Acerto (pressionar botão na presença do

alvo), erros (não pressionar botão na

Atenção;

Atenção Sustentada;

Atenção Visual

presença do alvo), rejeição correta (não

pressionar botão para não-alvos), falso-

alarme (pressionar botão para não alvos; se I; E; C; P; A .

Sustentada; Motivação; o alvo for a dica, é chamado de "target", se

Memória for outro estímulo, "non-target").

Latências de todas pressões são

registradas.

É apresentado um conjunto de três números. O participante deve reproduzir os números na mesma sequência (digit span forward) ou de trás para frente (digit span backward). Cada

Digit Span vez que o participante acerta a sequência, essa é aumentada. O

Test (DST) teste termina após um determinado critério de falha ter sido atingido, ou quando completa-se uma sequência de nove números corretamente.

\begin{tabular}{|c|c|c|c|c|}
\hline $\begin{array}{l}\text { Match to } \\
\text { Sample Test } \\
\text { (MTS) }\end{array}$ & $\begin{array}{l}\text { Um estímulo modelo (formado em uma matriz de dez por dez) } \\
\text { é apresentado e, posteriormente, retirado da tela. Após um } \\
\text { dado intervalo de tempo (atraso), três figuras (estímulos) são } \\
\text { apresentadas e o participante deve escolher dentre as três qual } \\
\text { delas é igual ao estímulo modelo. }\end{array}$ & $\begin{array}{c}\text { Memória; } \\
\text { Memória Visual }\end{array}$ & $\begin{array}{l}\text { Número de respostas corretas, incorretas e } \\
\text { omissões (i.e., ausência de respostas em } \\
\text { um dado intervalo de tempo) são } \\
\text { registradas. Latência das respostas. São } \\
\text { registradas medidas gerais ou para cada } \\
\text { atraso. }\end{array}$ & I; E; C; P; A. \\
\hline $\begin{array}{l}\text { Progressive } \\
\text { Ratio Test } \\
\quad(\text { PRT })\end{array}$ & $\begin{array}{l}\text { Respostas ao botão são seguidas de um "()" e do aumento no } \\
\text { número de respostas (quantidade fixa) necessárias para } \\
\text { produzir outro "(;). Neste sentido, a razão das respostas } \\
\text { aumenta progressivamente. }\end{array}$ & Motivação & 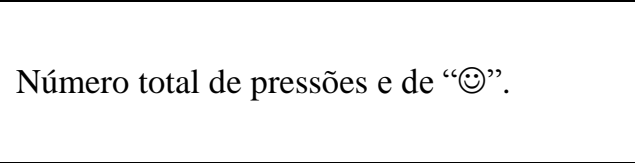 & $\mathrm{I} ; \mathrm{E} ; \mathrm{C} ; \mathrm{P} ; \mathrm{A} ; \mathrm{U}$. \\
\hline
\end{tabular}

Atenção;

Memória

Maior sequência completada sem erros.

I; E; C; P; A; U

Continua... 


\begin{tabular}{|c|c|c|c|c|}
\hline $\begin{array}{l}\text { Reversal } \\
\text { Learning Test } \\
\quad(\text { RLT })\end{array}$ & $\begin{array}{l}\text { O participante aprende a correspondência entre dois números- } \\
\text { símbolos. Uma vez atingido o critério de aprendizagem, a } \\
\text { relação é invertida, o que ocorre algumas vezes ao longo do } \\
\text { teste. }\end{array}$ & $\begin{array}{c}\text { Aprendizagem; } \\
\text { Mudanças de tarefa }\end{array}$ & $\begin{array}{l}\text { Número de tentativas para atingir o critério } \\
\text { de aprendizagem. Latências das respostas. } \\
\text { Total, antes e após a reversão. }\end{array}$ & I; E; C; P; A; U. \\
\hline $\begin{array}{l}\text { Selective } \\
\text { Attention Test } \\
\quad(\text { SAT })\end{array}$ & $\begin{array}{l}\text { São projetados dois quadrados no monitor (uma a esquerda e } \\
\text { outro à direita da tela). Um pequeno ponto pode aparecer } \\
\text { dentro ou fora de cada quadrado. O participante deve apertar } \\
\text { um determinado botão quando o ponto aparecer dentro do } \\
\text { quadrado da esquerda, outro botão quando o ponto aparecer } \\
\text { dentro do quadrado da direita e não apertar nenhum botão } \\
\text { quando os pontos forem projetados fora dos quadrados. }\end{array}$ & $\begin{array}{c}\text { Atenção; } \\
\text { Atenção Sustentada }\end{array}$ & $\begin{array}{l}\text { Número total de tentativas, número de } \\
\text { acertos, erros e omissões, são registrados. } \\
\text { A latência média e a mediana do intervalo } \\
\text { inter-estímulo (ISI) são apresentadas no } \\
\text { total, ou distribuídas em cinco blocos ao } \\
\text { longo da avaliação. }\end{array}$ & I; E; C; P; A; U. \\
\hline $\begin{array}{l}\text { Serial Digit } \\
\text { Learning } \\
\text { (SDL) }\end{array}$ & $\begin{array}{l}\text { Um número de até nove dígitos é apresentado } \\
\text { sequencialmente e o participante deve repetir essa sequência } \\
\text { até atingir o critério de sucesso ou falha. }\end{array}$ & Aprendizagem & Escore (variável entre 0 e 24). & I; E; C; P; A. \\
\hline $\begin{array}{c}\text { Simple } \\
\text { Reaction } \\
\text { Time (SRT) }\end{array}$ & $\begin{array}{l}\text { O participante deve apertar o mais rápido possível um dado } \\
\text { botão, quando um estímulo-alvo é projetado na tela do } \\
\text { computador. }\end{array}$ & Velocidade da Resposta & $\begin{array}{l}\text { Latência média das respostas (em ms) e } \\
\text { contagem de respostas corretas, no geral, e } \\
\text { dividido em cinco blocos ao longo da } \\
\text { avaliação. Número total de erros e de } \\
\text { respostas lentas. }\end{array}$ & I; E; C; P; A; U. \\
\hline $\begin{array}{l}\text { Symbol-Digit } \\
\text { Test (SDT) }\end{array}$ & $\begin{array}{l}\text { Apresenta uma matriz com duas linhas e nove colunas } \\
\text { (modelo). A primeira linha é composta por nove símbolos e a } \\
\text { linha abaixo compreende nove números (1-9), formando pares } \\
\text { específicos símbolo-número. Uma segunda matriz abaixo } \\
\text { dessa apresenta somente os símbolos e a tarefa compreende } \\
\text { em escolher os números para os respectivos símbolos, } \\
\text { conforme os pares "símbolo-número" do modelo. }\end{array}$ & $\begin{array}{l}\text { Aprendizagem; } \\
\text { Atenção; } \\
\text { Funções Complexas }\end{array}$ & $\begin{array}{l}\text { Latência (em ms.) de respostas corretas e } \\
\text { erros, no total ou divididos em cinco } \\
\text { blocos ao longo da avaliação. }\end{array}$ & I; E; C; P; A; U. \\
\hline $\begin{array}{l}\text { Finger } \\
\text { Tapping Test } \\
\text { (TAP) }\end{array}$ & $\begin{array}{l}\text { Por um dado período de tempo, o participante deve pressionar } \\
\text { um botão o mais rápido possível, o máximo de vezes que } \\
\text { conseguir. O desempenho é testado com cada uma das mãos, } \\
\text { isoladamente e as duas mãos alternadamente. }\end{array}$ & $\begin{array}{l}\text { Velocidade da Resposta; } \\
\text { Coordenação Motora }\end{array}$ & $\begin{array}{l}\text { Número de respostas em um dado período } \\
\text { de tempo. }\end{array}$ & I; E; C; P; A; U. \\
\hline
\end{tabular}


Muitos testes delineados no BARS foram retirados da neuropsicologia, incluindo aqueles com ampla história de uso em pesquisas transculturais. Outros testes têm como origem a psicologia cognitiva e de modelos animais de desempenho cognitivo para avaliar atenção, memória, aprendizagem, motivação, respostas psicomotoras, velocidade e coordenação motora. Outros testes (match-to-sample, reversal learning, progressive ratio, selective attention), por sua vez, possuem pouca história de uso em pesquisas de neurotoxicologia com humanos (Anger et al., 1996; Rohlman et al., 2003). O BARS tem apresentado boa acurácia, confiabilidade, validade e sensibilidade (cf. Rohlman et al., 2003), em geral, em todos os testes. A bateria tem provado ser sensível a variáveis que afetam o desempenho neurocomportamental e, desta forma, supõe-se que o BARS pode ser útil na avaliação de pessoas expostas a agentes físico-químicos, por meio da comparação de pessoas não expostas.

\section{Avaliação Neurocomportamental e n-Hexano}

Avaliações neurocomportamentais podem ser empregadas em delineamentos experimentais, buscando identificar diferenças entre grupos de pessoas expostas e não expostas a um dado toxicante. Entretanto, a caracterização das alterações neurocomportamentais específicas do hexano, é difícil. Este agente dificilmente não é aplicado isoladamente. Em geral, há dificuldade na caracterização acurada do grau de exposição, e um pequeno número de publicações com distintas baterias neurocomportamentais para caracterizar estas diferenças, dificulta a generalidade das relações funcionais obtidas.

Armstrong (1995) apresenta um estudo de caso que investiga aspectos neuropsicológicos em uma técnica de laboratório de uma indústria petroquímica. A funcionária lá atuava por 10 anos e, apesar de reportar pequenas exposições diárias a solventes e gasolina com chumbo, essas estavam dentro dos limites de tolerância da OSHA. Uma de suas atribuições era o teste da viscosidade de óleos e parte do trabalho consistia em lavar os tubos com hexano. Nesse período, ela passou a apresentar sinais agudos de intoxicação e buscou por avaliação médica 10 dias após a exposição, queixando-se de desorientação, lapsos de memória, lentidão no pensamento, fala e andar. As avaliações médicas mostraram lentificação cognitiva e motora, disgnosia visual e tátil e prejuízo na evocação de informações declaradas. Uma bateria neuropsicológica foi aplicada 10 semanas e 18 meses após a exposição, investigando funções motoras, de memória, atenção e velocidade de informação. Os resultados 
demonstraram que a paciente apresentou supressão bilateral na percepção tátil, que perdurou até 18 meses. Porém, com melhora gradual com o passar do tempo. A velocidade no Finger Tapping não foi anormal, embora a coordenação motora fina tenha diminuído significativamente. Alterações de memória não foram notavelmente prejudicadas, embora o Digit Span Test tenha mostrado piora na avaliação de 18 meses. A memória visual também apresentou prejuízo na primeira avaliação, melhorando nos 18 meses seguintes. A pesquisa conclui que as queixas sensoriais e motoras e os efeitos fisiológicos tardiamente desenvolvidos são consistentes com uma neuropatia, embora não tenha sido confirmado em testes neurológicos. Portanto, os efeitos do hexano podem ter resultado em um caso de neuropatia periférica subclínica e os dados cognitivos teriam sido os primeiros preditores dessa patologia, visto que funções cognitivas tendem a ser mais facilmente perturbadas do que as anormalidades motoras ou sensoriais derivadas de avaliação neurológica.

Trabalhos neuropsicológicos que caracterizam a participação do hexano são escassos. Entretanto, a literatura que engloba "solventes" tem sido mais eficaz em reportar déficits neurocomportamentais, muito embora esses sejam influenciados, simultaneamente, por substâncias como o hexano, benzeno, tolueno, xileno, MBK, acetona, dentre outros. Tsai, Chen, Chao e Wang (1997) realizaram uma investigação com trabalhadores de uma fábrica de tinta, em condições que controlavam efeito de exposição aguda e horário de aplicação de testes neurocomportamentais (e.g., limiar de vibração nos dedos, limiar térmico, Neurobehavior Evaluation System 2 - NES2). Dentre os testes do NES2, listam-se: Finger Tapping, Continuous Performance Test, Symbol-Digit Test, Pattern Memory, Visual Digit Span, Attention Switching. Os trabalhadores foram divididos em grupos, baseados em seus índices de exposição e suas atribuições (administrativo ou técnicos) na indústria. Uma regressão múltipla (controlada para os confundidores: sexo, idade, educação e consumo de álcool), para técnicos, identificou diferenças estatisticamente significativas no continuous performance test, pattern comparison (latência) e pattern memory (latência). No grupo administrativo, a regressão múltipla mostrou diferenças apenas no continuous performance test. Novamente os pesquisadores concluem que a atenção e memória são as funções cognitivas afetadas antes do estabelecimento de uma neuropatia induzida por solventes em condições ocupacionais. Kang et al. (2005), que avaliam também o desempenho neurocomportamental em trabalhadores expostos ao tolueno. Os resultados mostraram que o grupo com maior exposição apresentou menores índices nas medidas 
neurocomportamentais do que os grupos com exposição média ou baixa, para os testes: Digit Spam, Tempo de Reação, Finger Tapping, Symbol-Digit e Selective Attention.

Em conjunto, os trabalhos aqui descritos sugerem que funções cognitivas podem ser afetadas em condições subclínicas ou que antecedem uma neuropatia induzida por solventes como o hexano. Dentre as principais funções estão a coordenação motora, memória e atenção (Armstrong, 1995; Kang et al., 2005; Tsai et al., 1997). Baterias neurocomportamentais podem prover um screening toxicológico para funções neurocomportamentais afetadas previamente ao estabelecimento de uma neuropatia periférica e, nesse quesito, o BARS tem-se mostrado sensível ao efeito de toxicantes, a despeito das diferenças culturais nas quais é utilizado. Deste modo, o objetivo deste trabalho é realizar uma investigação neurocomportamental da exposição ao n-hexano em trabalhadores da indústria de extração de óleo vegetal, direcionada aos efeitos crônicos desta exposição. 


\section{MÉTODO}

\section{PARTICIPANTES E LOCAL}

Participaram deste estudo 81 homens com idades variando entre 18 e 54 anos (méd.: 31,11 anos; dp: 8,50 anos), provenientes de duas indústrias distintas (A e B), porém ambas extratoras de óleo vegetal. Uma dessas indústrias possuía duas plantas de extração (A e A') e a outra, somente uma planta (B). Os participantes do Grupo Exposto possuíam diferentes atribuições na planta de extração, a saber: preparação da soja e extração do óleo. Compuseram o Grupo Exposto - GE, 12 (14,81\%) participantes da planta A, $12(14,81 \%)$ participantes da planta A' e $11(13,58 \%)$ participantes da planta B. O Grupo Controle - GC foi composto por outros $46(56,79 \%)$ participantes que provinham da área de envase de ambas as indústrias (ver Tabela 6).

Tabela 6. Origem e distribuição dos participantes em seus respectivos grupos.

\begin{tabular}{cccccc}
\hline Indústria & Área & Grupo & Setor & N & N (\%) \\
\hline \multirow{2}{*}{ A } & & & Preparação & 4 & 4,94 \\
& Planta A & Exposto (GE) & Extração & 8 & 9,88 \\
\cline { 3 - 6 } & & & Preparação & 8 & 9,88 \\
& Planta A' & Exposto (GE) & Extração & 4 & 4,94 \\
\cline { 3 - 6 } & Envase & Controle (GC) & Envase & 33 & 40,74 \\
\hline \multirow{2}{*}{ B } & Planta B & Exposto (GE) & Preparação & 7 & 8,64 \\
& & & Extração & 4 & 4,94 \\
\hline & Envase & Controle (GC) & Envase & 13 & 16,05 \\
\hline
\end{tabular}

O estudo foi aprovado pelo Comitê de Ética em Pesquisa da Universidade Federal de Goiás (protocolo 033/13) em 15 de abril de 2013. A explicação e coleta de assinaturas do Termo de Consentimento Livre e Esclarecido (TCLE - Apêndice 01) foi obtida de todos os participantes.

A coleta de dados foi realizada nas próprias indústrias, durante o horário de trabalho dos funcionários. De maneira geral, tratavam-se de salas amplas, com temperatura controlada $\left(22-25{ }^{\circ} \mathrm{C}\right)$. As aplicações do BARS eram realizadas individualmente. 


\section{QUESTIONÁRIOS}

Cada participante respondeu a dois questionários, administrados por um assistente de pesquisa, sendo um denominado anamnese e outro questionário toxicológico (Apêndices 2 e 3, respectivamente). Os questionários coletavam informações sócio-econômicas, educacionais, histórico ocupacional, médico e toxicológico prévio, uso de substâncias psicoativas, dentre outros. Portanto, todos os dados constitucionais (i.e., sócio-demográficos e saúde) eram auto-referidos.

\section{BATERIA DE TESTES NEUROCOMPORTAMENTAIS}

Foram utilizado um "notebook" com sistema operacional da Windows XP Professional - 32 Bits®, com uma tela de 15 polegadas para a visualização dos testes realizados. Um teclado especial (9Button $®)$ foram sobreposto ao teclado do “notebook", deixando apenas as teclas do próprio 9Button ${ }^{\circledR}$ aparentes. O teclado possuía nove teclas $(1,5 \times 2,5 \times 1 \mathrm{~cm})$, dispostas semicircularmente sobre o console e podiam ser independentemente iluminadas. As teclas eram altamente resistentes e a sua iluminação individualizada facilitava o manuseio por parte do participante (Gimenes et al., 2010). No notebook estava instalado o programa BARS 4.0pc®, criado para rodar em plataforma da Microsoft $®$.

Foram utilizados 10 testes do BARS, todos traduzidos para a língua portuguesa, na ordem que segue: Finger Tapping (TAP); Symbol-Digit (SDT); Match-to-Sample (MTS); Continuous Performance (CPT); Digit Span (DST); Simple Reaction Time (SRT); Serial Digit Learning (SDL); Progressive Ratio (PRT); Selective Attention (SAT) e Reversal Learning (RLT). Essa ampla gama de avaliações permite uma triagem, em humanos, dos efeitos do hexano sobre as seguintes funções neurocomportamentais: atenção, memória, aprendizagem, motivação e funções motoras (e.g., velocidade da resposta e coordenação).

Os parâmetros de avaliação dos testes foram aqueles indicados pelo fabricante como os valores-padrão (default parameter values), uma vez que esses foram obtidos em estudos preliminares, mostrando-se sensíveis à avaliação transcultural de agentes neurotóxicos (ver Apêndice 4).

Complementando os testes neurocomportamentais, o teste de Romberg (Rom) também foi realizado. Essa avaliação permite aferir o equilíbrio dos participantes, medida secundária da integridade de fibras nervosas longas relativas ao sistema proprioceptivo (Agrawal, Carey, Hoffman, Sklare, \& Schubert, 2011). Para tanto, os 
participantes eram filmados por duas câmeras, uma à sua frente e outra ao seu lado, o que permitia a visualização simultânea de balanços no sentido do plano coronal e sagital (respectivamente). Dois registros foram realizados: (a) registro categórico da forma do balanço, (b) registro da latência de balanço.

Para o registro categórico, foi criada uma escala de severidade, variando de 1 a 3: (1) balanço típico, no qual existem pequenos movimentos tanto no sentido sagital como coronal, sempre com os pés e braços na posição determinada, com o corpo em posição ereta (i.e., sem deflexão ou inflexão de abdômen, pernas ou joelhos) e sem apresentar movimentação de membros; (2) balanço atípico, no qual existem fortes alterações no sentido sagital e/ou coronal, mostrando mudanças na posição corporal (i.e., com deflexão ou inflexão de abdômen, pernas ou joelhos), porém, sem movimentação de membros (i.e., a despeito da dificuldade em manter a posição, o participante mantém seus pés e braços na posição, sem abrir os olhos); (3) balanço atípico, no qual existe forte alteração na posição corporal como descrito no nível 2 , porém, com movimentação de membros (i.e., existe uma dificuldade em manter a posição, e o participante abre os olhos, move os pés e/ou braços).

Para o registro da latência de balanço, o cronômetro era iniciado quando do princípio da condição olhos fechados e era interrompido no momento que o participante apresentava algum grau de balanço. Dois observadores fizeram essas avaliações e os dados utilizados no presente trabalho são do observador cego à condição dos sujeitos.

\section{PROCEDIMENTO}

Após o contato prévio com representantes das indústrias, os participantes foram informados e convidados a participar da pesquisa que buscava avaliar se e como a exposição a solventes orgânicos pode afetar o comportamento (ver TCLE no Apêndice 1). Anamnese de triagem para a composição dos grupos foi em seguida aplicada (ver Apêndice 2).

Foram excluídos das amostras participantes que apresentavam algum problema neurológico, cegueira, surdez, ou que possuíam menos de 8 anos de educação formal (cf. Inserra et al., 2004; Kang et al., 2005; Rohlman et al., 1996). Os participantes remanescentes responderam ao Questionário Toxicológico (Apêndice 3), o permitia avaliar o histórico do uso de substâncias psicoativas e se esses estavam sob efeito de alguma, durante a testagem. Caso isso fosse verdadeiro para substâncias como álcool ou outras drogas (excluindo-se medicamentos de uso contínuo), a coleta de dados 
neurocomportamentais era adiada para a semana seguinte (i.e., após o segundo dia de folga dos mesmos).

O experimentador solicitava que o participante desligasse seu aparelho celular durante o experimento. Breves esclarecimentos eram fornecidas ao participante (e.g., tempo estimado da avaliação). O experimentador permanecia na sala (atrás do participante) durante a avaliação (BARS) e dava o comando para iniciarem-se as atividades. As avaliações (BARS, Romberg, Questionários) não seguiam nenhuma ordem pré-determinada e ocorriam tão logo eram possíveis de serem realizadas.

\section{ANÁLISE DOS DADOS}

Duas abordagens estatísticas foram utilizadas. Na primeira abordagem, uma comparação entre grupo exposto e controle foi desenvolvida considerando os valores brutos das avaliações e a análise sistemática de confundidores da pesquisa. Para tanto, foram utilizados o teste $\mathrm{t}$ não pareado e de qui-quadrado (em caso de variáveis categóricas), para averiguar a confiabilidade das amostras, e o teste de permutação para comparação dos resultados obtidos entre os testes (Little, 2013). Na segunda abordagem estatística, uma adaptação de Rohlman et al. (2014) foi adotada. Quanto à regressão linear múltipla, foi utilizado o método inserir para as variáveis independentes grupos, idade e escolaridade dos participantes. Essas permaneceram constante para o teste de cada variável dependente testadas (i.e., variáveis neurocomportamentais).

Tanto na primeira análise, análise intergrupo (controle e exposto), como na segunda análise (controlando variáveis constitucionais - idade e nível de escolaridade), o valor de $\mathrm{p}<0,05$ foi adotado. Com exceção do teste de permutação (realizado em r), todas as análises foram realizadas no pacote estatístico SPSS 21.

\section{RESULTADOS}

Um levantamento preliminar do número de indústrias extratoras de óleo vegetal no estado de Goiás foi realizado, o que revelou a existência de 8 companhias. Dessas, 2 permitiram que a pesquisa fosse realizada (25\%).

No contato prévio com essas 2 indústrias, um total de 38 participantes poderiam compor o Grupo Exposto (GE). Entretanto, dois participantes da indústria A foram excluídos por possuírem problemas auditivos e um participante da indústria B não participou da coleta pois estava de férias no transcorrer da coleta. Desta forma, 35 foi o máximo de participantes possíveis dentro da previsão máxima de 38 (92,11\%). 
O número de dados coletados para cada uma das atividades variou entre 64 e 81 . Os dados de quatro participantes para a latência do MTS com $1 \mathrm{~s}$ de atraso não foram registrados e o mesmo ocorreu com um participante para o atraso de $8 \mathrm{~s}$. Um total de dezessete participantes não concluíram o RLT, quer seja por desistência, quer seja por terem perseverado em um padrão de respostas que não avançava no teste durante, pelo menos, 5 minutos. Um dano em um dos DVDs gravados para o teste de Romberg inviabilizou o uso do dado de 7 participantes (Tabela 7).

Tabela 7. Números absolutos/percentual de testes completados pelos participantes.

\begin{tabular}{cccccccccccc}
\hline & TAP & SDT & MTS & CPT & DST & SRT & SDL & PRT & SAT & RLT & Rom \\
\hline \multirow{3}{*}{ GC } & $46 /$ & $46 /$ & $42 /$ & $46 /$ & $46 /$ & $46 /$ & $46 /$ & $46 /$ & $46 /$ & $36 /$ & $41 /$ \\
& 56,79 & 56,79 & 53,08 & 56,79 & 56,79 & 56,79 & 56,79 & 56,79 & 56,79 & 44,44 & 50,62 \\
& & & & & & & & & & & \\
GE & 43,21 & 43,21 & $44 /$ & $35 /$ & $35 /$ & $35 /$ & $35 /$ & $35 /$ & $35 /$ & $28 /$ & $33 /$ \\
& & & & 43,21 & 43,21 & 43,21 & 43,21 & 43,21 & 43,21 & 34,57 & 40,74 \\
\hline \multirow{2}{*}{ Tot } & $81 /$ & $81 /$ & $76 /$ & $81 /$ & $81 /$ & $81 /$ & $81 /$ & $81 /$ & $81 /$ & $64 /$ & $74 /$ \\
& 100 & 100 & 93,83 & 100 & 100 & 100 & 100 & 100 & 100 & 79,01 & 91,36
\end{tabular}

GC: Grupo Controle; GE: Grupo Exposto; TAP: Finger Tapping Test; SDT: Symbol-Digit Test; MTS: Match-to-Sample Test; CPT: Continuous Performance Test; DST: Digit Span Test; SRT: Simple Reaction Time Test; SDL: Serial Digit Learning Test; PRT: Progressive Ratio Test; SAT: Selective Attention Test; RLT: Reversal Learning Test; Rom: Romberg Test.

\section{COMPARAÇÃO ENTRE GRUPOS}

\section{Confiabilidade da Amostra}

Para analisar o controle estatístico de variáveis confundidores entre os grupos (Seeber, 2008), dados sócio-demográficos, de saúde e das condições de testagem foram coletados (ver Apêndices 2 e 3). Dentre os dados sócio-demográficos estavam: idade, anos de escolaridade e renda per capita (somatório da renda bruta mensal de todos residentes de um domicílio/número de residentes do domicílio). Dentre os dados de saúde, foram coletados: índice de massa corporal; suspeita de exposição prévia a agentes tóxicos; suspeita de perturbações neuropsiquiátricas o participante ou na família; uso rotineiro de medicação psicotrópica, cafeína, tabaco, álcool e outras drogas (i.e., substâncias ilícitas). Quanto às condições de testagem, foram coletados: horário da aplicação dos testes; uso de cafeína, tabaco, e/ou outras drogas anterior a testagem.

Entre 11 casos sendo 3 do GE e 8 do GC, 3,70\% e 9,88\%, respectivamente, se o participante relatasse uso de correção visual, era solicitado que usasse óculos. Um total de 33 do GC (40,74\%) e 20 do GE (24,69\%) relataram uso de café e/ou tabaco em até 
$24 \mathrm{~h}$ antes da testagem. Participantes que relataram uso de bebida alcoólica anterior à testagem foram reagendados.

Dentre os dados sócio-demográficos, o teste $\mathrm{t}$ para amostras independentes apontou a inexistência de uma diferença estatisticamente significativa para as variáveis idade $(\mathrm{t}(50)=-1,29 ; 0,27)$ e anos de escolaridade $(\mathrm{t}(50)=-0,43 ; 0,19)$. A renda per capita foi uma tentativa de averiguar diferenças sócio-econômicas entre os grupos. Em média, os participantes do grupo exposto (méd.: 1003,53; dp: 470,60) recebiam mais do que os do grupo controle (méd.: 745,48; dp: 288,25). Essa diferença foi estatisticamente significativa $(\mathrm{t}(36,92)=-2,34 ; \mathrm{p}<0,05)$, com um tamanho de efeito ( $\mathrm{r}$ de Pearson), médio $(\mathrm{r}=0,36)($ ver Tabela 8$)$.

Quanto aos dados de saúde, o teste t para amostras independentes apontou a inexistência de uma diferença estatisticamente significativa para as variáveis IMC (t(50) $=2,41 ; 0,42)$. $\mathrm{E}$ o teste de qui-quadrado demonstrou não haver diferença estatisticamente significativa entre os grupos no que diz respeito à suspeita de exposição prévia à agentes tóxicos $\left(\mathrm{x}^{2}(1)=0,93,0,34\right)$, à suspeita de perturbações neuropsiquiátricas na família $\left(\mathrm{x}^{2}(1)=0,41,0,52\right)$ e uso rotineiro de café $\left(\mathrm{x}^{2}(1)=0,32\right.$, $0,57)$ ou álcool $\left(\mathrm{x}^{2}(1)=0,10,0,75\right)$. Todos os participantes declararam não fazer uso ilícito de substâncias.

O teste estatístico não pôde ser realizado para as variáveis "suspeita de perturbações neuropsiquiátricas do participante", "uso rotineiro de medicação psicotrópica" e "uso de tabaco", pois violavam as premissas do qui-quadrado (número mínimo de ocorrências em cada célula). Por essa razão, as variáveis nominais desse subconjunto (i.e., suspeita de exposição prévia a agentes tóxicos; suspeita de perturbações neuropsiquiátricas do participante ou na família; uso rotineiro de medicação psicotrópica, cafeína, tabaco, álcool e outras) foram organizados em uma outra variável denominada "confundidores de saúde". Neste caso, a ocorrência para qualquer um desses eventos era caracterizado com o número 1 e a soma (que variava de 0 a 8), estabelecia o valor desta nova variável. O teste t para amostras independentes também apontou inexistência de uma diferença estatisticamente significativa para essa variável $(\mathrm{t}(79)=0,58 ; 0,75)($ ver Tabela 8$)$.

Dentre as condições de testagem e quanto ao horário de aplicação do BARS, esses foram divididos em três turnos com aplicações realizadas entre 6:30 e 14:29, 14:30 e 22:29 e 22:30 e 6:29. A escolha desses horários para a delimitação dos turnos deveu-se à sua aproximação com os turnos empregados nas indústrias. O teste de qui- 
quadrado foi realizado para avaliar uma possível diferença na distribuição dos trabalhadores dos GC e GE, em relação ao horário de aplicação dos testes. Não houve diferença estatisticamente significativa para esta distribuição entre os grupos $\left(\mathrm{x}^{2}(2)=\right.$ $1,18,0,55)$. Novamente, como aplicado à variável denominada confundidores de saúde, o uso de substância psicotrópica anterior ao teste também foi organizado em uma variável cujo valor mínimo era 0 (nenhuma ingestão de substância psicotrópica 24 hs anterior à testagem) e 3 (uso de três substâncias dentre as listadas acima, anterior à testagem). Essa nova variável foi denominada confundidores de testagem. $\mathrm{O}$ teste $\mathrm{t}$ para amostras independentes também apontou inexistência de uma diferença estatisticamente significativa para essa variável $(\mathrm{t}(79)=1,01 ; 0,08)($ ver Tabela 8$)$.

Tomadas em conjunto, as variáveis confundidoras críticas podem ser consideradas sob controle a partir das análises estatísticas. Com exceção da variável "renda per capita" eventuais diferenças entre os grupos deve ser atribuídas apenas à variáveis característica da exposição (ver Tabela 8).

A baixa ocorrência para "suspeita de perturbações neuropsiquiátricas" (4 participantes do GC), "uso rotineiro de medicação psicotrópica" (7 participantes, 5 do GC e 2 do GE) e "uso rotineiro de tabaco" (6 participantes, 3 do GC e 3 do GE), embora tenha impossibilitado a análise pelo qui-quadrado não sugerem impacto desses fatores com baixa ocorrência e "distribuída" entre os dois grupos na maioria dos casos. No entanto, o "uso de substâncias anterior à testagem" (café: 30 GC e 18 GE; tabaco: 1 GC e 0 GE; tabaco+café: 2 GC e 2 GE) foi mais representado no grupo controle. Embora o qui-quadrado não possa ser utilizado para confirmar se essa diferença é significante, o manejo dessas variáveis ("Confundidores de Saúde" e "Confundidores de Testagem") demonstrou a não ocorrência de significância estatística (ver Tabela 8).

Tabela 8. Análise descritiva da amostra comparando grupos controle e exposto conforme média de cada variável e desvio padrão (entre parênteses).

\begin{tabular}{ccc}
\hline & Controle & Exposto \\
\hline Idade (anos) & $27,75(6,46)$ & $30,46(8,62)$ \\
Escolaridade (anos) & $9,71(2,21)$ & $9,96(1,81)$ \\
Renda per capita (reais) & $745,48(288,25)$ & $1.003,53(470,60)^{*}$ \\
IMC (peso/altura $\left.{ }^{2}\right)$ & $26,80(4,07)$ & $24,20(3,65)$ \\
Confundidores de Saúde & $2,04(1,26)$ & $2,25(1,07)$ \\
Confundidores de Testagem & $0,68(0,48)$ & $0,67(0,57)$ \\
\hline
\end{tabular}

IMC: Índice de Massa Corporal. O asterisco representa a significância $(\mathrm{p}<0,05)$. 


\section{Finger Tapping Test (TAP)}

As medidas avaliadas no Finger Taping Test (TAP) foram: máximo de toques com a mão dominante (MD); máximo de toques com a mão não dominante (MND); máximo de toques alternando a mão dominante (Alt MD) e máximo de toques alternando a mão não dominante (Alt MND). Estes valores são uma medida direta de proficiência do teste.

O teste de permutação para duas amostras comparou os grupos CG e CG. Não houve diferença estatisticamente significativa para as pressões no TAP, para a MD ( $\mathrm{p}=$ 0,59), MND ( $\mathrm{p}=0,93)$, Alt MD ( $\mathrm{p}=0,29)$ ou Alt MND $(\mathrm{p}=0,11)$ como mostra a Figura 3.

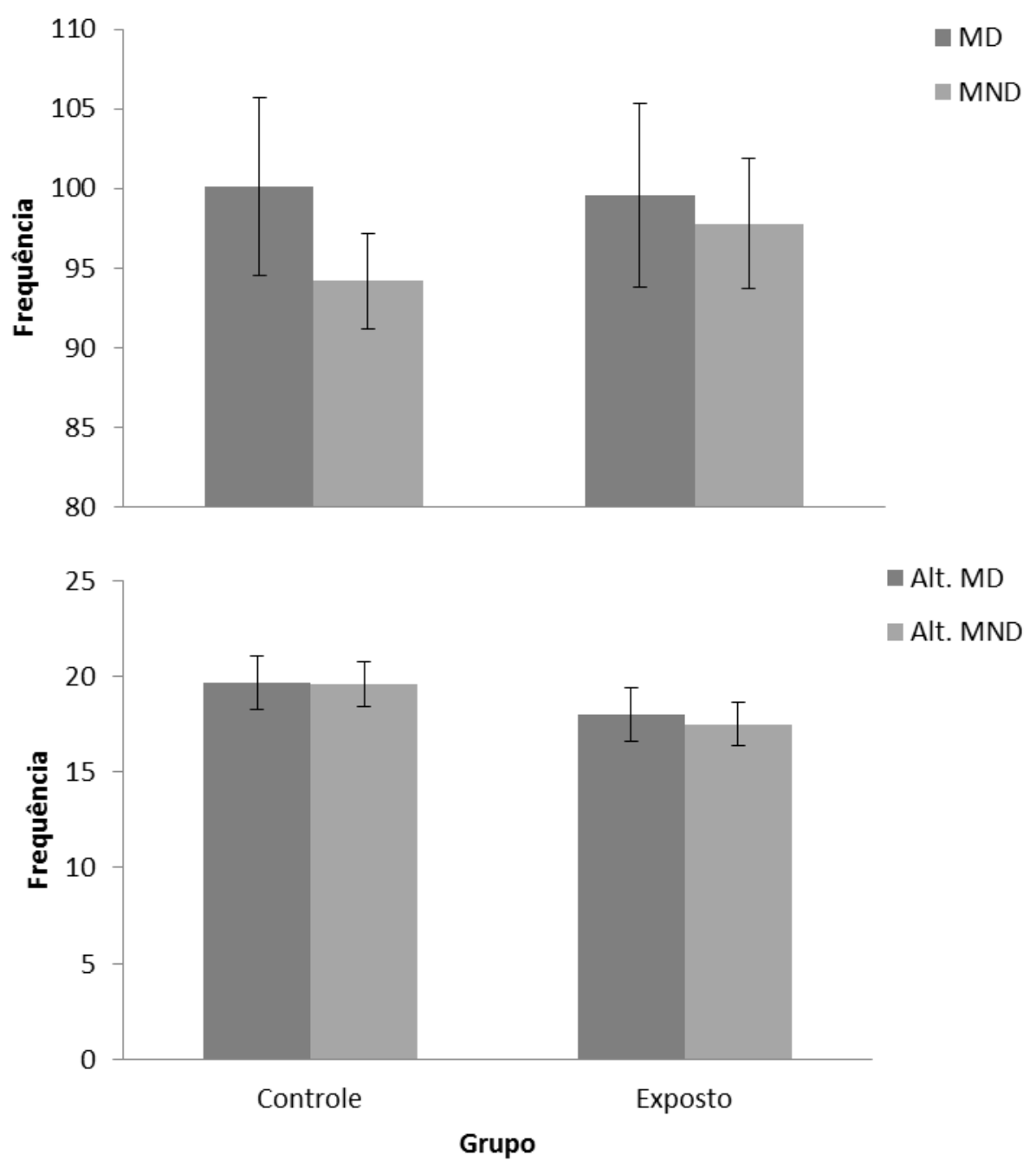

Figura 3. Frequência de toques durante o teste Finger Tapping dos grupos controle e exposto. O gráfico superior mostra os toques com a mão dominante - MD (barra preta) e com a mão não dominante - MND (barra cinza), e o gráfico inferior os toques alternando (Alt.) MD e MND, em preto e cinza, respectivamente. As linhas sobre a barra representam o erro padrão da média. 


\section{Symbol Digit Test (SDT)}

As medidas avaliadas no Symbol Digit Test (SDT) foram: número total de erros; latência média de todos os acertos e a latência dos acertos divididos em cinco 5 blocos de tentativas (9 tentativas por bloco). Estes valores são medidas indiretas da proficiência do teste.

O teste de permutação para duas amostras não mostrou diferença estatisticamente significativa para as medidas avaliadas: número total de erros $(\mathrm{p}=$ 0,69) (Figura 04), latência total dos acertos $(\mathrm{p}=0,74)$, ou latência dos acertos para os blocos $1(\mathrm{p}=0,43), 2(\mathrm{p}=0,85), 3(\mathrm{p}=0,99), 4(\mathrm{p}=0,47)$ e $5(\mathrm{p}=0,91)$ (ver Figura 05).

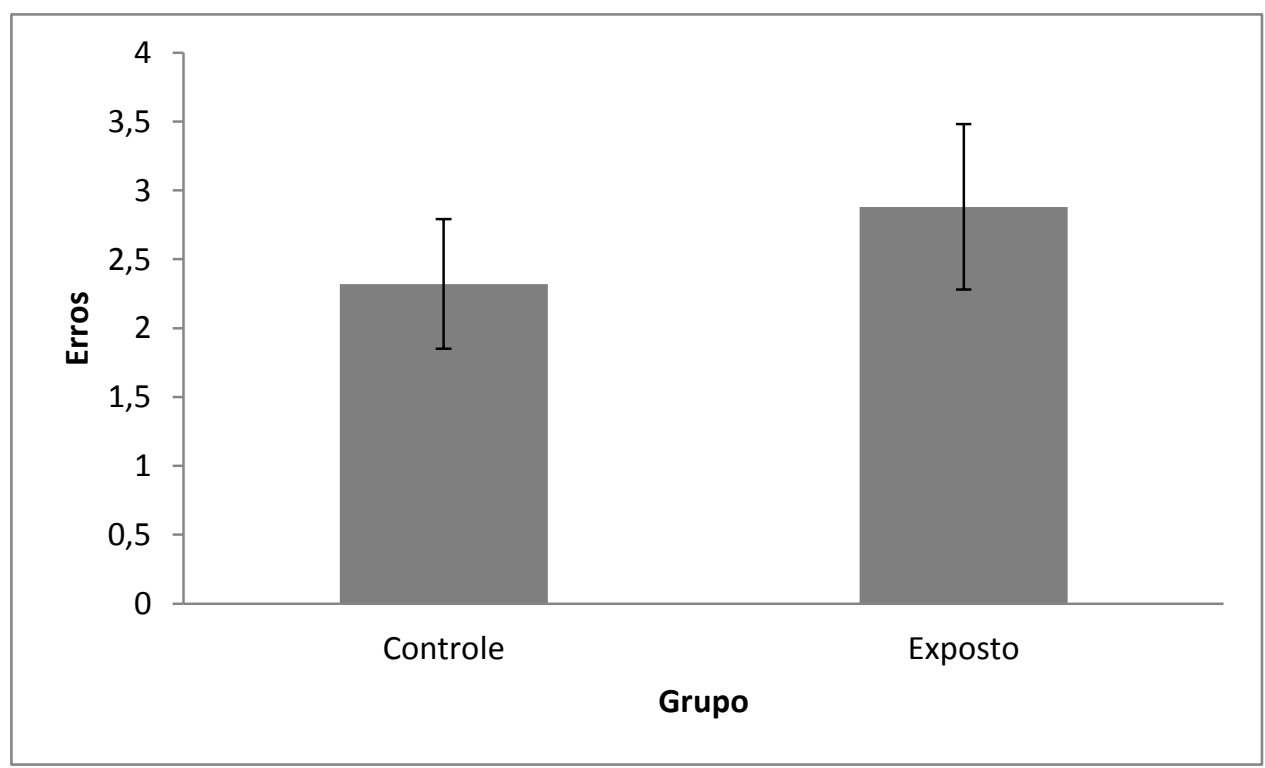

Figura 4. Frequência de erros no Symbol Digit Test. Para os grupos controle e exposto. As linhas sobre a barra representam o erro padrão da média. 


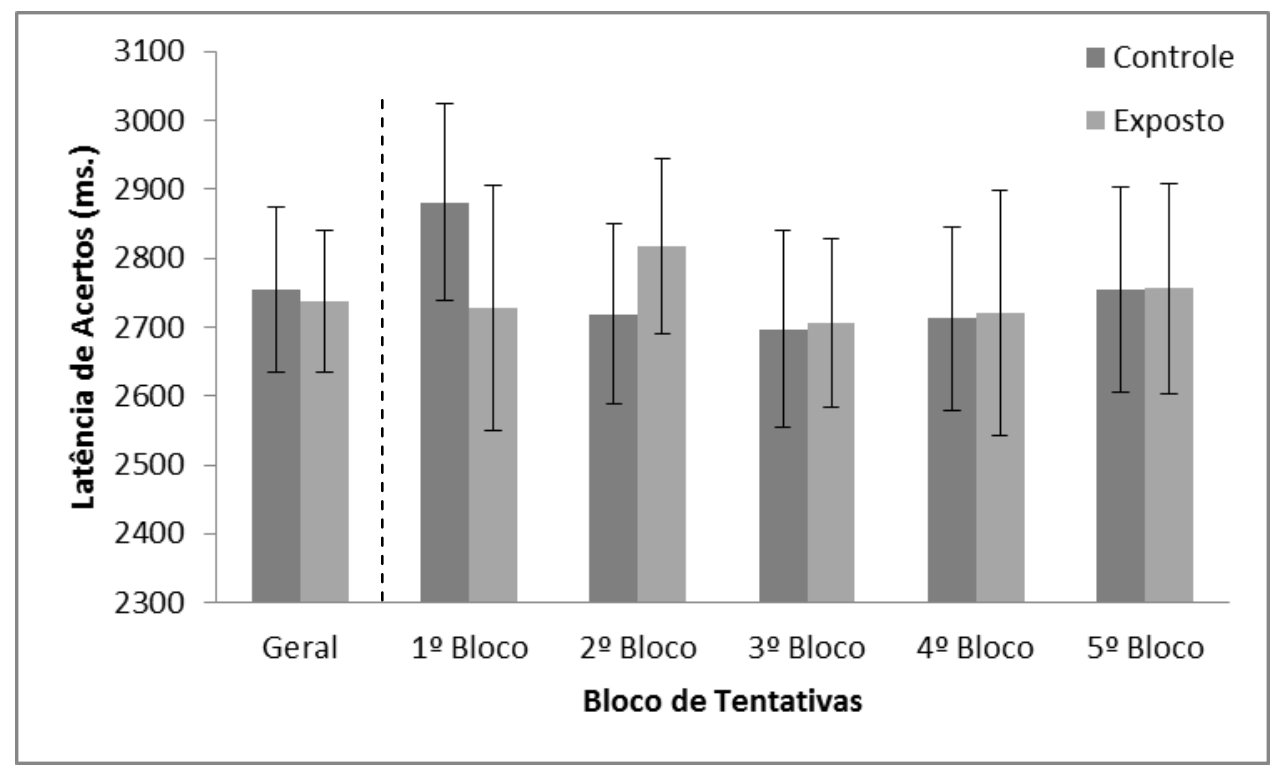

Figura 5. Latências média de acertos no Symbol Digit Test para os grupos controle e exposto, em função dos blocos de tentativas (Blocos 1 a 5), ou de todo o teste (Geral). As linhas sobre a barra representam o erro padrão da média.

\section{Match To Sample Test (MTS)}

As medidas avaliadas no Match To Sample Test (MTS) foram: percentual de acertos em todo o teste (geral), e em função dos atrasos de 1, 4 e 8 segundos, assim como a latência média de acerto geral. Enquanto os valores percentuais são uma medida direta de proficiência do teste, as latências de acertos são uma medida inversa de proficiência no teste.

O teste de permutação para duas amostras não mostrou diferenças entre os grupos para as variáveis percentual de acertos geral $(\mathrm{p}=0,69)$ (ver Figura 6) ou para os atrasos de $1 \mathrm{~s}(\mathrm{p}=0,86)$ e $4 \mathrm{~s}(\mathrm{p}=0,62)$ e $8 \mathrm{~s}(\mathrm{p}=0,15)$ (ver Figura 7). Não foi observado também diferenças entre os grupos para as latências médias de acerto geral ( $\mathrm{p}$ $=0,47)($ ver Figura 6) e para as latências nos atrasos de $1 \mathrm{~s}(\mathrm{p}=0,60), 4 \mathrm{~s}(\mathrm{p}=0,25)$ e 8 s $(\mathrm{p}=0,51)$ (ver Figura 7). 

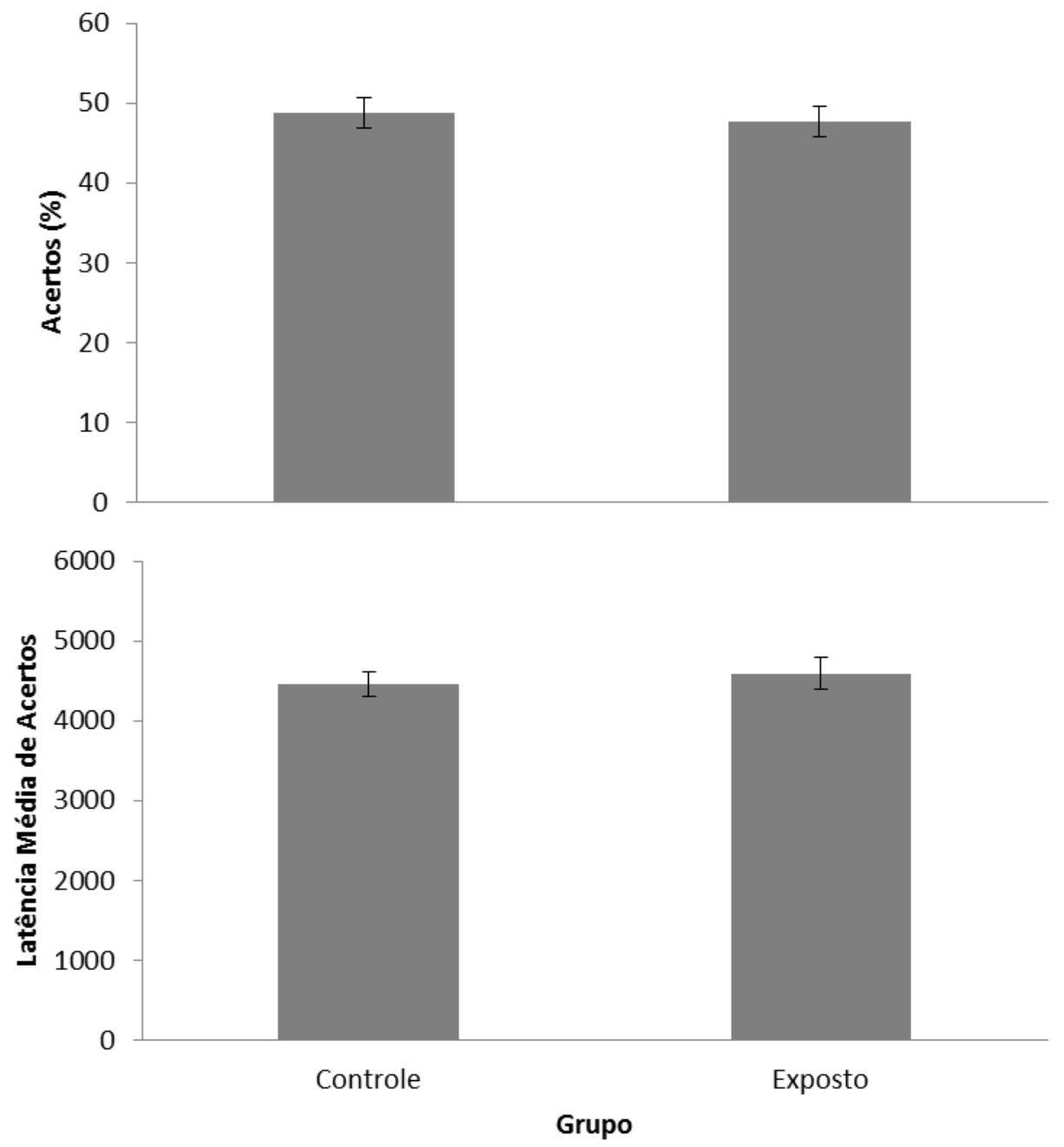

Figura 6. Percentual de acertos e latência média de acertos geral. Para os grupos controle e exposto. As linhas sobre a barra representam o erro padrão da média. 

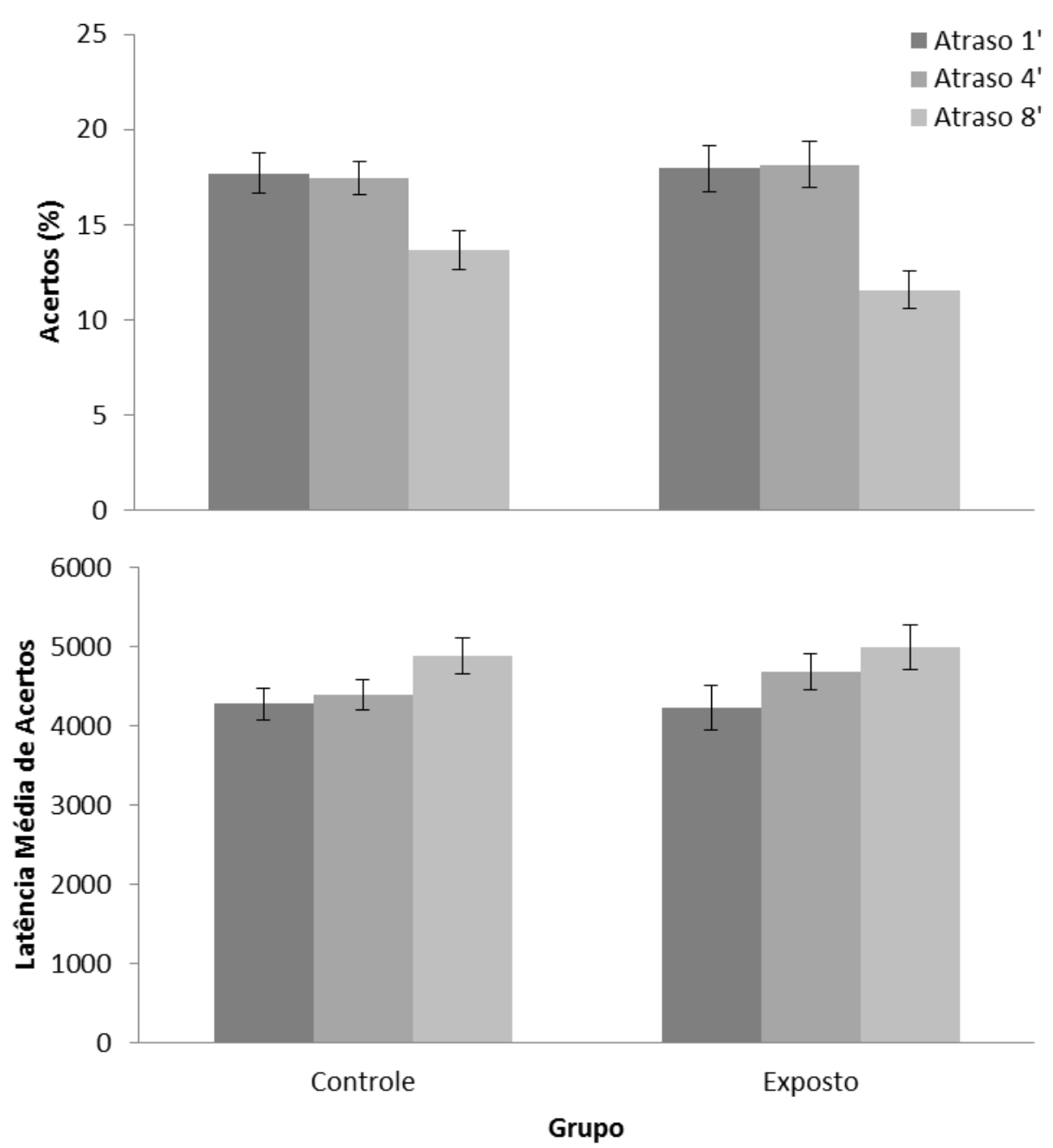

Figura 7. Percentual de acertos e latência média de acertos geral para os grupos controle e exposto, em função do período dos atrasos. As linhas sobre a barra representam o erro padrão da média.

\section{Digit Span Test (DST)}

A medida avaliada no Digit Span Test (DST) foi o número máximo de acertos em uma sequência crescente de números, tanto na ordem direta de seu aparecimento, quanto na ordem inversa. Portanto, o escore desse teste é uma medida direta de proficiência. O teste de permutação para duas amostras não mostrou diferença estatisticamente significativa para o escore no DST nas ordens direta $(\mathrm{p}=0,78)$, inversa $(\mathrm{p}=0,89)$ (ver Figura 08). 


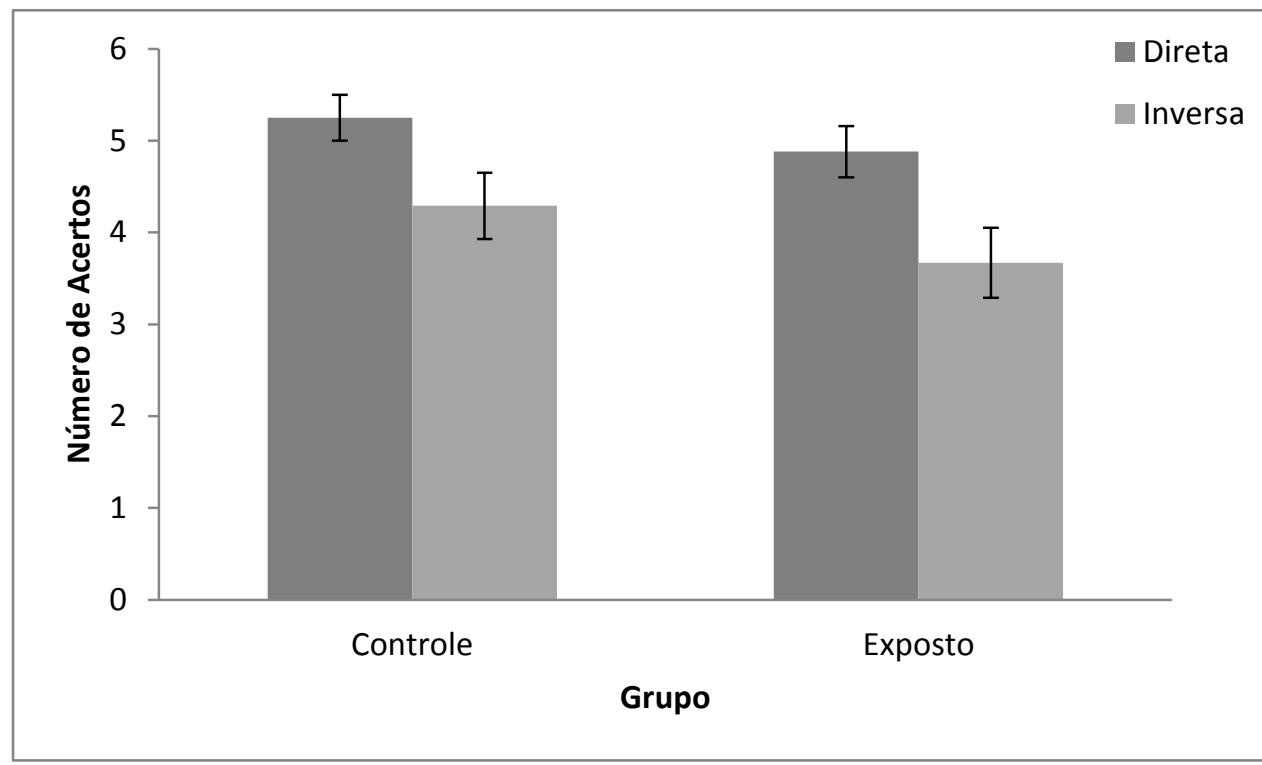

Figura 8. Frequência de acertos no Digit Span Test dos grupos controle e exposto na ordem direta e inversa. As linhas sobre a barra representam o erro padrão da média.

\section{Simple Reaction Time (SRT)}

As medidas avaliadas no Simple Reaction Time Test (SRT) foram: latência média de todos os acertos ao longo do teste (geral) e a latência dos acertos divididos em cinco blocos de tempo ( 2 min por bloco); percentual de todos os acertos ao longo do teste (geral) e o percentual dos acertos divididos em cinco blocos de tempo. Enquanto os valores percentuais são uma medida direta de proficiência do teste, as latências de acertos são uma medida inversa de proficiência no teste.

O teste de permutação para duas amostras para cada uma das medidas possíveis do teste, não mostrou diferença estatisticamente significativa para as latências de acertos no geral $(\mathrm{p}=0,66), \operatorname{nos}$ blocos $1 \mathrm{~s}(\mathrm{p}=0,43), 2 \mathrm{~s}(\mathrm{p}=0,60), 3 \mathrm{~s}(\mathrm{p}=0,48), 4 \mathrm{~s}(\mathrm{p}=$ $0,19)$ e $5 \mathrm{~s}(\mathrm{p}=0,60)$ (ver Figura 9).

Houve diferença estatisticamente significativa para o percentual de acertos no $5^{\circ}$ bloco $(\mathrm{p}=0,04 ; \mathrm{p}<0,05)$, embora essa tendência não tenha sido demonstrada para a medida geral no percentual de acertos $(\mathrm{p}=0,18)$ ou para os blocos $1 \mathrm{~s}(\mathrm{p}=0,58), 2 \mathrm{~s}(\mathrm{p}$ $=0,33), 3 \mathrm{~s}(\mathrm{p}=0,15)$ e $4 \mathrm{~s}(\mathrm{p}=0,13)$. A média do percentual de acertos do GC no $5^{\circ}$ Bloco foi de 99,36\% (dp: 1,22) e no GE foi de 99,92\% (dp: 0,41) (ver Figura 9). O tamanho do efeito ( $\mathrm{r}$ de Pearson) para as diferenças estatisticamente significativas encontradas foi médio $(\mathrm{r}=0,36)$ para o percentual de respostas corretas no $5^{\circ}$ bloco. 

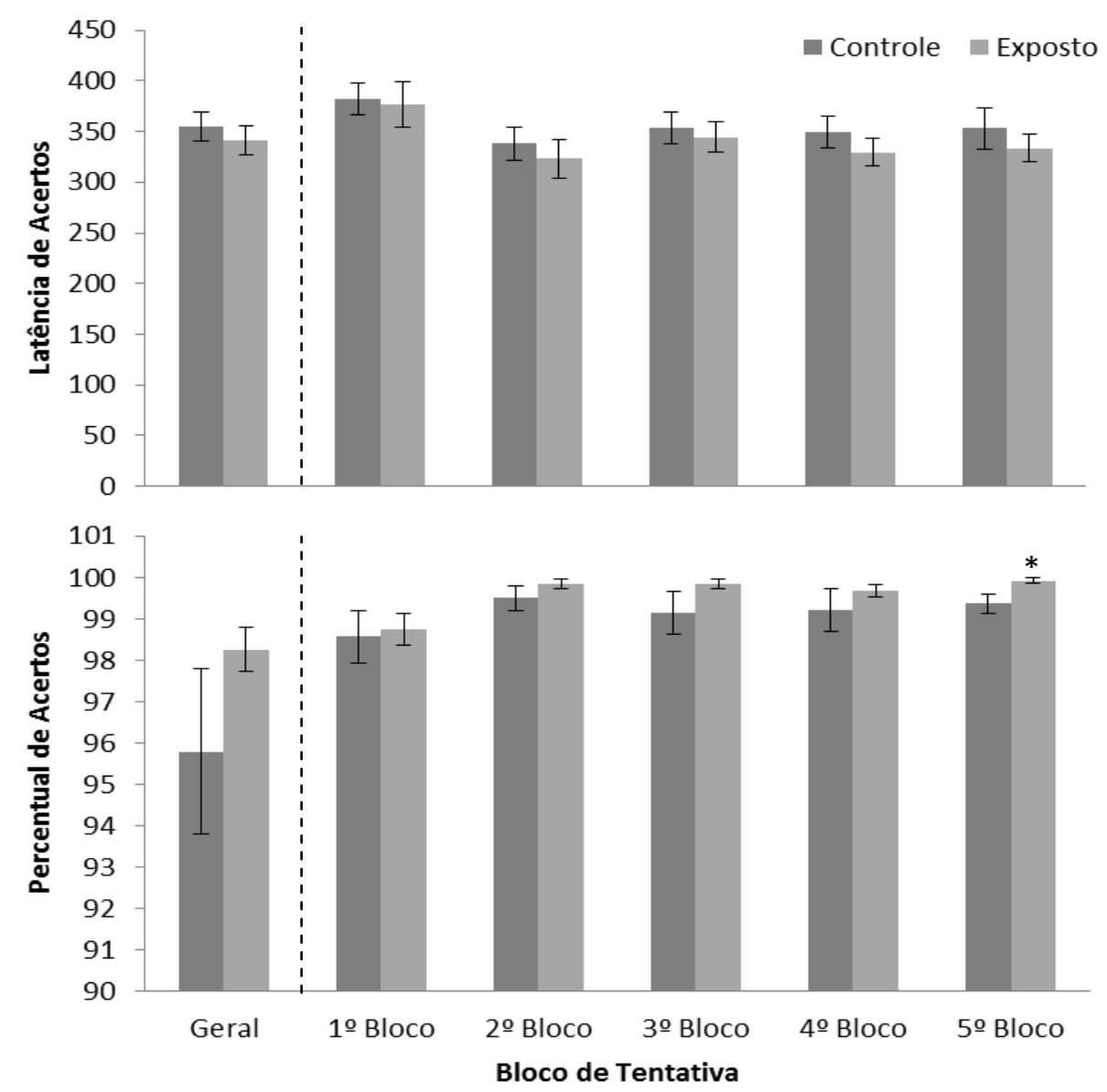

Figura 9. Latência média das respostas corretas e acertos (\%) para o Simple Reaction Time Test. Os grupos controle e exposto, em função dos blocos de tentativas (Blocos 1 a 5), ou de todo o teste (Geral). As linhas sobre a barra representam o erro padrão da média. Os sinais sobre o erro padrão da média representam a significância $(* p<0,05)$.

\section{Serial Digit Learning Test (SDL)}

A medida avaliada no Serial Digit Learning Test (SDL) foi o número necessário de repetições para a aprendizagem da sequência numérica de 9 dígitos. Portanto, o escore desse teste é uma medida inversa de proficiência no mesmo.

A Figura 10 mostra que a partir do teste de permutação para duas amostras, não houve diferença estatisticamente significativa para o escore no SDL $(p=0,60)$. 


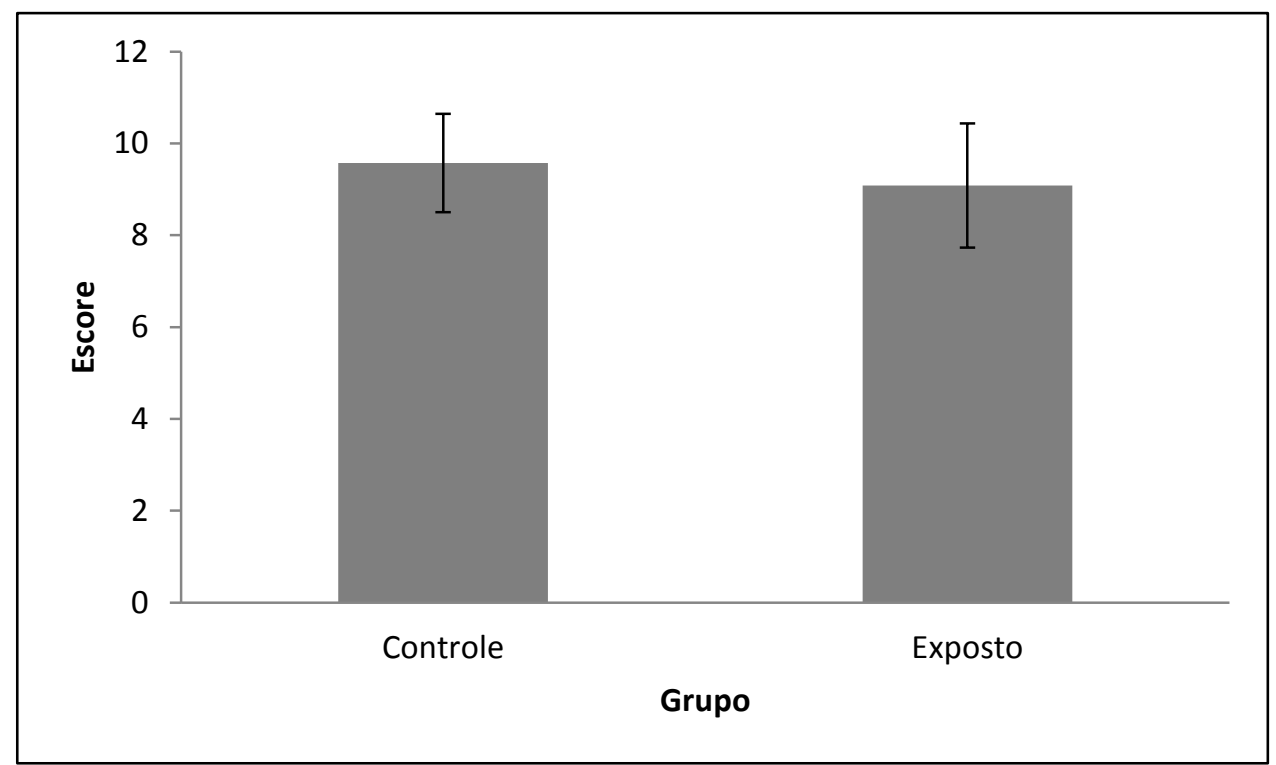

Figura 10. Escore no Serial Digit Learning Test, a partir da frequência de tentativas para aprendizagem da sequência numérica dos grupos controle e exposto. As linhas sobre a barra representam o erro padrão da média.

\section{Progressive Ratio Test (PRT)}

As medidas avaliadas no Progressive Ratio Test (PRT) foram o número máximo de pressões e o número máximo de reforços obtidos, os quais são medidas diretas de proficiência no teste. A Figura 11 mostra que no teste de permutação para duas amostras não houve diferença estatisticamente significativa para o número de pressões no DST ( $p$ $=0,79)$, nem no número de reforços $(\mathrm{p}=0,63)$. 

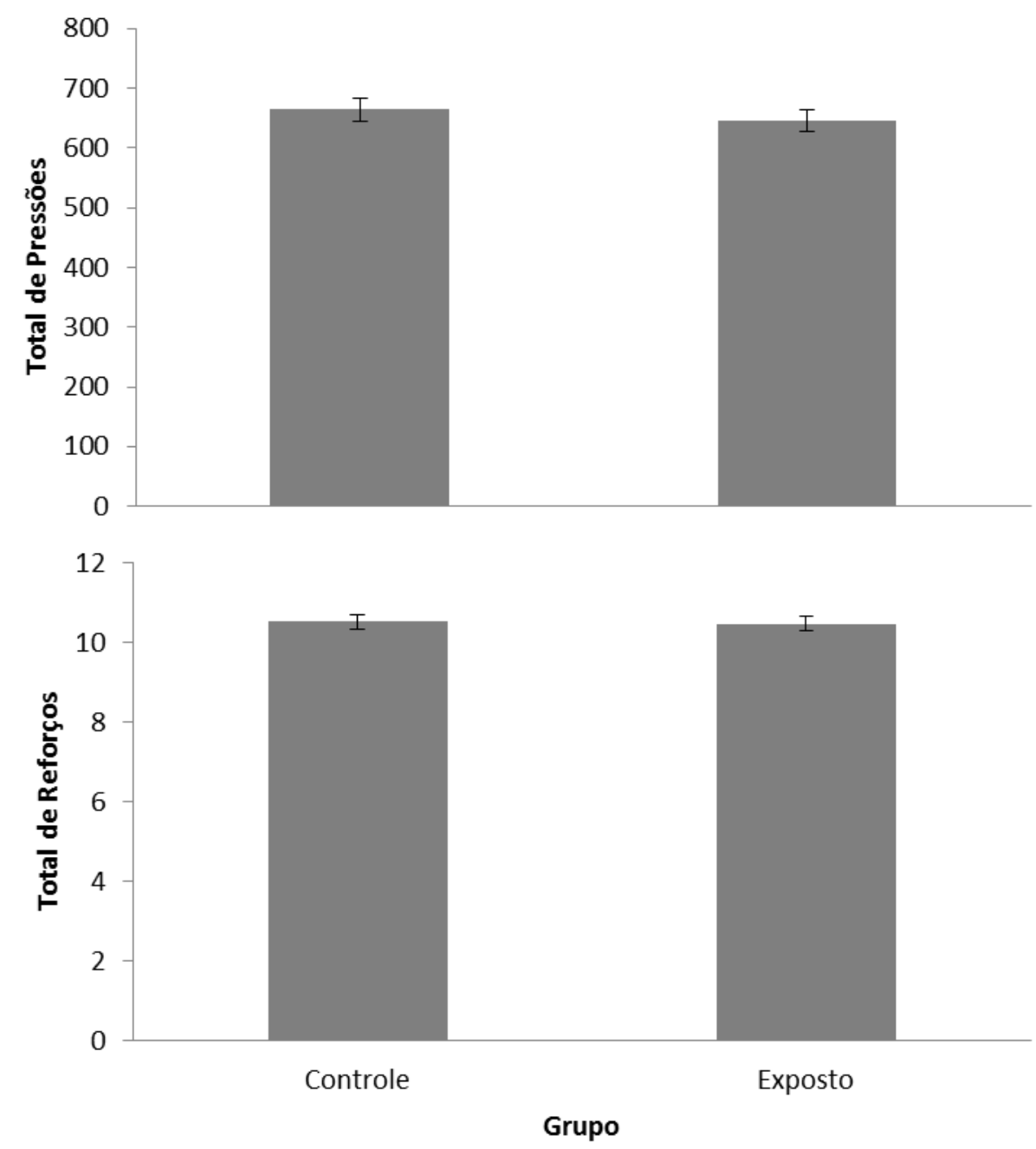

Figura 11. Frequência de respostas e reforços obtidos no PRT. As linhas sobre a barra representam o erro padrão da média.

\section{Selective Attention Test (SAT)}

O SAT é um teste de titulação no qual, ao longo de 10 min de avaliação, tenta-se definir o Intervalo entre estímulos (ISI) de não diferença, isto é, onde cerca de $50 \%$ das respostas do participante estão corretas e cerca de 50\% incorretas. Portanto, o número total de tentativas ao longo do teste varia entre os participantes, bem como o ISI e a latência média das respostas corretas. Enquanto o número total de tentativas é uma medida direta da proficiência do teste, o ISI e a latência média de respostas corretas são medidas inversas da proficiência no SAT.

A Figura 12 mostra que no teste de permutação para duas amostras não houve diferença estatisticamente significativa para o número total de tentativas ao longo do teste $(p=0,61)$ ISI $(p=0,32)$, e latência média de acertos $(p=0,17)$. 

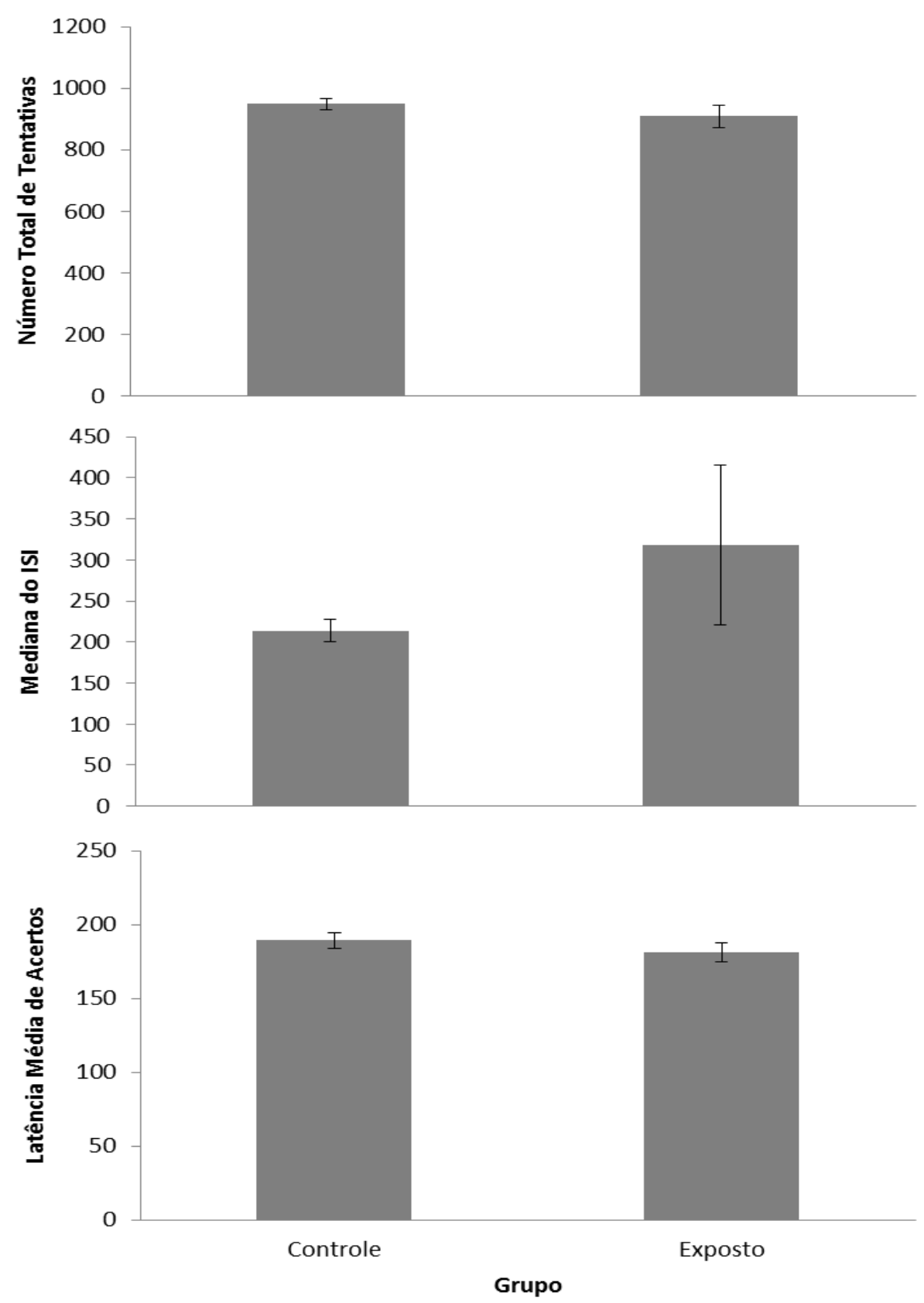

Figura 12. Frequência de tentativas, intervalo entre estímulos (ISI) e latência de acertos no SAT. As linhas sobre a barra representam o erro padrão da média. 


\section{Reversal Learning Test (RLT)}

As medidas avaliadas no Reversal Learning Test (RLT) foram frequência total de tentativas (certas e erradas, antes ou após as repetições), das repetições após erros (antes e após a reversão) e a latência das respostas nas repetições após erros (antes e após a reversão). Portanto, todas essas variáveis são medidas inversas de proficiência no teste.

O teste de permutação para duas amostras não mostrou diferença estatisticamente significativa para a frequência total de tentativas ao longo do teste ( $\mathrm{p}=$ 0,18) (ver Figura 13), frequência de repetições antes $(p=0,21)$ e após a $(p=0,57)$ reversão, e ainda para a latência média das respostas de repetição antes e $(\mathrm{p}=0,50)$ após a reversão $(\mathrm{p}=0,45)$ (ver Figura 14).

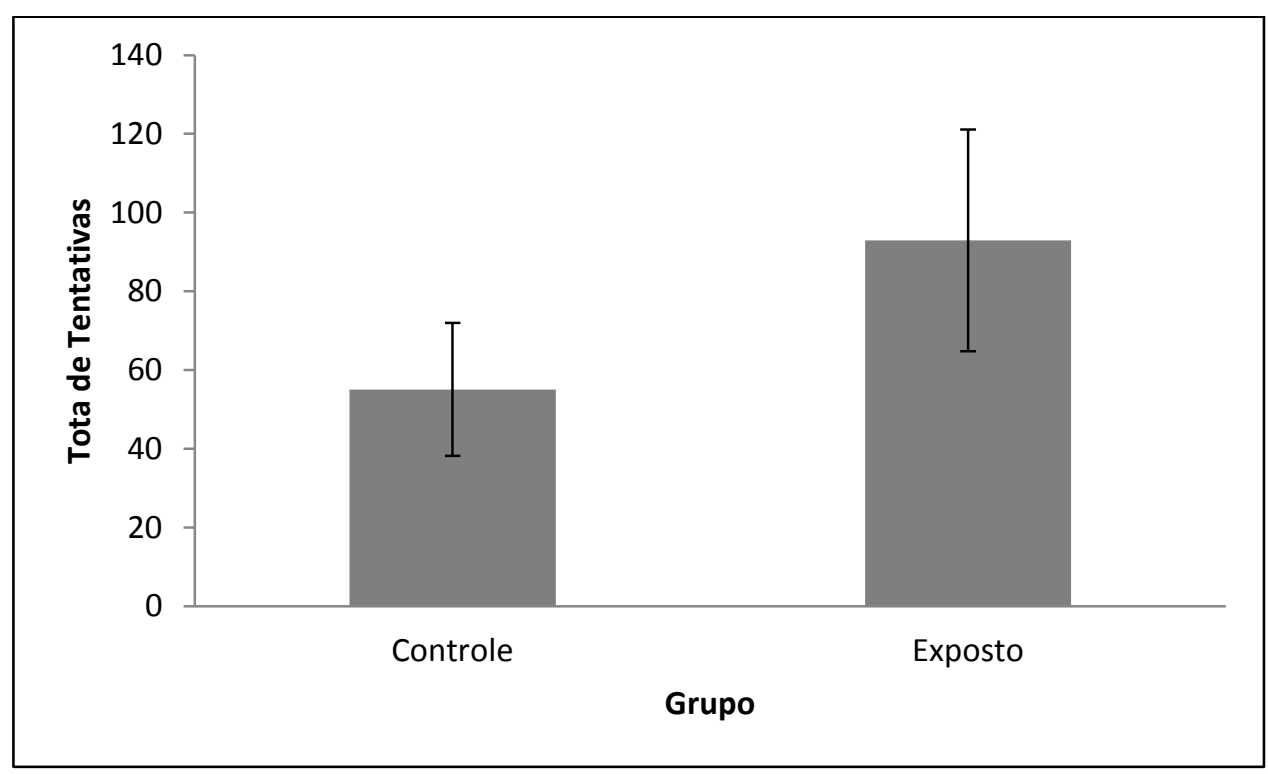

Figura 13. Total de tentativas no RLT para os grupos controle e exposto. As linhas sobre a barra representam o erro padrão da média. 

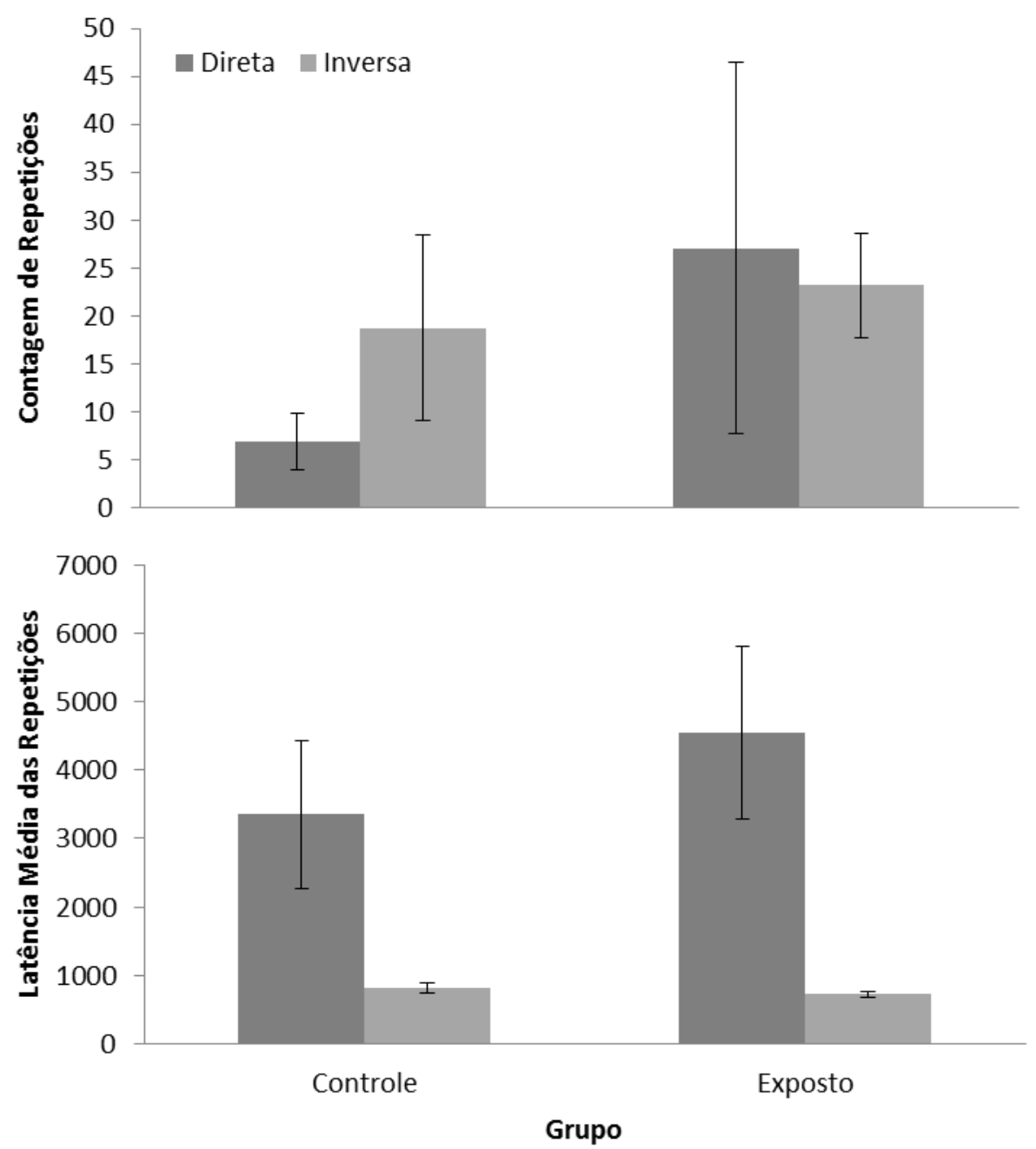

Figura 14. Frequência e latência média de repetições no RLT para os grupos controle e exposto, e a latência média das repetições, ambas as medidas antes e após a reversão. As linhas sobre a barra representam o erro padrão da média.

\section{Teste de Romberg (Rom)}

A medida avaliada no Teste de Romberg foi a latência para início do balanço (s), uma medida direta da proficiência no teste. O teste de permutação para duas amostras foi realizado. Em média, os participantes do grupo exposto (méd.: 1,70; dp: 0,53) apresentaram menor latência de balanço quando comparado ao grupo controle (méd.: 1,99; dp: 0,91). Essa diferença foi estatisticamente significativa $(\mathrm{p}=0,04 ; \mathrm{p}<0,05)$, com um tamanho de efeito pequeno $(r=0,21)$ (ver Figura 15). 


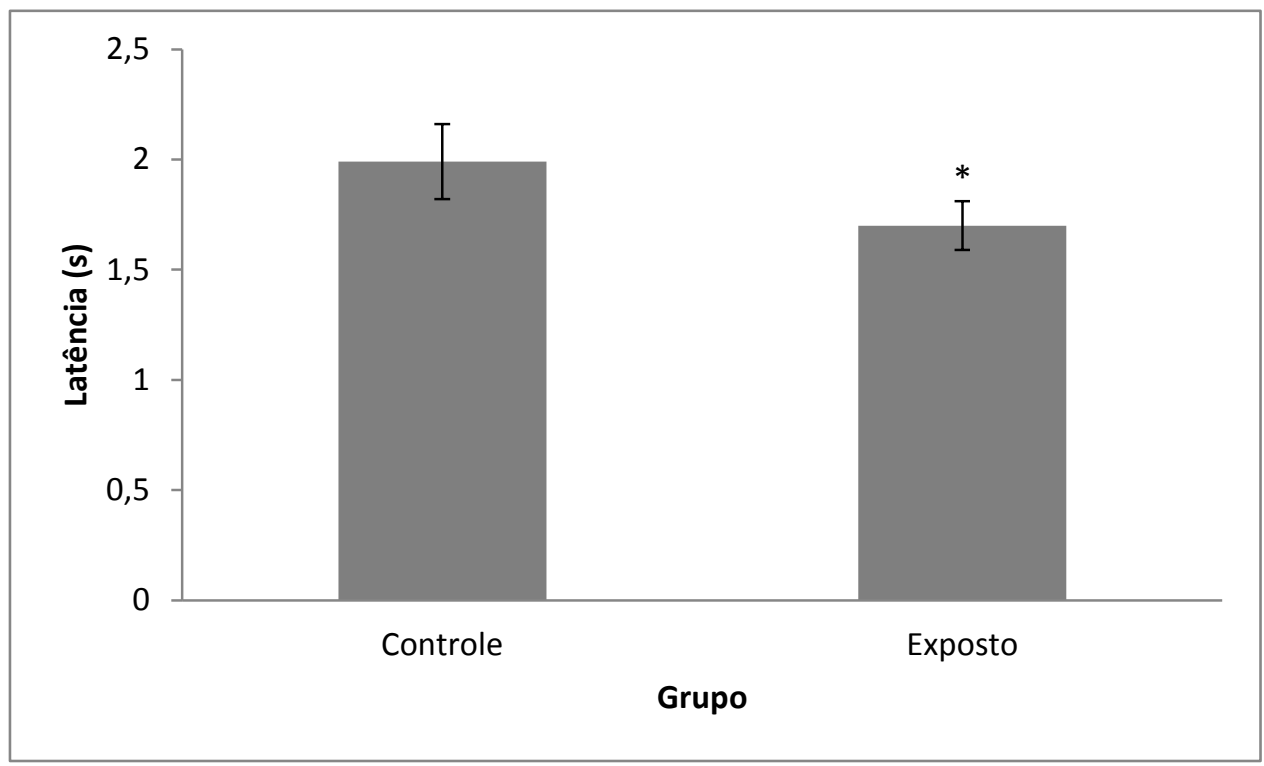

Figura 15. Latências para o início do balanço no Teste de Romberg para os grupos controle e exposto. As linhas sobre a barra representam o erro padrão da média. $\mathrm{O}$ asterisco sobre o erro padrão da média representam a significância $(\mathrm{p}<0,05)$.

\section{Continuous Performance Test (CPT)}

As medidas avaliadas no Continuous Performance Test (CPT) foram a latência das respostas corretas e dos falsos alarmes, bem como o "d-prime", que é uma medida da diferença entre os acertos (sinal) e falsos alarmes (sinal + ruído), transformados em escore-z, interpretados como sensibilidade ao sinal/percepção do sinal. O valor máximo alcançado no d-prime é de 6,93. Portanto, enquanto o d-prime e latência de respostas incorretas são medidas diretas de proficiência, a latência de respostas corretas é medida inversa.

O teste de permutação para duas amostras foi e não mostrou diferença estatisticamente significativa para latência de acertos $(\mathrm{p}=0,86)$, falsos alarmes $(\mathrm{p}=$ $0,97)$ e d-prime $(p=0,15)$ (ver Figuras 16 e 17). 


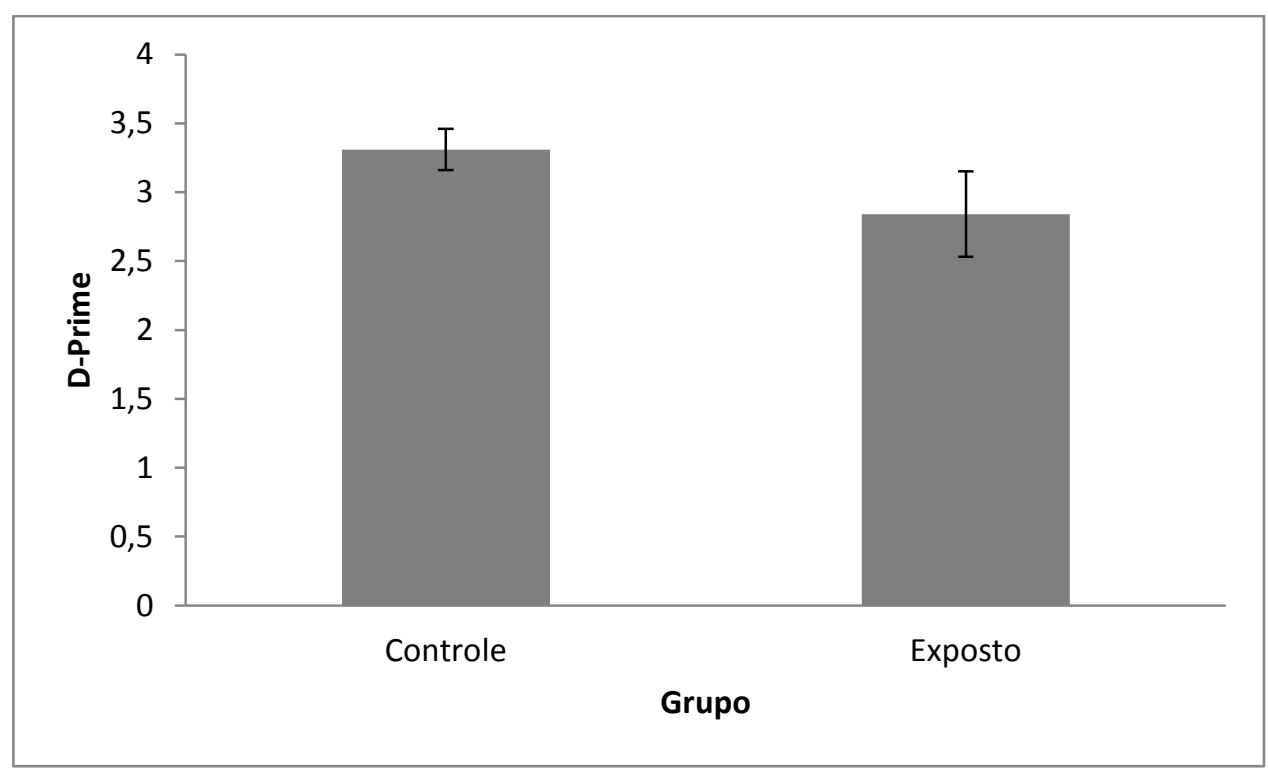

Figura 16. D-Prime no CPT dos grupos controle e exposto. As linhas sobre a barra representam o erro padrão da média.

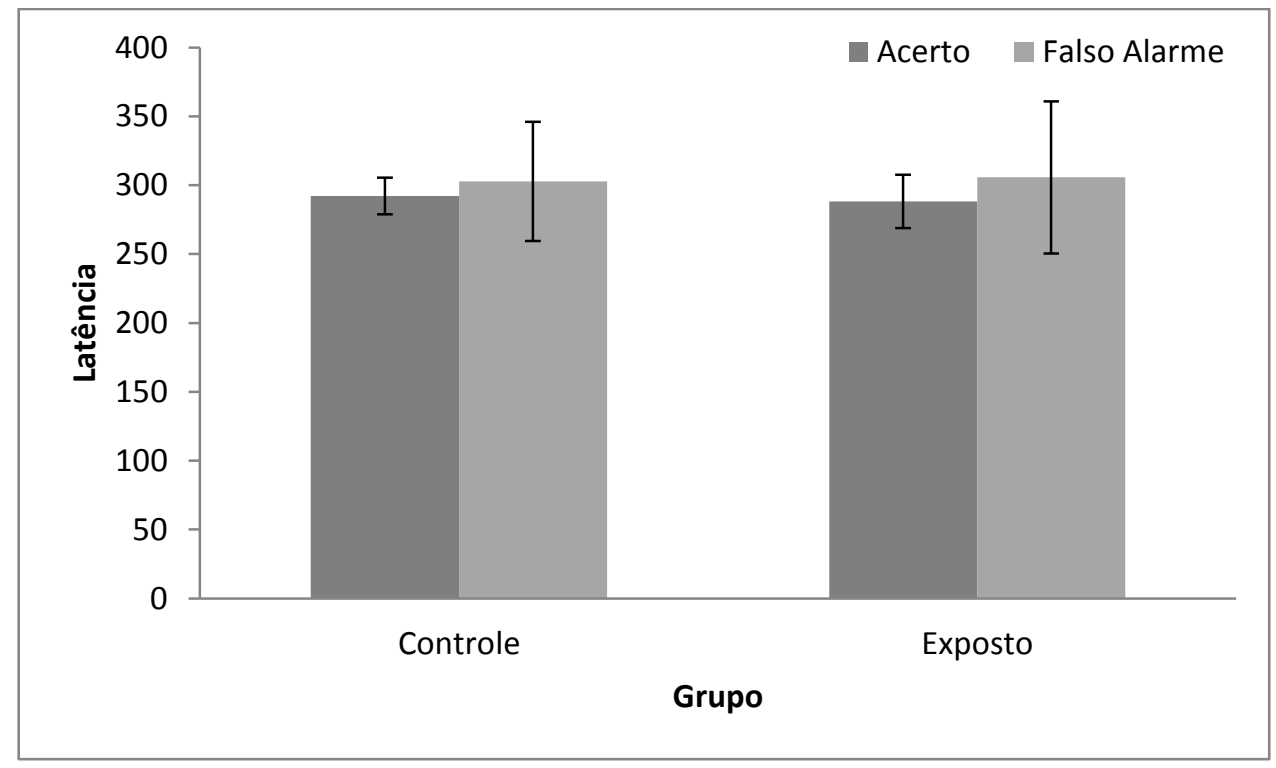

Figura 17. Latências de Acerto e Falso Alarme no CPT dos grupos controle e exposto. As linhas sobre a barra representam o erro padrão da média. 
De acordo com a análise de Rohlman et al. (2014), e para evitar redundâncias, as 48 VDs neurocomportamentais foram neste estudo reduzidas para 27, como mostra a Tabela 9. Em um primeiro momento, os desempenhos neurocomportamentais foram transformados em escore-z. Nove resultados de avaliações neurocomportamentais (latências de respostas corretas no MTS, CPT; RLT; SRT; SAT SDT; erros no SDT; frequência no RLT; ISI no SAT) tiveram a direção da medida do escore-z revertida (multiplicando por -1), de forma que, quanto mais alto o escore positivo, melhor o desempenho no teste. Os escore-z foram analisados para diferenças de grupos utilizando a regressão linear tendo todos os modelos sido ajustados para idade e escolaridade. Nenhuma diferença estatisticamente significativa foi encontrada na comparação entre grupos, em todas as 27 variáveis analisadas (ver Tabela 9). 
Tabela 9. Desempenho de trabalhadores expostos e não expostos em medidas comportamentais avaliadas. Os modelos foram ajustados para idade e escolaridade.

\begin{tabular}{|c|c|c|c|c|c|c|c|c|c|}
\hline \multirow{2}{*}{$\begin{array}{c}\text { Medida } \\
\text { Neurocomportamental }\end{array}$} & \multicolumn{3}{|c|}{ Controle } & \multicolumn{3}{|c|}{ Exposto } & \multirow{2}{*}{ Dif. } & \multicolumn{2}{|c|}{$\begin{array}{l}\text { Ajuste } \\
\qquad 95 \% \text { IC }\end{array}$} \\
\hline & $\mathrm{N}$ & Média & EPM & $\mathrm{N}$ & Média & EPM & & Inf. & Sup. \\
\hline TAP (Mão Dom.) & 46 & 0,052 & 0,138 & 35 & $-0,068$ & 0,185 & 0,027 & $-0,406$ & 0,460 \\
\hline TAP (Mão N. Dom.) & 46 & $-0,008$ & 0,116 & 35 & 0,011 & 0,210 & 0,161 & $-0,275$ & 0,597 \\
\hline TAP (Alt. Mão Dom.) & 46 & 0,101 & 0,153 & 35 & $-0,132$ &, 160 & $-0,262$ & $-0,696$ & 0,171 \\
\hline TAP (Alt. Mão N. Dom) & 46 & 0,154 & 0,151 & 35 & $-0,202$ & 0,159 & $-0,351$ & $-0,794$ & 0,092 \\
\hline SDT (Erros) & 46 & 0,036 & 0,143 & 35 & $-0,048$ & 0,177 & $-0,087$ & $-0,507$ & 0,334 \\
\hline SDT (Latência) & 46 & $-0,032$ & 0,159 & 35 & 0,043 & 0,153 & 0,072 & $-0,347$ & 0,492 \\
\hline MTS (Escore 1") & 46 & $-0,017$ & 0,149 & 35 & 0,022 & 0,169 & 0,003 & $-0,460$ & 0,466 \\
\hline MTS (Escore 4") & 46 & $-0,048$ & 0,136 & 35 & 0,063 & 0,187 & 0,088 & $-0,367$ & 0,542 \\
\hline MTS (Escore 8") & 46 & 0,138 & 0,150 & 35 & $-0,181$ & 0,148 & $-0,363$ & $-0,826$ & 0,100 \\
\hline MTS (Latência 1") & 43 & $-0,051$ & 0,140 & 34 & 0,065 & 0,189 & $-0,011$ & $-0,474$ & 0,452 \\
\hline MTS (Latência 4") & 46 & 0,110 & 0,147 & 35 & $-0,145$ & 0,169 & $-0,236$ & $-0,697$ & 0,225 \\
\hline MTS (Latência 8") & 45 & 0,066 & 0,144 & 35 & $-0,084$ & 0,178 & $-0,220$ & $-0,678$ & 0,238 \\
\hline CPT (D-Prime) & 46 & 0,140 & 0,103 & 35 & $-0,184$ & 0,217 & $-0,315$ & $-0,778$ & 0,149 \\
\hline DST (Escore Direta) & 46 & 0,028 & 0,139 & 35 & $-0,037$ & 0,184 & $-0,003$ & $-0,427$ & 0,421 \\
\hline DST (Escore Inversa) & 46 & 0,014 & 0,158 & 35 & $-0,018$ & 0,154 & 0,022 & $-0,433$ & 0,477 \\
\hline SRT (Latência) & 46 & $-0,043$ & 0,155 & 35 & 0,056 & & 0,189 & $-0,275$ & 0,652 \\
\hline SRT (Escore) & 46 & $-0,127$ & 0,190 & 35 & 0,167 & 0,057 & 0,134 & $-0,308$ & 0,576 \\
\hline SDL (Escore) & 46 & 0,050 & 0,141 & 35 & $-0,065$ & 80 & $-0,030$ & $-0,484$ & 0,425 \\
\hline PRT (Pressões) & 46 & 0,025 & 0,159 & 35 & $-0,033$ & 0,153 & 0,002 & $-0,462$ & 0,467 \\
\hline SAT (Tentativas) & 46 & 0,050 & 0,130 & 35 & $-0,066$ & 0,193 & $-0,089$ & $-0,561$ & 0,383 \\
\hline SAT (ISI Mediana) & 46 & 0,091 & 0,061 & 35 & $-0,120$ & 0,245 & $-0,199$ & $-0,670$ & 0,272 \\
\hline SAT (Latência) & 46 & $-0,132$ & 0,150 & 35 & 0,174 & 0,164 & 0,395 & $-0,063$ & 0,852 \\
\hline RLT (Escore Direta) & 36 & 0,129 & 0,039 & 28 & $-0,166$ & 0,281 & $-0,323$ & $-0,851$ & 0,205 \\
\hline RLT (Escore Reversão) & 36 & 0,055 & 0,202 & 28 & $-0,071$ & 0,124 & $-0,243$ & $-0,749$ & 0,262 \\
\hline RLT (Latência Direta) & 36 & 0,072 & 0,161 & 28 & $-0,093$ & 0,199 & $-0,152$ & $-0,685$ & 0,380 \\
\hline RLT (Latência Reversão) & 36 & $-0,083$ & 0,198 & 28 & 0,106 & 0,131 & 0,272 & $-0,247$ & 0,791 \\
\hline Romberg (Lat. Balanço) & 41 & 0,212 & 0,178 & 33 & $-0,263$ & 0,126 & $-0,448$ & $-0,936$ & 0,040 \\
\hline
\end{tabular}

As diferenças no desempenho em medidas neurocomportamentais dos trabalhadores expostos e não expostos são apresentadas na Figura 18. Em uma análise posterior buscou-se minimizar o número de variáveis neurocomportamentais de 27 para 5, empregando a análise de componente principal. As combinações lineares (componentes) foram rotacionadas (oblimin direto) para minimizar que um teste pudesse integrar múltiplos componentes simultaneamente. 


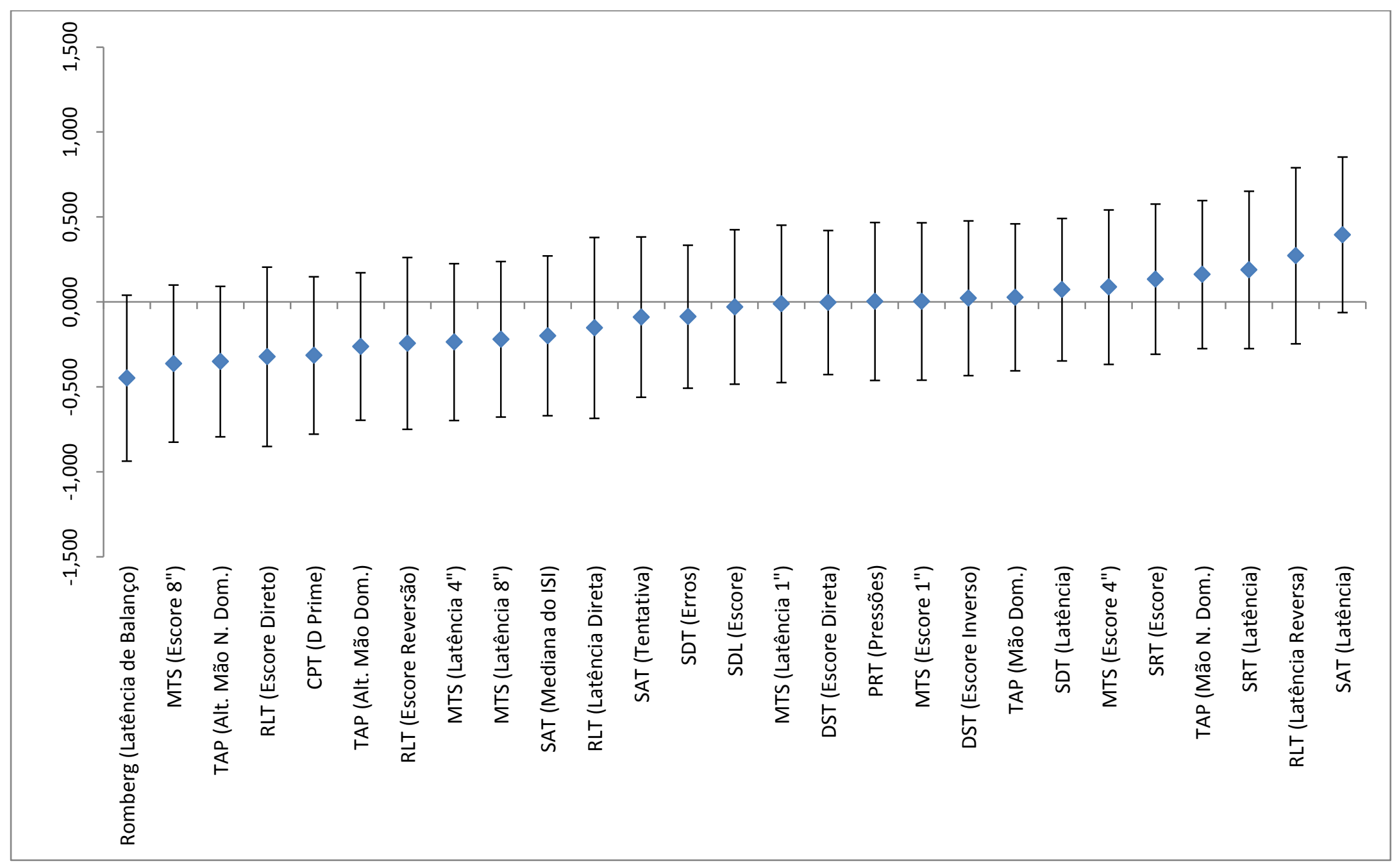

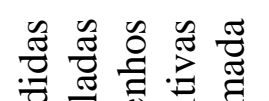

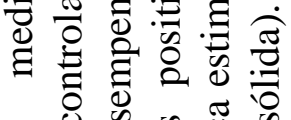

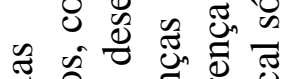
० ๙ क

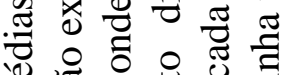
娄 0 造

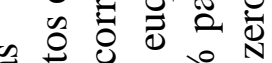

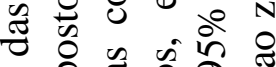
खे 0

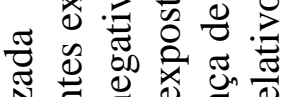
政

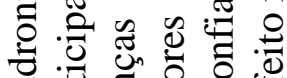
¿ 인 \%

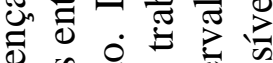

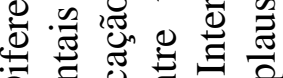

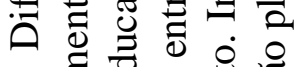

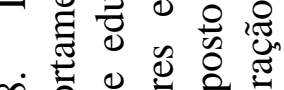

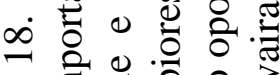

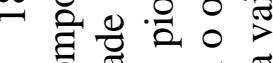
ซ⿻ำ

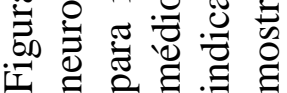


A média ponderada dos escores de cada sujeito em cada teste que ocupava um dado componente formou uma nova variável (Componente 1 a 5; PC1 a PC5). Esses componentes foram, então, utilizados como respostas, da mesma forma que os modelos de regressão linear descritos anteriormente, a fim de determinar se esse conjunto dessas variáveis combinadas a associada com grupos, após ajuste para idade e nível de escolaridade. Os primeiros 5 componentes explicam $56,76 \%$ da variância total dos 27 testes. Nenhuma diferença estatisticamente significativa foi encontrada na comparação entre grupos, em todas as 27 variáveis analisadas (ver Tabela 10).

Tabela 10. Análise de Componente Principal para as medidas neurocomportamentais avaliadas.

\begin{tabular}{|c|c|c|c|c|c|}
\hline Neurobehavioral measure & PC1 & PC2 & PC3 & PC4 & PC5 \\
\hline TAP (Mão Dom.) & ,880 &,- 019 &, 065 & 042 &,- 102 \\
\hline TAP (Mão N. Dom.) & ,873 & ,037 &, 009 &,- 094 &,- 031 \\
\hline PRT (Pressões) & ,772 & 151 & 091 & 080 & 127 \\
\hline TAP (Alt. Mão N. Dom.) & ,660 & ,252 &,- 413 &, 180 &, 025 \\
\hline SRT (Latência) & ,465 &, 079 &,- 075 & ,405 &, 150 \\
\hline MTS (Escore 8") & ,336 & ,061 & ,226 &,- 029 & ,297 \\
\hline SAT (Mediana do ISI) & 054 & 974 & 100 &, 015 & ,003 \\
\hline RLT (Escore Direta) &,- 121 & 972 &, 005 & 072 & 055 \\
\hline SAT (Tentativa) & ,369 & ,776 &,- 086 &,- 071 &,- 121 \\
\hline SAT (Latência) & 484 &,- 516 &,- 071 &,- 205 &,- 412 \\
\hline Romberg (Latência de Balanço) &, 062 &, 254 &,- 038 &,- 072 & ,008 \\
\hline SRT (Escore) &,- 126 &,- 008 &,- 857 &,- 085 &,- 078 \\
\hline RLT (Escore Reversão) &,- 230 &, 133 &,- 769 & ,073 &,- 108 \\
\hline SDT (Latência) & 233 &,- 093 &,- 715 &, 190 & ,234 \\
\hline TAP (Alt. Mão Dom.) & ,452 &, 262 &,- 577 &, 181 &,- 038 \\
\hline MTS (Escore 1") & ,003 &,- 382 &,- 473 &,- 123 & , 164 \\
\hline CPT (D Prime) & ,211 &,- 032 &,- 454 &,- 331 &,- 127 \\
\hline SDT (Erros) &,- 116 &, 065 &,- 402 &,- 109 & ,386 \\
\hline MTS (Latência 4") & ,099 &,- 172 & 011 & ,797 & 081 \\
\hline MTS (Latência 8") &, 116 & ,009 &,- 015 & ,718 &,- 227 \\
\hline MTS (Latência 1") &,- 134 &, 153 &,- 038 & ,708 &,- 164 \\
\hline DST (Escore Direta) &, 245 & ,038 &,- 096 &,- 124 & ,625 \\
\hline RLT (Latência Direta) &,- 037 &,- 239 &, 100 & ,298 & ,499 \\
\hline MTS (Escore 4") &,- 080 & ,049 &,- 033 &,- 112 & ,499 \\
\hline SDL (Escore) &, 057 &, 253 &,- 384 &,- 082 & ,468 \\
\hline DST (Escore Inversa) & ,353 & 075 &,- 317 &,- 149 & ,369 \\
\hline RLT (Latência Reversa) & ,203 &,- 073 & , 138 &,- 103 & ,243 \\
\hline
\end{tabular}




\section{DISCUSSÃO}

O presente estudo teve como objetivo identificar as possíveis alterações neurocomportamentais que a exposição ao hexano poderia gerar em trabalhadores de indústria da extração de óleo vegetal. Esse objetivo partiu do pressuposto que a exposição ao hexano afeta funções neurocomportamentais, como aspectos motores (Armstrong, 1995; Kang et al., 2005) e de tempo de reação (Kang et al., 2005), de atenção, memória (Kang et al., 2005; Tsai et al., 1997) e aprendizagem (Kang et al., 2005). Essa triagem toxicológica parece ser promissora com o uso de BARS, uma vez que essa bateria possui vários testes que avaliam cinco diferentes funções neurocomportamentais, além do fato dessa ter sido transculturalmente empregada e mostrando consistência interna em suas medidas.

\section{Teste DE Romberg}

Os resultados foram analisados a partir de duas abordagens estatísticas, uma que compara sistematicamente os grupos (controle e exposto), tanto para variáveis constitucionais, quanto para as variáveis de interesse. E outra, que compara grupo exposto e controle, controlando as variáveis constitucionais (idade e escolaridade) ajustando-as à uma regressão múltipla. Ambas abordagens estatísticas foram consistentes ao não evidenciar diferença em grande parte das variáveis, exceto pela menor latência de tempo de balanço no teste de Romberg e um sutil aumento no percentual de acertos no $5^{\circ}$ bloco do SRT, que foram destaques somente na primeira abordagem estatística.

A adoção de técnicas de regressão têm acompanhado a tendência da literatura nesta área (e.g., Rohlman et al., 2014; Tsai et al., 1997). As Análises de Covariância (ANCOVA) também são empregadas, ajustando confundidores para a análise (e.g., Kang et al., 2005). Mas, em estudos de campo, a comparação ponto a ponto ( $1^{\mathrm{a}}$ abordagem), não é, em geral, utilizada, sendo mais adequada a contextos experimentais de investigação. Porém, é útil ressaltar a contribuição de análises estatísticas nestes delineamentos experimentais e não experimentais como o estudo de campo desenvolvido neste trabalho.

A significância no teste de Romberg perde-se quando a regressão ajusta os valores para os confundidores idade e escolaridade. O teste de Romberg é um teste motor (não verbal) e, neste sentido, o fator escolaridade pode não ser determinante. A 
idade é uma variável que altera o equilíbrio postural de pessoas submetidas a essa avaliação (Jalali, Gerami, Heidarzadeh, \& Soleimani, 2014). Deste modo, é possível que o ajuste por idade tenha sido o determinante ao retirar a diferença entre os grupos nesta variável, quando comparada à primeira abordagem estatística. Esse ajuste considera o efeito deste confundidor dentro do modelo. A primeira abordagem estatística não considera esse ajuste, tomando somente a medida geral para cada análise realizada e, por essa razão, pode trazer um viés em seu resultado.

Outro fator a ser considerado é o próprio tamanho da amostra. A amostra de 81 foi reduzida para 74 participantes, haja vista os danos nos DVDs. Embora a análise bivariada tenha encontrado a associação entre exposição e o teste de Romberg, esta associação não se confirmou na análise ajustada, o que pode derivar da falta de poder estatístico.

Embora o emprego do teste de permutação possa ser adequado a esta amostra (Proschan, Glimm, \& Posch, 2014) e, embora o teste de Romberg pode ser afetado pela exposição a solventes orgânicos (Herpin et al., 2009; Iwata, Mori, Dakeishi, Onozaki, \& Murata, 2005), não é possível concluir neste estudo que o efeito observado na primeira abordagem estatística tenha derivado dessa exposição. Como apresentado anteriormente, o tamanho do efeito foi pequeno e, por essa razão, “volátil”, a depender da abordagem empregada. Parte disso pode ter derivado do próprio delineamento deste estudo. Foi realizada avaliação após os dois dias de folga dos funcionários, ao reiniciarem sua rotina de trabalho. Neste momento, presumivelmente, seus organismos estariam sem a presença do solvente.

A realização do teste ao final da jornada de trabalho poderia prover elementos mais concretos para identificação do efeito do hexano sobre as medidas neurocomportamentais utilizadas. Entretanto, neste caso considerar-se-ia o efeito da exposição aguda ao solvente. Como o presente estudo objetivou a análise do possível efeito crônico de exposição, a investigação do efeito agudo permanece como sugestão para investigações futuras.

Ainda no teste de Romberg, há de se considerar o efeito teto dessa medida. Agrawal, Carey, Hoffman, Sklare, e Schubert (2011) informam que diferentes "inputs" sensoriais estão relacionados com o teste de Romberg, a saber: visual, proprioceptivo e vestibular. Diferentes condições de testagem (olhos abertos, olhos fechados, superfície fixa e superfície instável) favorecem ou não esses "inputs". A condição de testagem realizada neste estudo (olhos abertos e fechados, em superfície estável) e os aparatos de 
registro e medição do balanço (julgamento de observadores frente ao registro filmado), não são os mais acurados e fidedignos (Johnston \& Pennypacker, 1993), a despeito da utilização de observadores cegos à condição de testagem para a o registro da latência de início de balanço. A dificuldade em precisar o início do balanço, dada a sutileza da medida, exige cautela de análise. A fim de evitar esse efeito teto e gerar uma condição de discriminabilidade entre os participantes e, afim de precisar ainda mais a condição de análise do "input" proprioceptivo, poder-se-ia (em condições favoráveis de registro dos movimentos), realizar um quociente entre o balanço na condição de olhos fechados e superfície estável/olhos fechados e superfície instável. Uma vez que, nesses casos, os principais "inputs" seriam, respectivamente: proprioceptivo + vestibular/vestibular, essa razão poderia dar uma medida mais acurada da integridade do sistema proprioceptivo. A melhoria na condição de registro de movimentos e este novo arranjo para a coleta dos dados devem ser investigados em futuros estudos.

\section{BEHAVIOR ASSESSMENT AND RESEARCH SYSTEM - BARS}

Quanto às demais medidas neurocomportamentais avaliadas pelo BARS, não houve uma diferença estatisticamente significativa, à exceção do quinto bloco do teste de tempo de reação simples (SRT), mostrando um pequeno aumento em relação ao grupo controle, na primeira abordagem estatística utilizada. Embora o r de Pearson tenha apontado para um tamanho de efeito médio, a inspeção visual da Figura 9 sugere que os grupos são semelhantes quanto ao percentual de acertos, ao longo de todos os cinco blocos do grupo. Essa diferença somente no quinto bloco permite interpretar que esta variação deriva, provavelmente, da fadiga da atividade, mais do que propriamente alguma alteração na velocidade de condução do sinal. Uma vez que todos participantes foram informados dos objetivos da pesquisa, é possível que tal informação tenha diferencialmente afetado o empenho dos mesmos na realização dos testes. Enquanto os trabalhadores do envase participavam e alguns argumentavam que o controle para a participação da pesquisa era o afastamento da rotina de trabalho, os trabalhadores da preparação e extração manifestavam determinação e interesse em realizar as tarefas propostas, preocupados com as condições higiênico-sanitárias as quais estavam expostos. Esta diferença na demanda provavelmente favoreceu o melhor desempenho no GE, que manteve melhores índices de atenção ao longo do teste, em oposição ao GC, que apresentou decremento na atenção ao longo das tentativas (ver Córdova et al., 2003, 
para uma discussão similar envolvendo jovens com retardo metal e tarefas com diferentes demandas de informação)

De modo geral, as duas análises apontam para a mesma tendência, isto é. Quanto maiores as diferenças entre o grupo controle e exposto ( $1^{\mathrm{a}}$ abordagem estatística), maiores os desvios em relação ao eixo zero da Figura 18 ( $2^{a}$ abordagem estatística), com a diferença que nesta abordagem estatística não se observou qualquer valor de significância estatística.

A seleção de variáveis para incorporar a segunda análise visou diminuir o número de variáveis, sendo que muitas delas eram redundantes, isto é, apontavam para uma mesma tendência, apesar de estarem relacionadas a diferentes instâncias quantificáveis de comportamento (e.g., latência de resposta e percentual de acertos). Quando várias análises pormenorizavam a distribuição das respostas ao longo do tempo (5 blocos), uma vez não existindo diferença entre esses, a medida geral foi utilizada para a $2^{\mathrm{a}}$ abordagem estatística. Assim, 48 variáveis foram reduzidas para 27.

A seleção das variáveis que deveriam entrar no modelo para a $2^{\mathrm{a}}$ abordagem estatística foi orientada por Rohlman et al. (2014), o que conduziu a inclusão da idade e escolaridade. Vários ensaios com as demais variáveis constitucionais foram realizados a fim de identificar outros preditores. Entretanto, todas enfraqueciam o modelo estatístico. Dentre as quais, a que melhor se encaixava como preditor era renda per capita, um parâmetro para avaliar diferenças sócio-econômicas, o qual foi excluída da análise por tratar-se de variável redundante. Considerando que trabalhadores que lidam com hexano recebem adicional de insalubridade por seu serviço (Brasil, 2014a) e que trabalhadores do grupo exposto recebiam mais do que o grupo controle (Tabela 8), essa variável tão somente identificava os GEs. Portanto, variáveis sócio-econômicas baseadas em renda, no Brasil, podem não servir como preditores em regressões, por serem redundantes em grupos que recebam adicional de insalubridade por lidarem com toxicantes.

Vale ressaltar que as variáveis que ficaram abaixo de zero, na Figura 18, são aquelas que tradicionalmente estão relacionadas às funções cognitivas prejudicadas quando da exposição a solventes, em geral, ou hexano, em específico. Essas funções cognitivas são tidas como preditores de neuropatias periféricas, mesmo em quadros subclínicos (Armstrong, 1995; Kang et al., 2005; Tsai et al., 1997). As medidas de "Latência de Balanço" no teste de Romberg, "Escores no MTS" (i.e., percentual de acerto) com atraso de 8" e 4", "No de pressões no TAP" na alternância da mão dominante e não dominante, "Escores no RLT" (i.e., número de repetições), na ordem 
direta e reversa, o "D-Prime no CPT" e "Mediana do ISI no SAT", foram as medidas mais prejudicadas nos trabalhadores expostos.

As medidas de Romberg e o $\mathrm{n}^{\mathrm{o}}$ de pressões no TAP são medidas motoras que envolvem vias extrapiramidais. Mais precisamente, o Romberg pode relacionar-se à integridade da propriocepção (modulada por fibras longas), ao passo que a alternância com a mão não dominante e dominante no TAP está mais propriamente relacionada a um componente motor envolvendo planejamento da ação, o que vincula-se à coordenação motora. Em seu estudo de caso, Armstrong (1995) observa prejuízo na coordenação motora identificada com o uso do pegboard, mas não há diferença na velocidade de pressões no Finger Oscillation Test (análogo ao TAP). O presente estudo confirma a não diferença na frequência de pressões no TAP, quando essas são realizadas com a mão dominante ou não dominante exclusivamente. Confirma, ainda, a alteração na coordenação motora, haja vista que a exigência de alternância entre os dois botões gerou maior diminuição entre os trabalhadores expostos, sobretudo com a mão não dominante. Alterações no TAP também foram observadas por Kang et al. (2005) em trabalhadores expostos ao tolueno, e avaliados com o BARS.

Os escores no MTS estão relacionados à medidas de memória e, com atrasos maiores, apresentaram maiores diferenças em relação aos trabalhadores não expostos. Esse achado é corroborado por Armstrong (1995), Kang et al. (2005) e Tsai et al. (1997) em outras atividades de memória como o pattern memory (exposição indiscriminada a solventes), evocação de figuras complexas (hexano) e Digit Span (tolueno). Pesquisas indicam que a memória visual (i.e., controle de estímulos mantido por formas) é mais prontamente afetada pelo hexano do que outros testes como os de memória verbal (i.e., controle de estímulos mantidos por palavras, letras ou números).

O D-Prime e a Mediana do ISI são medidas relativas à atenção. O D-Prime, especificamente, relacionado à percepção ao sinal e a mediana do ISI um indicador de proficiência no teste de atenção seletiva. Ambos os testes são parecidos no sentido em que o participante deve atentar às formas e julgar entre apertar ou não botões, em função de alguma instrução prévia, porém, são distintos no tipo de atividade a ser realizada. Tsai et al. (1997), utilizando o NES2, observaram que o CPT foi uma medida alterada em trabalhadores expostos à solventes. Seu resultado é interessante por apontar que essa medida foi diminuída, tanto em trabalhadores mais expostos, quanto trabalhadores da área administrativa, isto é, menos expostos aos solventes. Kang et al. (2005), por sua vez, observaram alterações no SAT em função da exposição ao tolueno, enquanto que 
Armstrong, (1995) não encontra diferenças em medidas de atenção, após exposição aguda ao hexano.

Escores do RLT são indicativos de alterações de aprendizagem. Embora diminuições nesses valores tenham ocorrido quando o GE foi comparado com trabalhadores não expostos, nenhuma alteração correspondente foi encontrada nos trabalhos investigados. A variável mortalidade de participantes para essa atividade merece destaque. No presente estudo somente 64 dos 81 participantes (79\%) completaram a tarefa (Tabela 7), de modo que a comparação estatística entre as amostras tornou-se ainda mais delicada. E, a dificuldade na realização da tarefa tem sido documentada em outros trabalhos. Rohlman et al. (2007) relataram perda de participantes na realização desse teste, tendo cerca de $68 \%$ da amostra completado o RLT, ao que conduziu a uma exclusão do teste.

No outro extremo da Figura 18, é observado melhor desempenho dos trabalhadores expostos ao hexano no escore do SRT, no número de toques do TAP para mão não dominante. Para além dessas, observa-se um maior escore dentre os trabalhadores expostos para as latências no SRT, SAT e RLT (reversão).

Quanto aos escores no SRT, como dito anteriormente, a inspeção visual (Figura 9) não mostra uma diferença qualitativa entre os grupos. E quanto ao TAP, as medidas sensíveis à exposição são mais relacionadas à coordenação motora do que propriamente o número de pressões isoladamente (Armstrong, 1995). O fato dos trabalhadores expostos serem mais rápidos ao pressionar em botões para as atividades de SAT e RLT, não os tornavam mais hábeis nas tarefas, haja vista que os escores para essas atividades foram inferiores quando comparados aos trabalhadores não expostos (Figura 18). Esses resultados sugerem que os trabalhadores expostos podem ter sido mais impulsivos em suas respostas que os não expostos, e medidas futuras de impulsividade poderiam somar-se às baterias utilizadas para investigação nessas populações.

Todavia, tanto o escore quanto latência no SRT dos trabalhadores expostos foram melhores quando comparados aos não expostos. Considerando que o SRT pode indicar a integridade das fibras nervosas nesses trabalhadores - o que não sugere neuropatia periférica. Estudos mostram que alterações em funções cognitivas antecedem manifestações clínicas da patologia (cf. Armstrong, 1995; Tsai et al., 1997). Assim, neste observa-se apenas uma sutil tendência, e investigações adicionais são necessárias para esclarecer se esses trabalhadores estão em risco. 


\section{ANÁLISE DE COMPONENTE PRINCIPAL}

A Análise de Componente Principal visou organizar as variáveis em subgrupos, tanto para a análise posterior que os consideravam novas variáveis, quanto para a identificação da forma como esses agrupavam-se. A partir das 27 variáveis apresentadas na Tabela 9, cinco componentes foram extraídos, e de modo geral, parece haver uma coerência em sua organização nestes componentes (ver Tabela 10). O Componente 1 apresenta medidas que relacionam-se mais ao comportamento motor como o TAP, PRT e latência no SRT. No entanto, o escore do MTS para o atraso de $8 \mathrm{~s}$ é que diverge das outras medidas relacionadas.

O segundo componente parece relacionar-se mais às medidas que envolvem atenção, uma vez que três diferentes medidas do SAT estão alocadas nesse componente. O RLT parece ser o caso anômalo nesta lista. O teste de Romberg apresentou um valor baixo $(0,25)$ e, embora a Análise de Componente principal sugira que este é o melhor componente para alocá-lo, considera-se que seu valor é fraco para este componente. O teste de Romberg é o único dentre os demais a teoricamente relacionar-se com medidas proprioceptivas e o fato desse não vincular-se a nenhum componente dentre os estabelecidos, é coerente com essa posição teórica.

O terceiro componente parece relacionar-se à acurácia de percepção em tarefas que exigem escolhas rápidas, mas escores como o RLT confundem esse tipo de proposição. O quarto componente parece relacionar-se à memória, uma vez que as latências de acertos do MTS encontram-se nesse fator. O último fator parece relacionarse à memória de trabalho, embora outras medidas também estejam ali alocadas.

O resultado da análise de componente principal é promissor ao agrupar os dados e favorecer uma compreensão global dos escores do BARS. Entretanto, os dados aqui apresentados divergem dos encontrados em Rohlman et al. (2014). Tais diferenças podem advir da heterogeneidade das medidas obtidas entre os participantes, que dificulta a organização dos dados em seus componentes. O estudo de Rohlman et al. (2014) conta com duas amostras claramente distintas quanto à exposição aos pesticidas e a população alvo com claros índices biológicos de exposição que os diferenciam do grupo controle. O presente estudo não contou com essa possibilidade de diferenciação entre os grupos, de modo que a estratificação entre os dois pode não ter sido suficientemente robusta (e de fato não o foi ao se considerar que as diferenças entre os grupos controle e exposto indicam tendências, com raros casos de significância estatística). Assim, enquanto no estudo de Rohlman et al. (2014) os 6 componentes 
explicam $76 \%$ da variância nos dados, no presente estudo os 5 componentes explicam 56\% da variância nas 27 variáveis testadas. Neste sentido, o emprego do BARS em população saudável e não exposta a toxicantes poderia prover dados para uma melhor compreensão do teste, e de como as respostas distribuem-se entre as categorias. Tal avaliação pode contribuir para uma melhor compreensão do teste.

\section{CONSIDERAÇÕES FinAIS}

O emprego da Análise de Componente Principal, no estudo de Rohlman et al. (2014) e no presente trabalho, visaram sistematizar análises de medidas neurocomportamentais, buscando uma diminuição nas variáveis analisadas. Um mesmo teste neurocomportamental pode prover: medidas de acertos e erros; suas latências; medidas gerais ou dispostas ao longo do tempo; medidas absolutas e relativas. Essa gama de dados, ao mesmo tempo que permite liberdade para pesquisa e análises, dificulta as escolhas do experimentador, haja vista que fatores como latência e frequência de tentativas para aprendizagem de uma nova sequência, mesmo em um mesmo teste, podem representar distintos aspectos.

O grande número de medidas neurocomportamentais pode dificultar a comparação de estudos que empregam um mesmo tipo de bateria comportamental. E o cenário torna-se ainda mais complexo quando comparam-se distintas baterias ou testes comportamentais. Assim, há necessidade de padronização de medidas para a investigação de efeitos de toxicantes sobre o comportamento, considerando as diferentes baterias empregadas cada qual com uma ampla gama de medidas que exigem sistematização adicional em busca de instrumentos transculturais. Pesquisas com solventes apresentam o desafio quanto ao isolamento do agente tóxico como o hexano, sobre medidas comportamentais. As rotinas dos trabalhadores expostos envolvem atividades relacionadas à risco de intoxicação (Kato et al., 1993), a saber: descarregamento do solvente dos caminhões, avaliação dos níveis do solvente em tanques (que, em geral, é feita por uma abertura no mesmo), manutenção dos equipamentos, eventuais vazamentos e etc.

A abordagem para diminuir o número de confundidores de saúde e de testagem, por meio da soma destes fatores em um único parâmetro, embora válida na busca de indicadores sintéticos, levanta questionamento quanto a este agrupamento não ter sido responsável por promover falta de diferença entre os grupos. Na prática, tomar café foi 
avaliado como sendo o mesmo que tomar medicação psicotrópica, ou possuir perturbação psiquiátrica. Essa justaposição entre fatores distintos pode ter contribuído para reduzir diferenças entre os grupos expostos e controle.

Ainda no sentido de reconhecer limitações deste estudo, sobretudo no que tange à seleção da amostra, há de se considerar que a presente investigação foi realizada em um indústrias relacionadas ao agronegócio, e provavelmente uma parte dos trabalhadores admitidos nessas, advieram do trabalho agrícola ou residiam em áreas rurais próximas às áreas de cultivo de soja. Desta forma, estes trabalhadores pode sido expostos a estes produtos, ou sofrer do efeito desta exposição. O fácil acesso aos defensivos agrícolas nestas regiões também levanta questionamento quanto ao uso de inseticidas neurotóxicos em domicílio, ou sua exposição para controle de vetores como mosquito da dengue. Esses podem ser fator de confusão, reduzindo diferenças entre grupos expostos e controle (se o grupo controle for composto de muitas pessoas com exposição prévia a estas condições supracitadas).

Por fim, há de se considerar que somente duas de oito indústrias procuradas permitiram a coleta de dados com seus funcionários. Presumindo que essas possuem maiores cuidados higiênico-sanitárias com o ambiente de trabalho, esse pode ter sido outro fator a diminuir o presumido efeito observado do hexano sobre as medidas neurocomportamentais. $\mathrm{O}$ aumento do número de participantes com o aumento de trabalhadores de outras indústrias favoreceria o esclarecimento dessa questão. A adequação de melhor tecnologia de análise ao teste de Romberg também favoreceria investigações futuras.

\section{CONCLUSÕES}

O estudo contribui por elucidar que - para pesquisas de campo - uma abordagem estatística que ajuste confundidores à análise de diferenças entre os grupos (e.g., técnicas de regressão) é mais adequada quando comparada a uma abordagem de exclusiva comparação entre escores de grupos, mesmo quando os valores dos confundidores são equilibrados entre si. E, vale ressaltar que as variáveis relacionadas à renda para estabelecer diferenças socioeconômicas podem não cumprir essa função e gerar uma variável redundante na análise uma vez que, no Brasil, trabalhadores que lidam com toxicantes podem receber adicional de insalubridade.

A busca de um teste transcultural e um protocolo de análise ainda permanecem em discussão. Embora resultados sejam promissores no sentido de apresentar o BARS 
como uma alternativa viável em contextos como o de trabalhadores agrícolas expostos a pesticidas, a investigação desta tecnologia com solventes ainda carece de mais investimento.

No contexto nacional este trabalho é o primeiro estudo realizado para avaliar efeito do hexano em trabalhadores da indústria de extração de óleo vegetal e, no contexto internacional, é o primeiro a fazê-lo utilizando o BARS, tecnologia validada transculturalmente para identificar efeitos de intoxicação precoce em trabalhadores vulneráveis. A falta de efeito estatisticamente significativo não ofusca o pequeno efeito sobre aquelas variáveis tradicionalmente prejudicadas em trabalhadores expostos aos solventes orgânicos. Assim, sugere-se que investigações futuras incluam dados após o fim da jornada de trabalho ou rotinas específicas de trabalho que, sabidamente, geram exposição adicional ao solvente (e.g., limpeza do maquinário). Estudos adicionais e os dados obtidos deste estudo, contribuirão para análises e intervenções voltadas para o impacto do solvente sobre o comportamento humano. 


\section{REFERÊNCIAS}

Abbritti, G., Siracusa, A., Cianchetti, C., Coli, C. A., Curradi, F., Perticoni, G. F., \& De Rosa, F. (1976). Shoe-makers' polyneuropathy in Italy: The aetiological problem. British Journal of Industrial Medicine, 33(2), 92-99.

Agrawal, Y., Carey, J. P., Hoffman, H. J., Sklare, D. A., \& Schubert, M. C. (2011). The modified Romberg balance test: Normative data in U.S. adults. Otology \& Neurotology, 32(8), 1309-1311.

Allen, N., Mendell, J. R., Billmaier, D. J., Fontaine, R. E., \& O’Neill, J. (1975). Toxic polyneuropathy due to methyl n-butyl ketone. Archives of Neurology, 32(4), 209218.

Anger, W. K. (1992). Assessment of neurotoxicity in humans. In H. Tilson \& C. Mitchell (Eds.), Neurotoxicology (pp. 363-386). New York: Raven Press.

Anger, W. K. (2003). Neurobehavioural tests and systems to assess neurotoxic exposures in the workplace and community. Occupational and Environmental Medicine, 60(7), 531-538.

Anger, W. K., Rohlman, D. S., Sizemore, O. J., Kovera, C. A., Gibertini, M., \& Ger, J. (1996). Human behavioral assessment in neurotoxicology: Producing appropriate test performance with written and shaping instructions. Neurotoxicology and Teratology, 18(4), 371-379.

Armstrong, C. (1995). Longitudinal neuropsychological effects of n-Hexane exposure: Neurotoxic effects versus depression. Archives of Clinical Neuropsychology, 10(1), $1-19$.

Blake, B. L. (2004). Toxicology of nervous system. In E. Hodgson (Ed.), A Textbook of Modern Toxicology (3rd ed., pp. 279-297). Hoboken: John Wiley \& Sons, Ltd.

Boekelheide, K. (1987). 2,5-Hexanedione alters microtubule assembly. I. Testitular atrophy, not nervous system toxicity, correlates with enhanced tubulin polymerization. Toxicology and Applied Pharmacology, 88(3), 370-382.

Brasil. NR 7 - Programa de Controle Médico de Saúde Ocupacional (2013). Presidência da República do Brasil: Ministério do Trabalho e Emprego.

Brasil. NR 15 - Atividades e operações insalubres (2014a). Presidência da República do Brasil: Ministério do Trabalho e Emprego.

Brasil. NR 9 - Programa de prevenção de riscos ambientais (2014b). Presidência da República do Brasil: Ministerio do Trabalho e Emprego.

Bus, J. S., Deyo, D., \& Cox, M. (1982). Dose-dependent disposition of n-hexane in F344 rats after inhalation exposure. Fundamental and Applied Toxicology, 2(5), 226-229. 
Cardona, A., Marhuenda, D., Prieto, M. J., Marti, J., Periago, J. F., \& Sánchez, J. M. (1996). Behaviour of urinary 2,5-hexanedione in occupational co-exposure to nhexane and acetone. International Archives of Occupational and Environmental Health, 68(2), 88-93.

Córdova, C. O. A., Bravin, A. A., Oliveira, R. J., \& Barros, J. F. (2003). Reaction time in socio-cultural adult retardates and its relationship with differences in motor development. Neurobiologia, 66, 53-60.

Cory-Slechta, D. A. (1989). Behavioral measures of neurotoxicity. Neurotoxicology, 10(2), 271-295.

DeCaprio, A. P. (2000). n-Hexane, metabolites, and derivatives. In P. S. Spencer, H. H. Schaumburg, \& A. C. Ludolph (Eds.), Experimental and Clinical Neurotoxicology (2nd ed., pp. 633-648). New York: Oxford University Press.

Dekant, W., \& Anders, M. W. (2008). Toxicology of solvents. In H. Greim \& R. Snyder (Eds.), Toxicology and Risk Assessment: A Comprehensive Introduction (pp. 604620). West Sussex: John Wiley \& Sons, Ltd.

Eckerman, D. A., Anger, W. K., Gimenes, L. S., \& Angerami, J. G. T. M. (2004). Avaliação neurocomportamental dos efeitos de agentes toxicos. In M. Z. S. Brandão, F. C. S. Conte, F. S. Brandão, Y. K. Ingberman, C. B. Moura, V. M. Silva, \& S. M. Oliane (Eds.), Sobre Comportamento e Cognição (Vol. 14). Estendendo a Psicologia Comportamental e Cognitiva aos Contextos da Saúde, das Organizações, das Relações Pais e Filhos e das Escolas. (pp. 190-200). Santo André: ESETec.

Eckerman, D. A., Coelho, C., Gimenes, L. S., Huber, E. R., Rohlman, D. S., \& Anger, W. K. (2009). Behavioral observation used to estimate pesticide exposure for farm workers in Brazil. Psychology \& Neuroscience, 2(1), 43-50.

Eckert, G. P., \& Müller, W. E. (2008). The nervous system. In H. Greim \& R. Snyder (Eds.), Toxicology and Risk Assessment: A Comprehensive Introduction (pp. 244264). West Sussex: John Wiley \& Sons, Ltd.

Elsner, J., Fellmann, C., \& Zbinden, G. (1988). Response force titration for the assessment of the neuromuscular toxicity of 2,5-Hexanedione in rats. Neurotoxicology and Teratology, 10(1), 3-13.

EPA - Environmental Protection Agency. (2005). Toxicological Review of n-Hexane. Washington: EPA.

Gimenes, L. S., Eckerman, D. A., \& Vasconcelos, L. A. (2010). Toxicologia comportamental e comportamento de segurança: Contribuições da análise do comportamento. In E. Z. Tourinho \& S. V. Luna (Eds.), Análise do Comportamento. Investigações Historicas, Conceituais e Aplicadas. (1st ed., pp. 219-238). São Paulo: Roca. 
Herpin, G., Gargouri, I., Gauchard, G. C., Nisse, C., Khadhraoui, M., Elleuch, B., Perrin, P. P. (2009). Effect of chronic and subchronic organic solvents exposure on balance control of workers in plant manufacturing adhesive materials. Neurotoxicity Research, 15(2), 179-186.

Ikeda, T., Katakura, Y., Kishi, R., \& Miyake, H. (1993). Acute neurobehavioral effects of co-inhalation of toluene and n-hexane on schedule-controlled behavior in rats. Environmental Research, 63(1), 70-81.

Inserra, S. G., Phifer, B. L., Anger, W. K., Lewin, M., Hilsdon, R., \& White, M. C. (2004). Neurobehavioral evaluation for a community with chronic exposure to hydrogen sulfide gas. Environmental Research, 95(1), 53-61.

Iwata, T., Mori, H., Dakeishi, M., Onozaki, I., \& Murata, K. (2005). Effects of mixed organic solvents on neuromotor functions among workers in buddhist altar manufacturing factories. Journal of Occupational Health, 47(1), 143-148.

Jalali, M. M., Gerami, H., Heidarzadeh, A., \& Soleimani, R. (2014). Balance performance in older adults and its relationship with falling. Aging Clinical and Experimental Research, Oct.

Johnston, J. M., \& Pennypacker, H. S. (1993). Strategies and Tactics of Behavioral Research (2nd ed., p. 393). Hillsdale: Lawrence Erlbaum Associates Inc.

Kang, S. K., Rohlman, D. S., Lee, M. Y., Lee, H. S., Chung, S. Y., \& Anger, W. K. (2005). Neurobehavioral performance in workers exposed to toluene. Environmental Toxicology and Pharmacology, 19(3), 645-650.

Kato, M., Rocha, M. L. R., Carvalho, A. B., Chaves, M. E. C., Raña, M. C. M., \& Oliveira, F. C. (1993). Occupational exposure to neurotoxicants: Preliminary survey in five industries of the Camaçari petrochemical complex, Brazil. Environmental Research, 61(1), 133-139.

Krasavage, W. J., O’Donoghue, J. L., DiVincenzo, G. D., \& Terhaar, C. J. (1980). The relative neurotoxicity of methyl-n-butyl ketone, n-hexane and their metabolites. Toxicology and Applied Pharmacology, 52(3), 433-441.

Kulig, B. M., Vanwersch, R. A. P., \& Wolthuis, O. L. (1985). The automated analysis of coordinated hindlimb movement in rats during acute and prolonged exposure to toxic agents. Toxicology and Applied Pharmacology, 80(1), 1-10.

Laffort, P., \& Dravnieks, A. (1973). An approach to a physico-chemical model of olfactory stimulation in vertebrates by single compoundst. Journal of Theoretical Biology, 2, 335-345.

Lam, H. R., Larsen, J. J., Ladefoged, O., Moller, A., Strange, P., \& Arlien-Soborg, A. (1991). Effects of 2,5-hexanedione alone and in combination with acetone on radial arm maze behavior, the "brain-swelling " reaction and synaptosomal functions. Neurotoxicology and Teratology, 13(4), 407-412. 
Leite, E. M. A. (2008). Soventes orgânicos. In S. Oga, M. M. A. Camargo, \& J. A. O. Batistuzzo (Eds.), Fundamentos de Toxicologia (3rd ed., pp. 275-324). São Paulo: Atheneu Editora.

Little, T. D. (2013). Handbook of Quantitative Methods in Psychology. Vol. 2. Statistical Analysis. (T. D. Little, Ed.). New York: Oxford University Press.

Mateus, M. L., Santos, A. P. M., \& Batoréu, M. C. C. (2002). Evidence of zinc protection against 2,5-hexanedione neurotoxicity: Correlation of neurobehavioral testing with biomarkers of excretion. Neurotoxicology, 23(6), 747-754.

Maurissen, J. P. J. (1995). Neurobehavioral methods for the evaluation of sensory functions. In L. W. Chang \& W. Slikker Jr. (Eds.), Neurotoxicology: Approach and Methods (pp. 239-264). San Diego: Academic Press.

Mutti, A., Ferri, F., Lommi, G., Lotta, S., Lucertini, S., \& Franchini, I. (1982). nHexane-induced changes in nerve conduction velocities and somatosensory evoked potentials. International Archives of Occupational and Environmental Health, 51(1), 45-54.

NIOSH - National Institute of Occupational Safety and Health. (1983). Health Hazard Evaluation Report (HETA 80-256-1386) (p. 13). Cincinnati, Ohio.

NIOSH - National Institute of Occupational Safety and Health. (2013). TLVs and BEIs. Cincinnati, Ohio: ACGIH.

Petrobras. (2011). Ficha de Informação de Segurança de Produto Químico (FISPQ BR 608 - Hexano) (p. 9). Rio de Janeiro, Rio de Janeiro.

Politis, M. J., Pellegrino, R. G., \& Spencer, P. S. (1980). Ultrastructural studies of the dying-back process. V. Axonal neurofilaments accumulate at sites of 2,5hexanedione application: Evidence for nerve fibre dysfunction in experimental hexacarbon neuropathy. Journal of Neurocytology, 9(4), 505-516.

Proschan, M., Glimm, E., \& Posch, M. (2014). Connections between permutation and ttests: relevance to adaptive methods. Statistics in Medicine, (Aug.).

Rohlman, D. S., Gimenes, L. S., Ebbert, C., Anger, W. K., Bailey, S. R., \& McCauley, L. (2000). Smiling faces and other rewards: Using the Behavioral Assessment and Research System (BARS) with unique populations. Neurotoxicology, 21(6), 973978.

Rohlman, D. S., Gimenes, L. S., Eckerman, D. A., Kang, S. K., Farahat, F. M., \& Anger, W. K. (2003). Development of the Behavioral Assessment and Research System (BARS) to detect and characterize neurotoxicity in humans. Neurotoxicology, 24(4-5), 523-531.

Rohlman, D. S., Ismail, A. A., Abdel-Rasoul, G., Lasarev, M., Hendy, O., \& Olson, J. R. (2014). Characterizing exposures and neurobehavioral performance in Egyptian adolescent pesticide applicators. Metabolic Brain Disease, 29(3), 845-855. 
Rohlman, D. S., Lasarev, M., Anger, W. K., Scherer, J., Stupfel, J., \& McCauley, L. (2007). Neurobehavioral performance of adult and adolescent agricultural workers. Neurotoxicology, 28(2), 374-380.

Rohlman, D. S., Sizemore, O. J., Anger, W. K., \& Kovera, C. A. (1996). Computerized neurobehavioral testing: Techniques for improving test instructions. Neurotoxicology and Teratology, 18(4), 407-412.

Sanagi, S., Seki, Y., Sugimoto, K., \& Hirata, M. (1980). Peripheral nervous system functions of workers exposed to n-hexane at a low level. International Archives of Occupational and Environmental Health, 47(1), 69-79.

Seeber, A. (2008). Behavioral neurotoxicology. In H. Greim \& R. Snyder (Eds.), Toxicology and Risk Assessment: A Comprehensive Introduction (pp. 265-279). West Sussex: John Wiley \& Sons, Ltd.

Shell, L., Rozum, M., Jortner, B. S., \& Ehrich, M. (1992). Neurotoxicity of acrylamide and 2,5-Hexanedione in rats evaluated using a functional observational battery and pathological examination. Neurotoxicology and Teratology, 14(4), 273-283.

Tanger, H. J., Vanwersch, R. A. P., \& Wolthuis, O. L. (1984). Automated quantitative analysis of coordinated locomotor behaviour in rats. Journal of Neuroscience Methods, 10(3), 237-245.

Tsai, S. Y., Chen, J. D., Chao, W. Y., \& Wang, J. D. (1997). Neurobehavioral effects of occupational exposure to low-level organic solvents among Taiwanese workers in paint factories. Environmental Research, 73(1-2), 146-155.

Weiss, B. (1983). Behavioral toxicology and environmental health science. Opportunity and challenge for psychology. The American Psychologist, 38(11), 1174-1187.

WHO - World Health Organization. (1991). Environmental Health Criteria 122: nHexane. Vammala: WHO. 
APÊNDICE 01

- Termo de ConSENTIMENTo LIVRe E ESClARECIDO - 


\section{TERMO DE CONSENTIMENTO LIVRE E ESCLARECIDO}

Você está sendo convidado(a) para participar, como voluntário(a), de uma pesquisa. Meu nome é André Bravin. Sou psicólogo, professor e pesquisador responsável por este estudo. Após receber os esclarecimentos e as informações a seguir, caso aceite participar da pesquisa, assine este documento ao final. São duas vias, uma delas é sua e a outra é do pesquisador responsável.

Caso se recuse em participar, você não será penalizado(a) de forma alguma. Se tiver dúvidas sobre a pesquisa, você poderá entrar em contato com o pesquisador responsável (André Bravin), a qualquer momento, pelo telefone (64) 3606-8127 (se necessário, você poderá realizar ligações a cobrar). Em caso de dúvidas sobre os seus direitos como participante neste estudo, você poderá entrar em contato com o Comitê de Ética em Pesquisa da Universidade Federal de Goiás, nos telefone (62) 3521-1075 ou (62) 3521-1076.

\section{INFORMAÇÕES IMPORTANTES SOBRE A PESQUISA}

Título: Avaliação Neurocomportamental do N-Hexano em Trabalhadores de Indústria de Extração de Óleo Vegetal.

Justificativa: $\mathrm{O}$ N-Hexano é um solvente amplamente utilizado na indústria de alimentos. $\mathrm{O}$ agente é volátil e potencialmente tóxico, caso as devidas medidas de proteção não sejam tomadas. Pouco se sabe sobre sua influência sobre processos psicológicos básicos como atenção, memória, etc., em humanos.

Objetivos: A presente pesquisa visa comparar o comportamento (avaliado por uma bateria neurocomportamental) e medidas biológicas (sangue e urina) de trabalhadores que lidam diretamente com o N-Hexano, com o de trabalhadores que não lidam com esta substância.

Procedimentos Utilizados: Em resumo, o participante é colocado em frente a um computador o qual fornece instruções via fone de ouvidos. O computador apresenta algumas tarefas que o participante deve executar por meio da pressão de alguns botões do teclado. O próprio computador registra as respostas, e estes dados serão utilizados para análise posterior. Antes do teste computadorizado, uma amostra de urina e sangue é coletada. Os pesquisadores se comprometem a utilizar estes materiais (resultados do teste computadorizado e a amostra de urina e sangue) exclusivamente para as finalidades deste projeto de pesquisa. 
Sobre desconforto, riscos e benefícios derivados da participação na pesquisa: 0 máximo de desconforto previsto para a participação nesta pesquisa é o do seu deslocamento para o local de aplicação do teste computadorizado, e coleta de material biológico (urina e sangue). Esta pesquisa pretende tão somente observar e registrar seus comportamentos no teste e, neste sentido, não gera qualquer tipo de risco ou benefício associado à participação na mesma. $\mathrm{A}$ bateria computadorizada não é um exame clínico, de modo que nenhum tipo de diagnóstico pode ser dela estabelecida. A amostra de urina e sangue será utilizada para um rastreamento toxicológico e a avaliação da possível existência residual de n-hexano no organismo. Contudo, salienta-se que nenhuma destas avaliações pretende estabelecer diagnósticos.

Ressarcimento de despesas derivados da participação na pesquisa: Não haverá nenhum tipo de pagamento ou gratificação financeira pela sua participação neste estudo. Todos os gastos estão sendo custeados pelos pesquisadores e a indústria (deslocamento, etc.), não havendo portanto razão para ressarcimento.

Sigilo das Informações, Privacidade e Confidencialidade: Seus dados de identificação, medidas comportamentais registradas pela bateria, análise da urina e sangue, e qualquer outro dado que venha a derivar desta pesquisa ficarão armazenados em papel e em mídia digital em um arquivo acessível somente à equipe envolvida nesse projeto. Isto é, os dados serão acessíveis somente aos pesquisadores envolvidos e não será permitido o acesso de terceiros (por exemplo, a empresa onde você trabalha). A divulgação dos resultados desta pesquisa será feitas em ambiente acadêmicos (de forma oral, impressa ou digital), sempre mantendo ocultas as informações que possam levar à identificação dos participantes da pesquisa, ou seu respectivo local de trabalho. Os dados produzidos serão utilizados neste estudo, e poderão compor banco de dados para a realização de pesquisas futuras.

Participação Voluntária: Todos os participantes desta pesquisa são voluntários e esta participação não trará ganhos financeiros para nenhuma das partes. Você é livre para recusar ou retirar sua concordância (em qualquer fase da pesquisa), sem nenhum tipo de prejuízo, penalização ou represália (CNS no 196/96 - IV. 3b).

Instituição e Pesquisador Responsável: Este projeto de pesquisa é vinculado ao Laboratório de Processos Psicológicos Básicos pertencente ao Curso de Psicologia da Universidade Federal de Goiás (UFG-Jataí) e foi aprovado pelo Comitê de Ética em Pesquisa (CEP/UFG) da referida 
instituição na 2a Sessão Ordinária, realizada em 15/04/2013, de acordo com os requisitos da Resolução do Conselho Nacional de Saúde número 196/96 (CNS - 196/96).

Equipe Envolvida: Esta pesquisa é realizada sob a responsabilidade do Prof. Me. André Amaral Bravin (docente da UFG-Jataí - SIAPE: 1624831 - e psicólogo regularmente inscrito no Conselho Regional de Psicologia - CRP: 09/6543), e do Prof. Dr. Cléber Douglas Lucínio Ramos (docente da UFG-Jataí - SIAPE: 1698708 - e biomédico). Ademais, fazem parte da equipe outros docentes/pesquisadores, e graduandos do curso de Psicologia e Biomedicina da UFGJataí, regularmente matriculados na instituição, sob orientação e supervisão dos professores supracitados. A equipe envolvida aceita todos os termos contidos nesse documento. 


\section{CONSENTIMENTO DA PARTICIPAÇÃO DA PESSOA COMO SUJEITO DA PESQUISA}

$\mathrm{Eu}$,

, (Nome/CPF/RG/n.o de cadastro da pesquisa), abaixo assinado, concordo em participar do estudo "Avaliação Neurocomportamental do N-Hexano em Trabalhadores de Indústria de Extração de Óleo Vegetal", como sujeito. Fui devidamente informado e esclarecido pelo pesquisador André Amaral Bravin sobre a pesquisa, os procedimentos nela envolvidos, assim como os possíveis riscos e benefícios decorrentes de minha participação. Foi-me garantido que posso retirar meu consentimento a qualquer momento, sem que isto leve à qualquer penalidade.

de de 2013.

Presenciamos a solicitação de consentimento, esclarecimentos sobre a pesquisa e aceite do sujeito em participar.

Nome: Assinatura:

Nome: Assinatura:

Testemunhas (não ligadas à equipe de pesquisadores). 
APÊNDICE 02

- ANAMNESE - 


\begin{tabular}{|l|l|}
\hline Cadastro do Participante: & $\square$ G0* $\square$ G1* \\
& $\square$ G2* $\square$ G3* \\
& $\square$ G4* \\
\end{tabular}

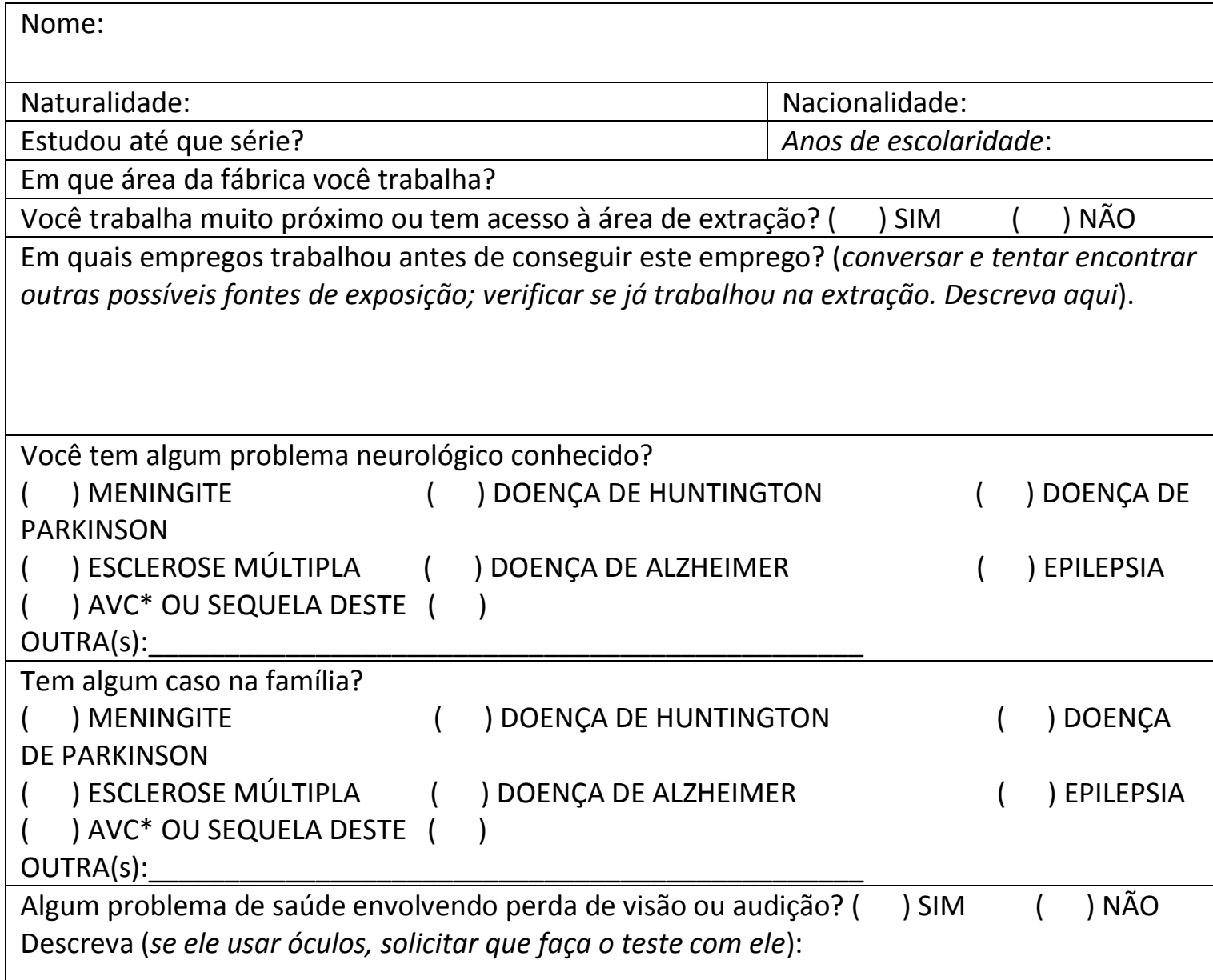

Telefone Celular:

Telefone Fixo:

Alguma outra forma de contato?

Percepções da entrevista (confiabilidade das respostas; impressões sobre eventuais problemas auditivos e visuais; precisão das respostas da anamnese): 
* G0: Grupo Envase - Controle;

G1: Grupo Degomagem - Baixa Exposição;

G2: Grupo Preparação - Média Exposição;

G3: Grupo Extração - Alta Exposição;

G4: Grupo Encarregados - Exposição Indiscriminada;

AVC: Acidente Vascular Cerebral (ler "derrame" durante a entrevista).

Serão excluídos da amostra:

1- Estrangeiros que não compreendem o português e cujo BARS não dispõe de tradução para a língua nativa do participante em questão.

2- Participante com menos de 8 anos de educação formal. Ou seja, para compor a amostra deverá ter concluído a 8 a série do primeiro grau.

3- Participante com problema neurológico conhecido.

4- Participante com severo déficit visual ou auditivo.

5- Para participantes do Grupo Envase - Controle (G0), excluir àqueles que possuem acesso à área da extração, ou que eventualmente já trabalharam lá. 
APÊNDICE 03

- QUESTIONÁRIO TOXICOLÓGICO - 


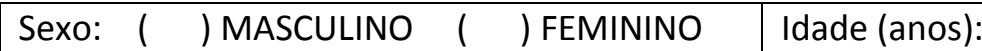

Quantas pessoas moram na mesma casa que você? $\quad$ Renda total familiar média:

\begin{tabular}{|l|l|}
\hline Há quanto tempo trabalha na empresa? & Com $R H$ - Confirmação pela empresa: \\
\hline Há quanto tempo trabalha no seu setor? & Com $R H$ - Confirmação pela empresa: \\
\hline
\end{tabular}

\begin{tabular}{|c|c|c|}
\hline \multicolumn{3}{|l|}{$\begin{array}{l}\text { Você utiliza algum medicamento? } \\
\text { Qual? Quantas vezes por dia? }\end{array}$} \\
\hline \multicolumn{2}{|l|}{$\begin{array}{l}\text { Você bebe café? } \\
\text { ) NÃO } \\
\text { Quantas xícaras por dia? }\end{array}$} & $\begin{array}{l}\text { Tomou café antes de vir para } \\
\text { cá? } \\
\begin{array}{ll}(\quad) \text { SIM* }^{*}(\text { ) NÃO }\end{array}\end{array}$ \\
\hline \multicolumn{2}{|l|}{$\begin{array}{l}\text { Você fuma? } \\
\text { I NÃO } \\
\text { Quantos cigarros por dia? }\end{array}$} & $\begin{array}{l}\text { Fumou antes de vir para cá? } \\
\left(\begin{array}{lll}( & \text { SIM* } & (\quad) \text { NÃO }\end{array}\right.\end{array}$ \\
\hline \multicolumn{2}{|l|}{$\begin{array}{l}\text { Você consome álcool (cerveja, etc)? } \\
\text { ) NÃO } \\
\text { O que bebe? Quantas vezes por dia? }\end{array}$} & $\begin{array}{l}\text { Bebeu antes de vir para cá? } \\
\begin{array}{lll}(\quad) \text { SIM }^{*} \quad(\quad) \text { NÃO }\end{array}\end{array}$ \\
\hline \multicolumn{2}{|c|}{$\begin{array}{l}\text { Você consome alguma outra substância (maconha, solvente, } \\
\text { cocaína, merla, crack, etc.)? } \\
\text { ) NÃO } \\
\text { Qual? Quantas vezes por dia? }\end{array}$} & $\begin{array}{l}\text { Você usou_antes de vir para } \\
\text { cá? } \\
\begin{array}{l}(\quad) \text { SIM }^{*} \quad(\quad \text { ) NÃO }\end{array}\end{array}$ \\
\hline \multicolumn{2}{|l|}{ Peso: } & Altura: \\
\hline $\begin{array}{l}\text { Dados do } \\
\text { Medicina }\end{array}$ & \multicolumn{2}{|c|}{$\begin{array}{l}\text { Dados do Serviço Especializado em Engenharia de Segurança e em } \\
\text { Medicina do Trabalho (SESMT): }\end{array}$} \\
\hline
\end{tabular}


* Caso tenha feito uso de alguma substância psicoativa, 24 horas anterior à avaliação ver como proceder abaixo.

Café, Tabaco ou medicamento de uso contínuo: Ok; realizar teste.

Álcool e outras drogas: reagendar aplicação. Explicar a importância de não estar sob efeito de substância. 
APÊNDICE 04

- Default Parameter Values - 


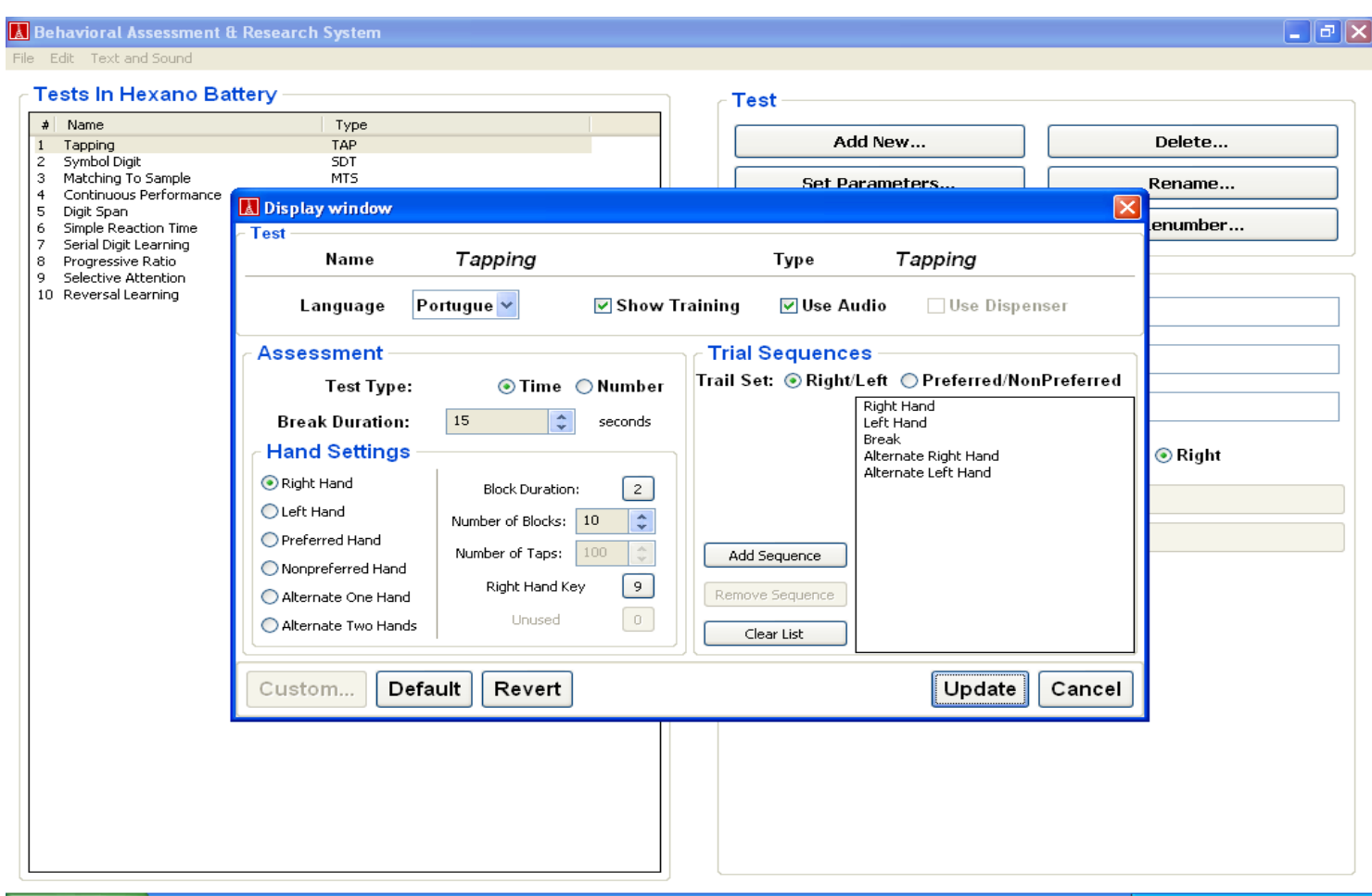

\section{CONFIGURAÇÕES DO TAPPING TEST (TAP)}

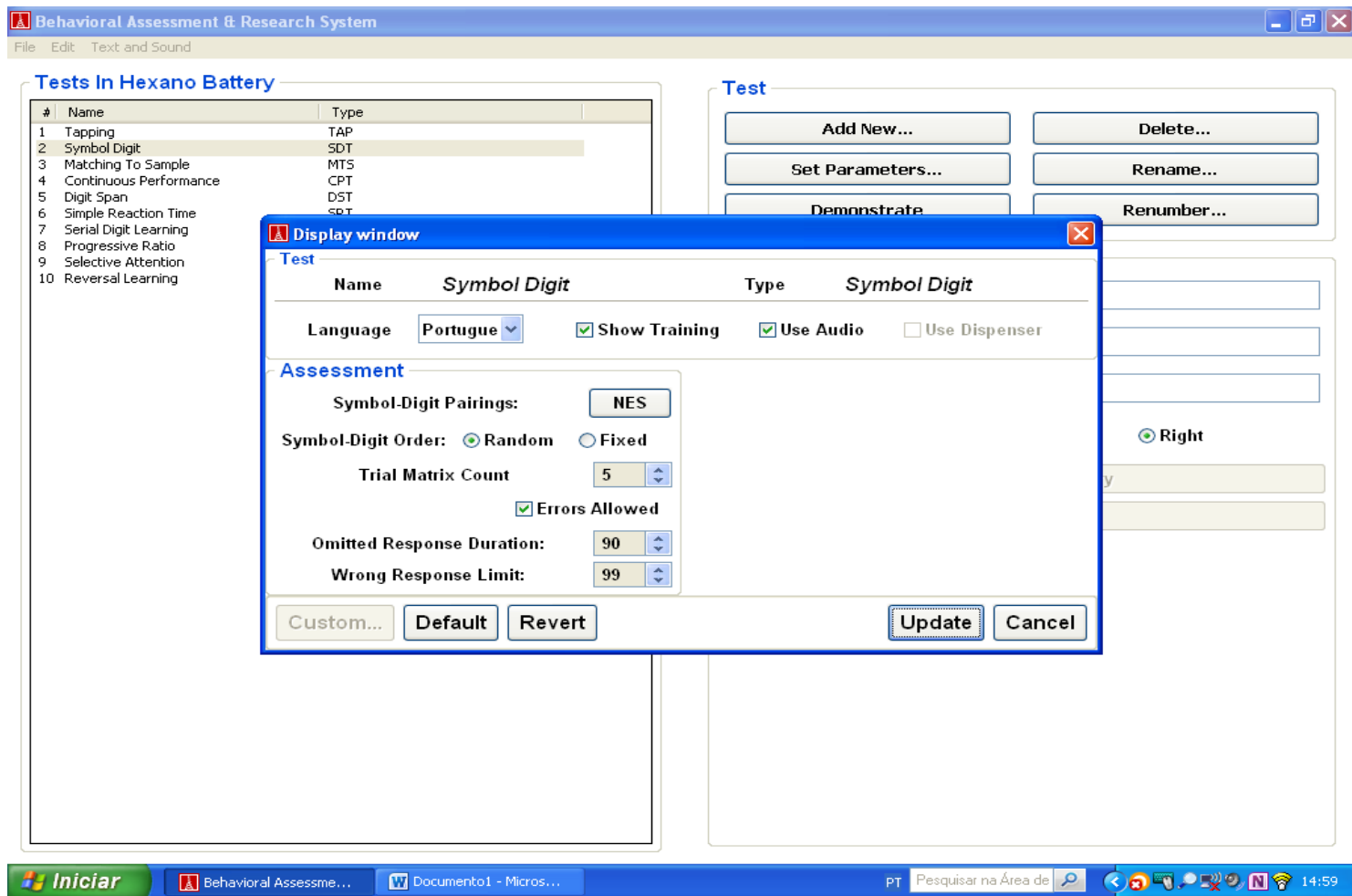

CONFIGURAÇõES DO SYMBOL Digit TEST (SDT) 


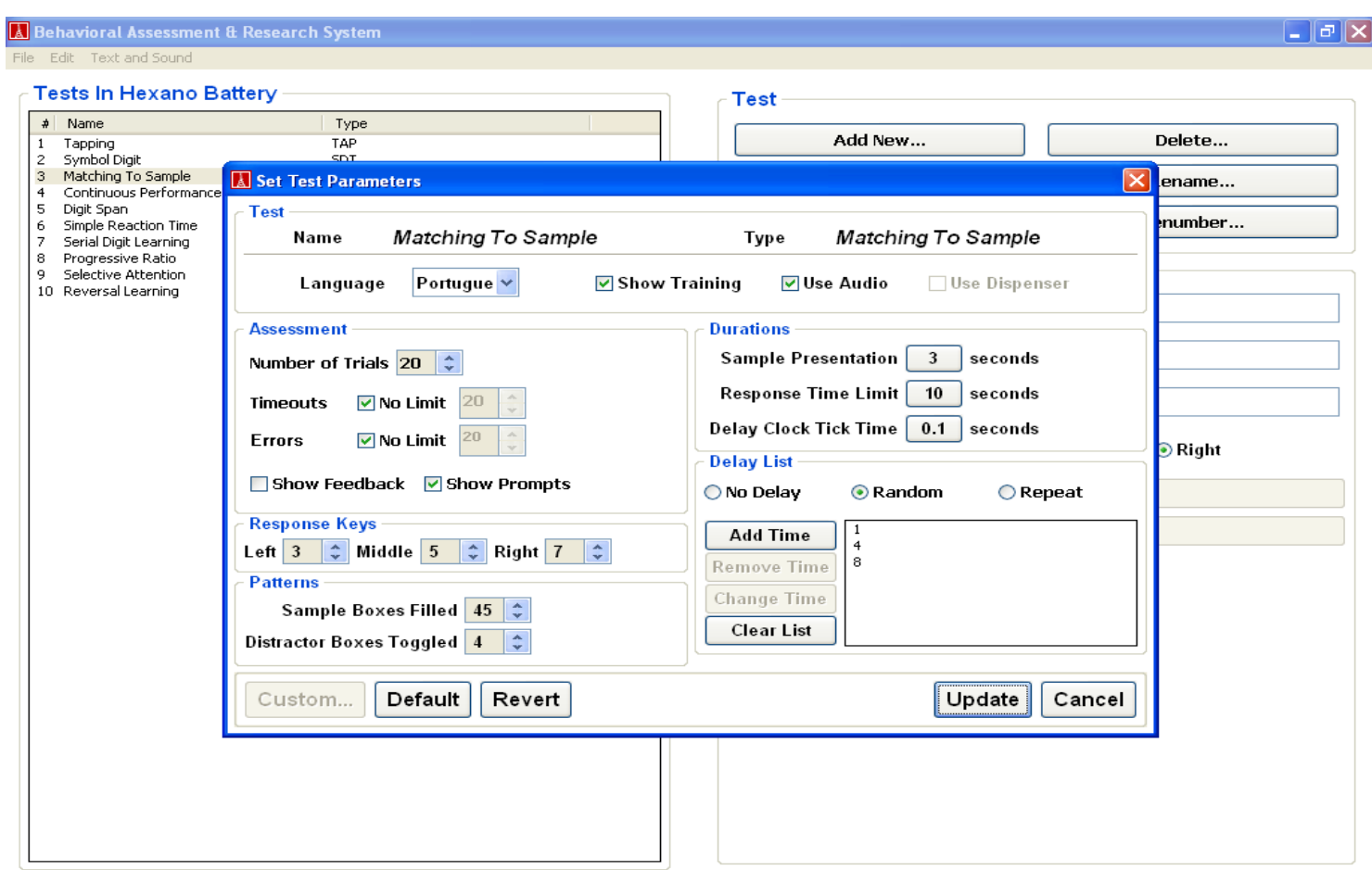

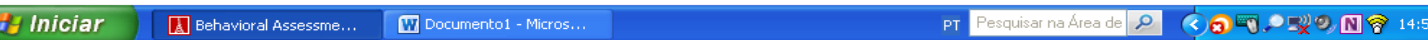

CONFIGURAÇÕES DO MATChING TO SAMPLE TEST (MTS)

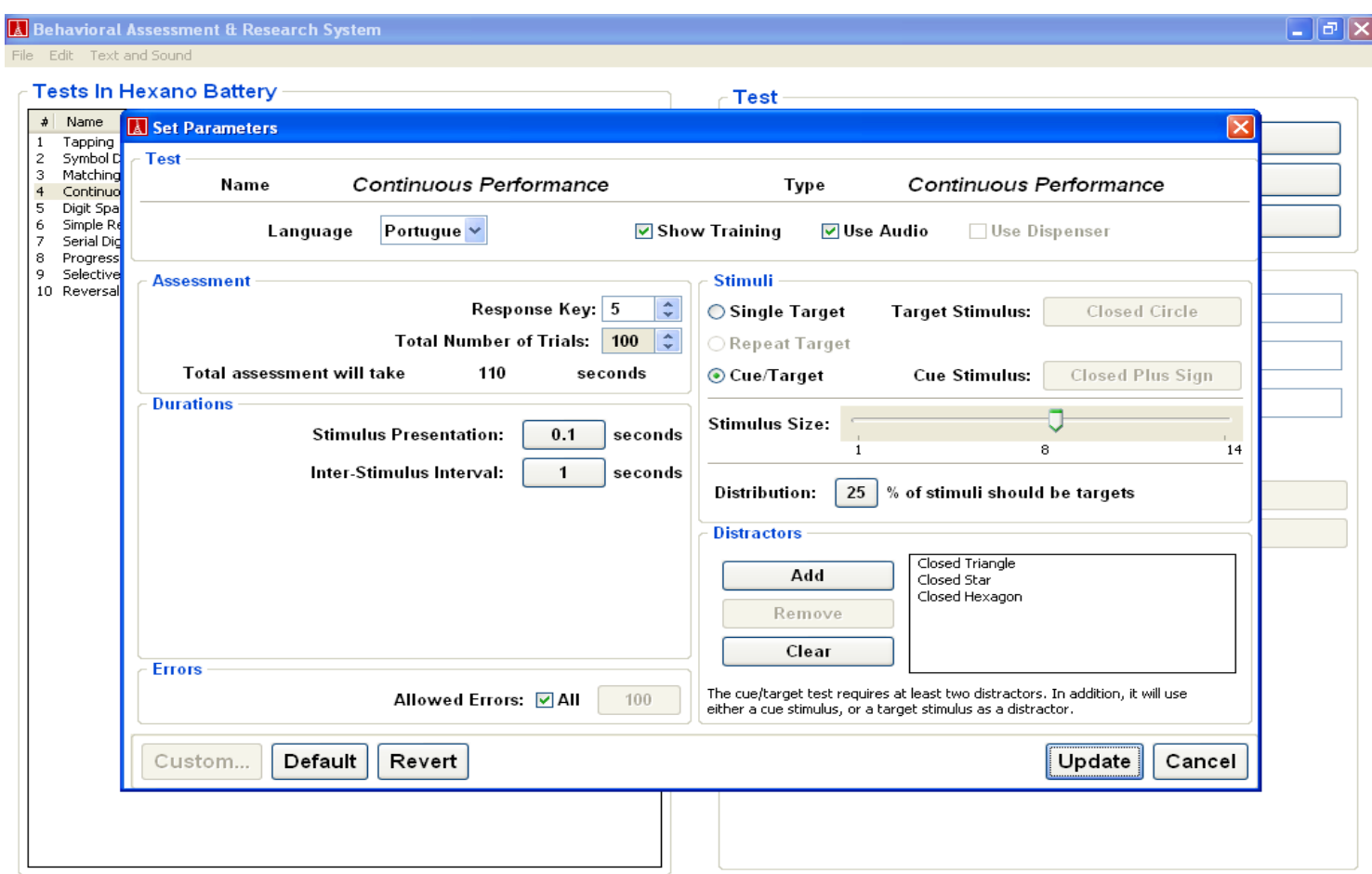

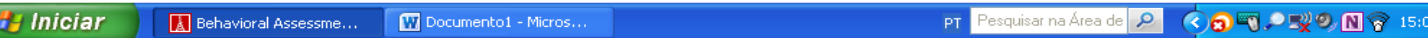

CONFIGURAÇÕES Do CONTINuOUS PERFormance TeSt (CPT) 


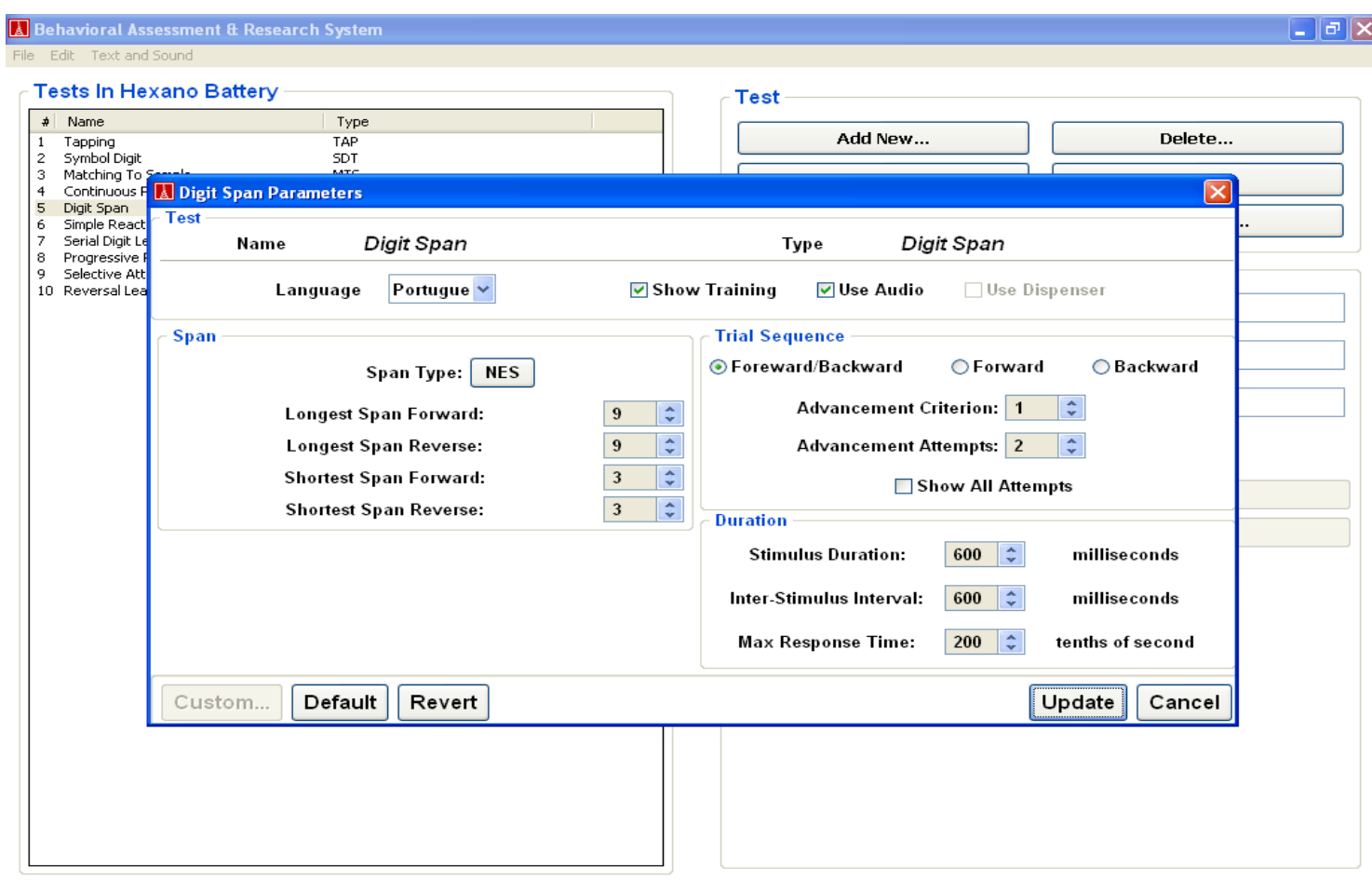

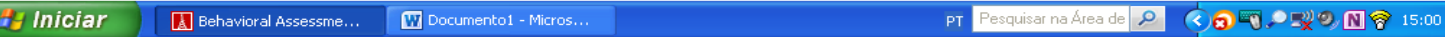

\section{CONFIGURAÇÕES Do Digit SPAN TeSt (DST)}

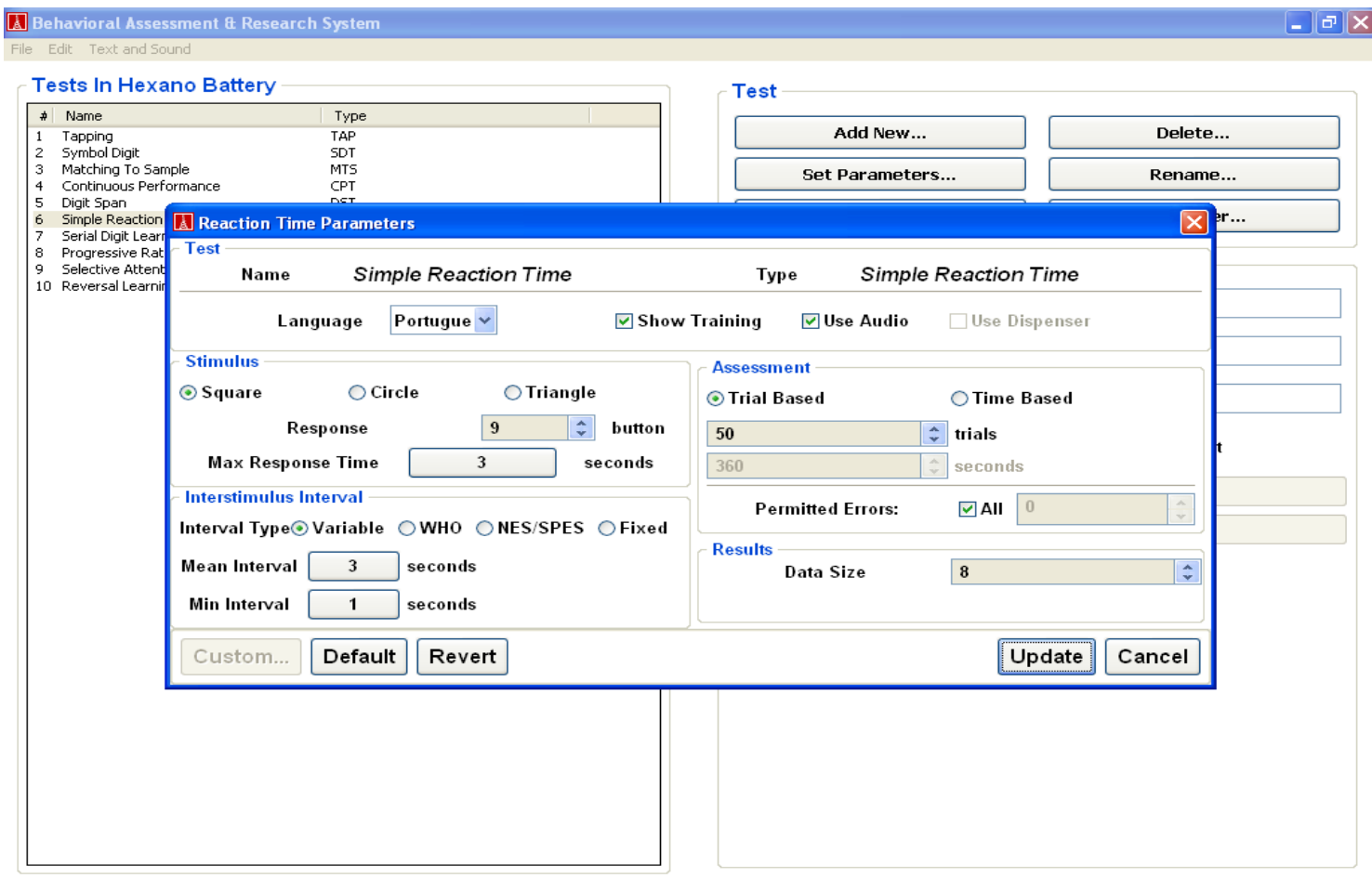

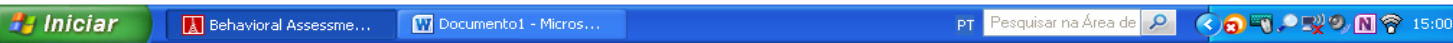

CONFIGURAÇÕES DO SimPle REACTION TIME TEST (SRT) 


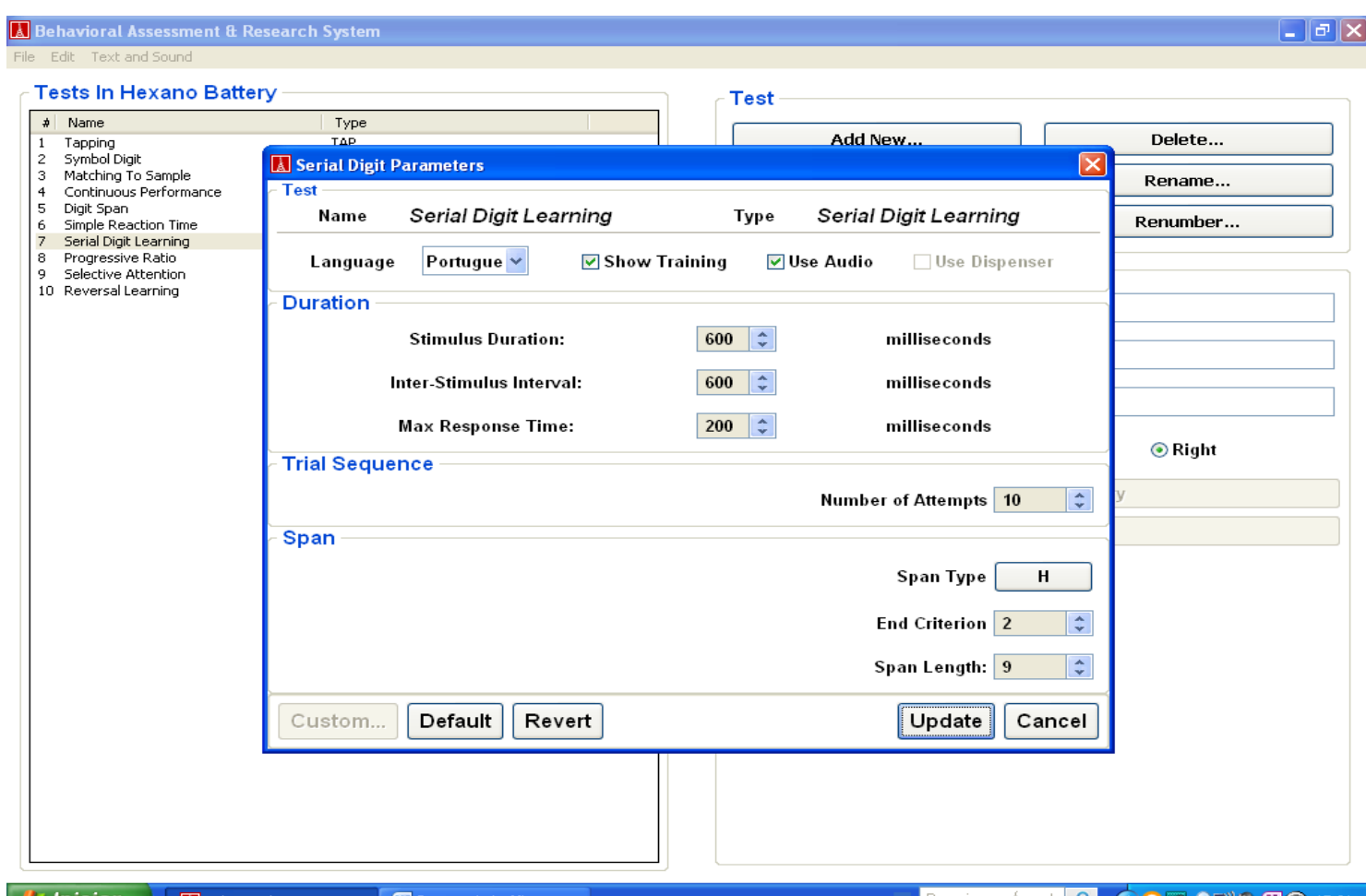

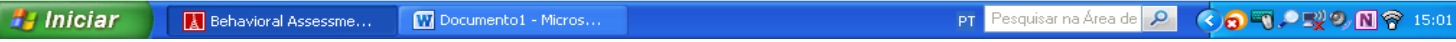

CONFIGURAÇÕES DO SERIAL DigIT LEARNING (SDL)

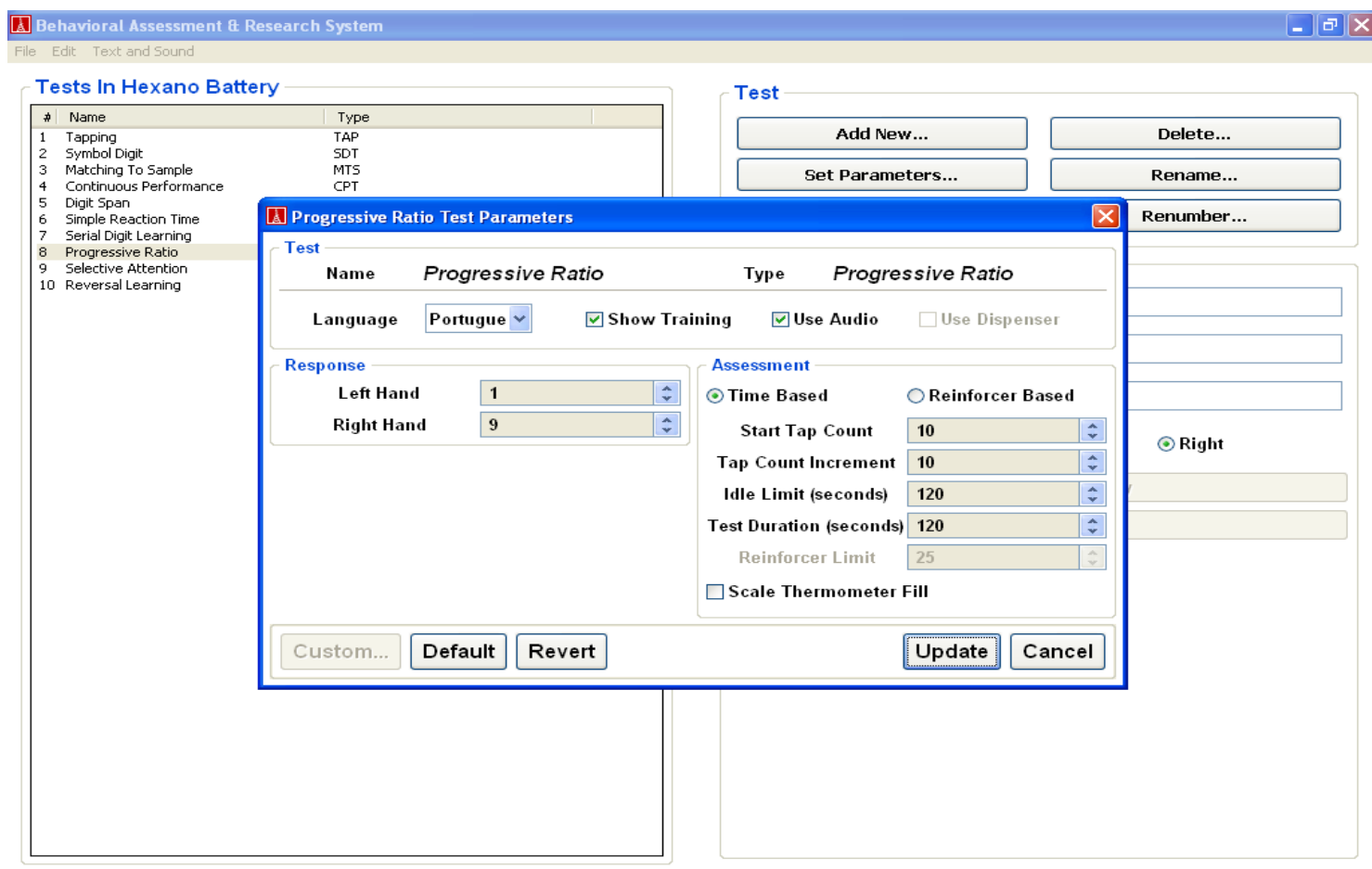

CONFIGURAÇÕES Do Progressive RAtio TEST (PRT) 


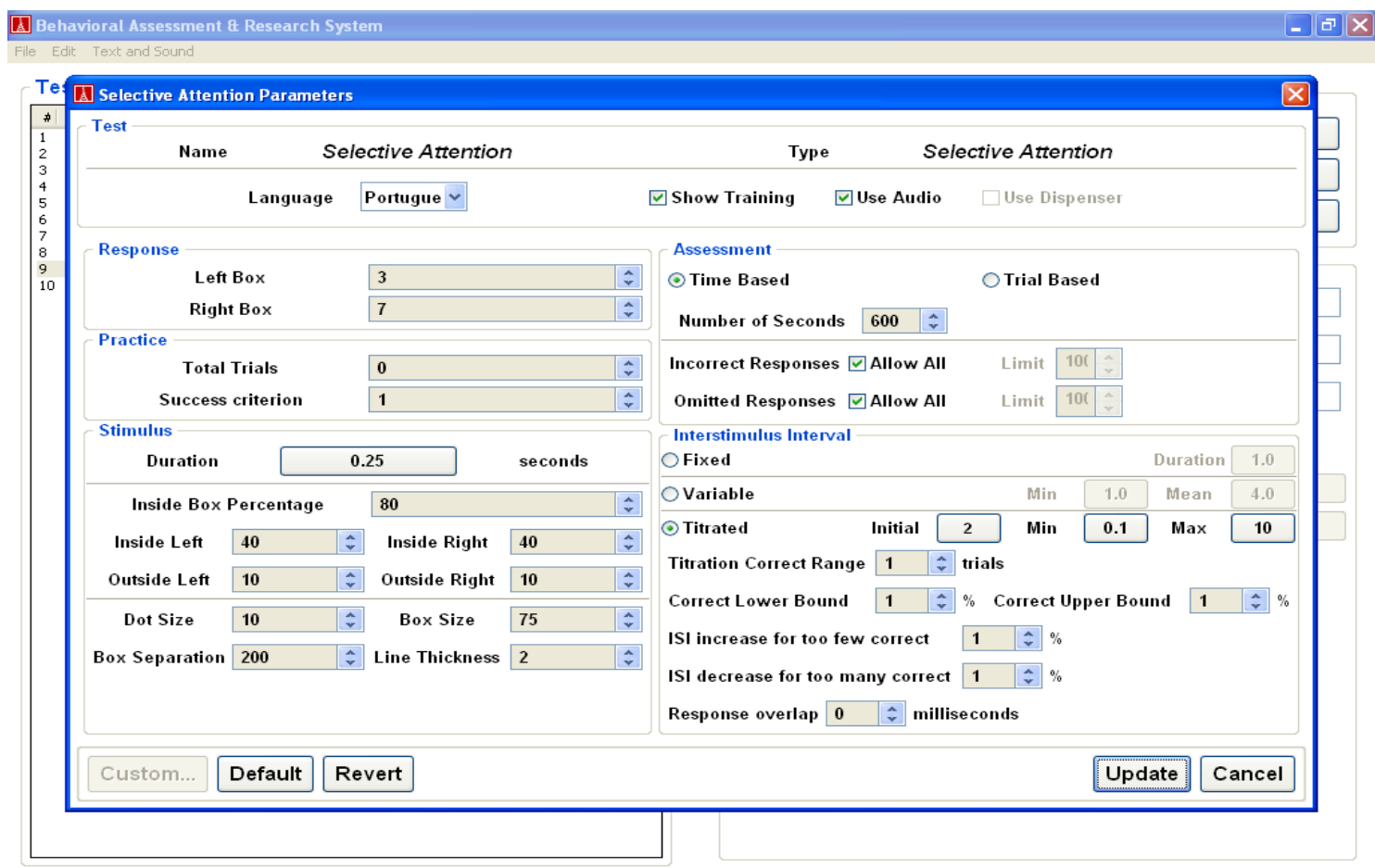

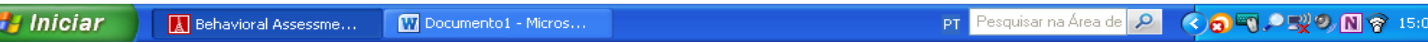

\section{CONFiguRAÇõES do SElective AtTENTION Test (SAT)}

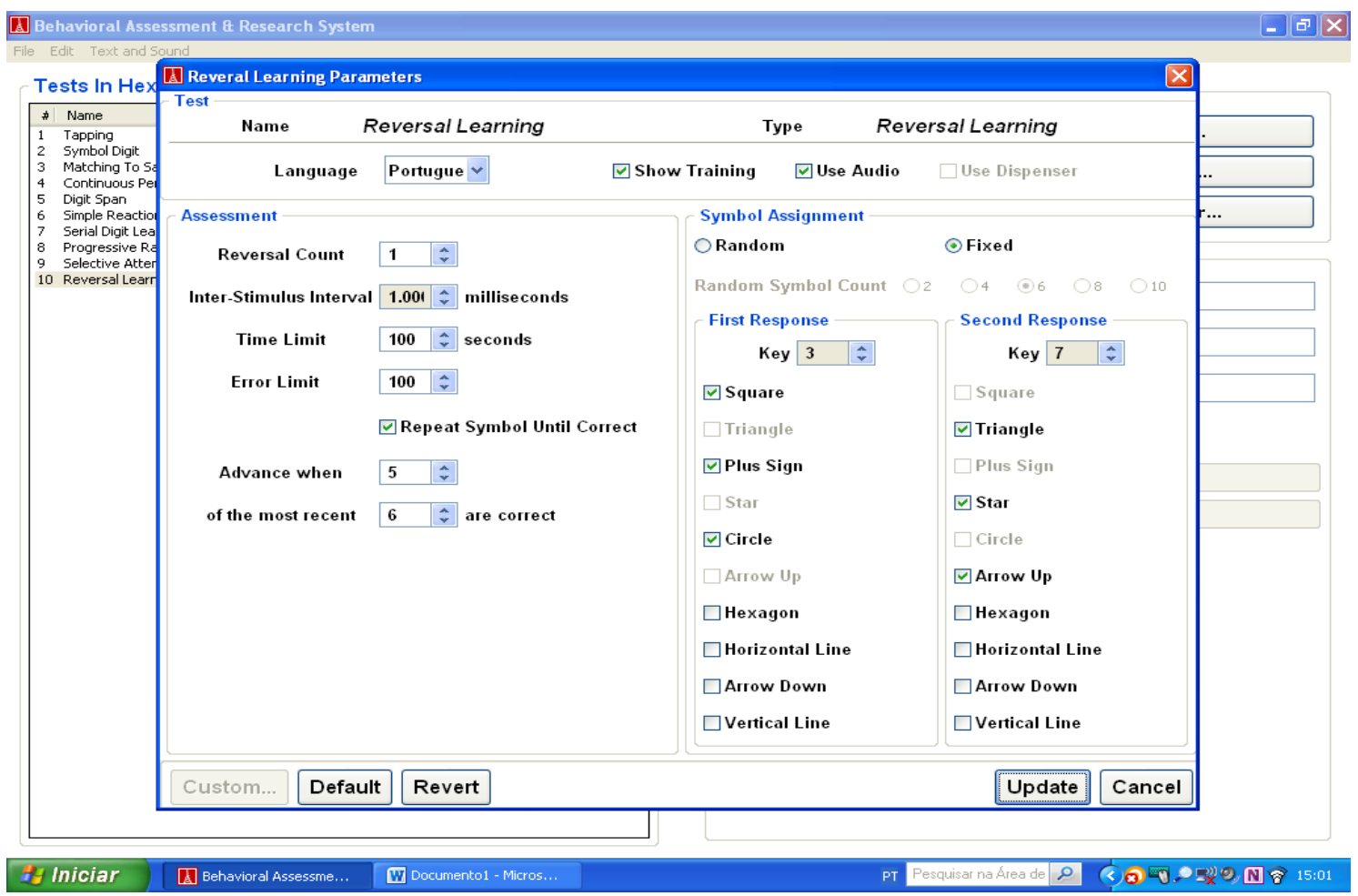

CONFIGURAÇÕES DO REVERSAL LEARNING TEST 
ANEXO 01

- Parecer Consubstanciado do Comitê de Ética em Pesquisa - 


\author{
MINISTERIO DA EDUCAC̄̃o \\ UNIVERSIDADE FEDERAL DE GOIẢS \\ PRO-REITORIA DE PESQUISA E PÓS-GRADUAÇÃo \\ COMITÊ DE ETICA EM PESQUISA
}

Goiânia, 23 de abril de 2012.

\title{
PARECER CONSUBSTANCIADO REFERENTE AO ATENDIMENTO DE PENDÊNCIAS EM PROJETO DE PESQUISA \\ Protocolo $n^{\circ} 033 / 13$
}

\section{Identificação:}

1. Tirulo do projeto: Avaliaça Neurocomportamental do N-Hexano em trabalhadores de indústria de extração de b́leo vegetul.

2. Pesquisador Responsável: André Amaral Bravin.

3. Unidade/Órgão: UFG/Campus de Jatai (Curso de Psicologia)..

4. Pesquisadores Participantes: Vanessa Assis Menezes; Cleber Douglas Lucinio Ramos (biomédico).

5. Data de apresentação do protocolo à CEP : 04/02/2013.

6. Data do Relato: 18/02/2013.

7. Data de Atendimento das Pendencias: 27/02/2013.

\section{II - Parecer do CEP:}

Informamos que o Comite de Ética em Pesquisa da Universidade Federal de Goiás, após análise das adequaçōes solicitadas, Aprovou, em 15 de abril de 2013, o projeto acima referido, e o mesmo foi considerado em acordo com os princípios éticos vigentes.

O pesquisador responsável deverá encaminhar ao CEP/UFG, relatórios da pesquisa, encerramento, conclusão(ōes) e publicação(ర̃es) de acordo com as recomendaçðes da Resolução 196/96.

\section{III - Data da reuniăo: 15/04/2013}

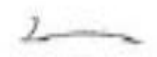

Assinatura do Relator:

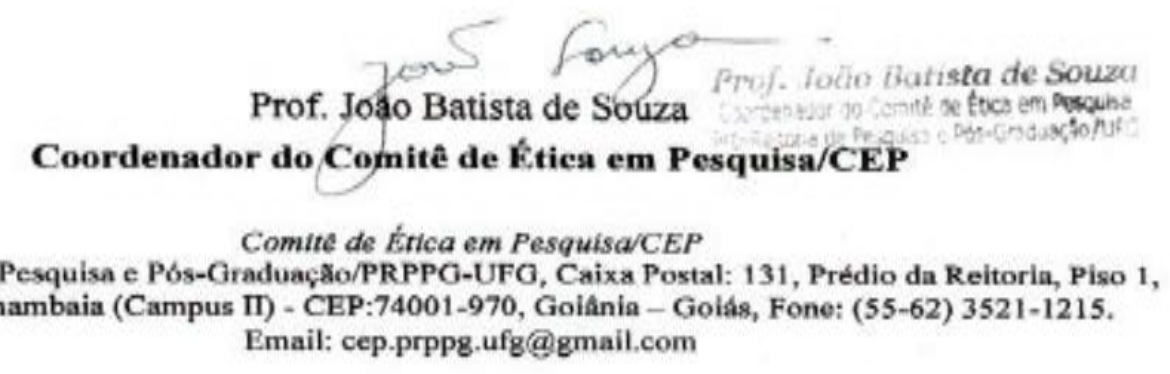

